\title{
Fxr signaling and microbial metabolism of bile salts in the zebrafish intestine
}

\section{Authors}

Jia Wen, ${ }^{1}$ Gilberto Padilla Mercado, ${ }^{1}$ Alyssa Volland, ${ }^{2 \dagger}$ Heidi L. Doden, ${ }^{2,3}$ Colin R. Lickwar, ${ }^{1}$ Taylor Crooks, ${ }^{2 \ddagger}$ Genta Kakiyama, ${ }^{4}$ Cecelia Kelly, ${ }^{1}$ Jordan L. Cocchiaro, ${ }^{1 \S}$ Jason M. Ridlon, ${ }^{2,3,5,6^{*}}$ and John F. Rawls ${ }^{1 *}$

\author{
Affiliations \\ ${ }^{1}$ Department of Molecular Genetics and Microbiology, Duke Microbiome Center, Duke \\ University School of Medicine, Durham, NC, USA. \\ ${ }^{2}$ Carl R. Woese Institute for Genomic Biology, University of Illinois at Urbana Champaign, \\ Urbana, IL, USA. \\ ${ }^{3}$ Department of Animal Sciences, University of Illinois at Urbana Champaign, Urbana, IL, USA. \\ ${ }^{4}$ Department of Internal Medicine, School of Medicine, Virginia Commonwealth University, \\ Richmond VA, USA. \\ ${ }^{5}$ Division of Nutritional Sciences, University of Illinois at Urbana Champaign, Urbana, IL, USA. \\ ${ }^{6}$ Cancer Center of Illinois, Urbana, IL, USA. \\ Current address: \\ ${ }^{\dagger}$ Elanco Animal Health Research and Exploratory Development, Bacteriology \& Microbiome, \\ Greenfield, IN, USA. \\ ${ }^{\ddagger}$ Microbiology, Immunology, and Cancer Biology Program, University of Minnesota Twin \\ Cities, Minneapolis, MN, USA. \\ ${ }^{\S}$ Duke Human Vaccine Institute, Duke University School of Medicine, Durham, NC, USA. \\ *Correspondence to Jason Ridlon (jmridlon@illinois.edu) or John Rawls (john.rawls@ duke.edu)
}

\begin{abstract}
Bile salt synthesis, secretion into the intestinal lumen, and resorption in the ileum occurs in all vertebrate classes. In mammals, bile salt composition is determined by host and microbial enzymes, affecting signaling through the bile salt-binding transcription factor Farnesoid X receptor (Fxr). However, these processes in other vertebrate classes remain poorly understood. We show that key components of hepatic bile salt synthesis and ileal transport pathways are conserved and under control of Fxr in zebrafish. Zebrafish bile salts consist primarily of a $\mathrm{C}_{27}$ bile alcohol and $\mathrm{C}_{24}$ bile acid which undergo multiple microbial modifications including bile acid deconjugation that augments Fxr activity. Using single-cell RNA sequencing, we provide a cellular atlas of the zebrafish intestinal epithelium and uncover roles for Fxr in transcriptional and differentiation programs in ileal and other cell types. These results establish zebrafish as a non-mammalian vertebrate model for studying bile salt metabolism and Fxr signaling.
\end{abstract}




\section{Introduction}

Bile salts are the end product of cholesterol catabolism in the liver of all vertebrates (1). Upon lipid ingestion, bile salts are released into the duodenum as emulsifiers to solubilize lipids and are then reabsorbed by the ileum into the portal vein to return to the liver, a process known as enterohepatic circulation. Bile salts also act as signaling molecules that exert diverse effects by activating nuclear or membrane-bound receptors (2). This includes the nuclear receptor Farnesoid X receptor (FXR/NR1H4), an evolutionarily conserved transcription factor that uses bile salts as endogenous ligands (3). Upon binding with bile salts, FXR regulates a large number of target genes involved in bile salt, lipid, and glucose metabolism (4). FXR activity can be modulated by the chemical structure of bile salts, which differ considerably across vertebrate species (5). For example, fish and amphibians contain predominantly 27 -carbon $\left(\mathrm{C}_{27}\right)$ bile alcohols, whereas mammals mainly possess 24 -carbon $\left(\mathrm{C}_{24}\right)$ bile acids $(1)$. Even within the same species, there can be substantial diversity in bile salt structures. One key contributor to this diversity is the gut microbiota, which can modify the side chain(s) or stereostructure of the conjugated primary bile salts synthesized by the liver (6). This leads to the production of various unconjugated or secondary bile salts in the intestine with different activities towards FXR, therefore altering FXR-mediated signaling pathways. Though bile salts and FXR are present in diverse vertebrate species $(7,8)$, our knowledge about bile salt-FXR signaling has been almost entirely limited to humans and rodents. It remains unclear when this signaling axis arose and whether its functions changed over the course of vertebrate evolution. Further, despite mice in particular have been effective at revealing FXR functions, there are substantial differences between mice and humans, including bile salt composition, the effects of bile salt on Fxr, and Fxr-mediated metabolic activities $(9,10)$. Therefore, additional vertebrate models are needed to provide complementary perspectives into the mechanistic relationships between microbiota, bile salts, and FXR signaling, and to potentially reveal new functions of FXR.

The zebrafish (Danio rerio) has emerged as a powerful model for studying bile salt-related liver diseases due to their conserved mechanisms of liver and intestinal development and bile secretion, facile genetic and transgenic manipulations, and ease of monitoring host-microbiota interactions and other physiological processes in vivo (11-14). The genome of zebrafish possesses orthologs of many mammalian genes known to be involved in bile salt homeostasis, including bile salt transporters, bile salt synthesis enzymes, and $\operatorname{FXR}(7,12,15,16)$. Further, genes involved in bile salt absorption are expressed in a conserved ileal region of the zebrafish intestine (17). However, the requirement for those zebrafish genes in enterohepatic circulation and bile salt signaling remains largely untested. Additionally, although primary bile salt composition in zebrafish has been assessed $(18,19)$, microbial metabolism of zebrafish bile salts has not been explored. 
Here, we establish zebrafish as a non-mammalian vertebrate model to study the bile salt-Fxr signaling axis. We establish the evolutionary conservation of key components of this axis between zebrafish and mammals, and assess the contribution of zebrafish gut microbes to the modulation of the bile salt-Fxr signaling. Further, we uncover the requirements of zebrafish Fxr in gene expression and differentiation in multiple intestinal epithelial cell types using single-cell transcriptomics. 


\section{Results}

Key components of the Fxr signaling pathway are conserved in zebrafish

We used CRISPR-Cas9 to generate $f x r$ mutant zebrafish $\left(f x r^{-10 /-10}\right.$, designated as $\left.f x r^{-/-}\right)$and then investigated the impacts on predicted Fxr targets (Fig 1A, S1A-B). Fatty acid binding protein 6 (fabp6), the gene encoding the ileal bile acid binding protein, is a known Fxr target in mammals and is highly expressed in the zebrafish ileum $(17,20)$. Using a new reporter line $T g(-$ 1.7fabp6:GFP) that expresses GFP in the ileal epithelium under control of the $1.7 \mathrm{~kb}$ fabp6 promoter, we observed striking attenuation of GFP fluorescence in $f x r^{-/}$zebrafish compared to $\mathrm{fxr}^{+/+}$wild-type (wt) controls (Fig 1B). This suggested that expression of fabp6 in the ileum is dependent on Fxr in zebrafish as it is in mammals (20), and that this reporter line can be used to monitor Fxr activity in vivo. Examination of a larger panel of predicted Fxr target genes involved in bile salt homeostasis revealed similar transcriptional changes in $f x r^{-/}$zebrafish as seen in Fxr knockout mice $(12,20-22)$. This includes reduced expression of fabp6, the fibroblast growth factor $f g f 19$, and the bile salt export pump abcb1 $1 b$, along with induction of the cyp $7 a 1$ which encodes the rate-limiting enzyme cholesterol 7alpha-hydroxylase in hepatic bile salt synthesis. Interestingly, the apical sodium-dependent bile acid transporter slc10a2, which is indirectly repressed by FXR in mice and humans, appeared to be positively regulated by Fxr in zebrafish, as slcl0a2 expression was reduced in $f x r^{-/-}$zebrafish. Nonetheless, these data reveal that Fxr is critical for the coordinated expression of bile salt metabolism genes in zebrafish as in mammals (Fig 1C).

\section{Bile salt-mediated Fxr activation is conserved in zebrafish as in mammals}

We next sought to test if bile salt mediated regulation of Fxr activity is conserved in zebrafish as in mammals. To do so, we first defined the level and diversity of zebrafish bile salts by analyzing the biliary bile extracted from pooled adult zebrafish gallbladders using ESI-LC/MS. Based on the mass ion, the major component $(83.4 \%)$ of the purified zebrafish bile was determined to be $5 \alpha$-cyprinol sulfate ( $5 \alpha \mathrm{CS}$ ), a $\mathrm{C}_{27}$ bile alcohol species commonly present in fishes (Fig. 2A) (23, 24). This was further validated by examining the $1 \mathrm{H}, 13 \mathrm{C}, \mathrm{COSY}$, and HSQC NMR spectra of this compound (Fig S2A). We also identified several minor bile salt species, including $8.8 \%$ taurocholic acid (TCA), a $\mathrm{C}_{24}$ bile acid commonly found in mammals, $7.8 \% 5 \alpha$-cholestane$3 \alpha, 7 \alpha, 12 \alpha, 26$-tetrol sulfate, a precursor of $5 \alpha \mathrm{CS}(1,23)$, and a trace amount of the dehydrogenated form of $5 \alpha \mathrm{CS}$ (Fig 2A).

The predominant zebrafish bile salt, the $\mathrm{C}_{27}$ bile alcohol $5 \alpha \mathrm{CS}$, differs drastically from the common mammalian bile salts, the $\mathrm{C}_{24}$ bile acids, in both the stereostructure and the number of carbon atoms. Therefore, we asked whether such distinct bile salt composition results in differential regulation of Fxr signaling between fishes and mammals. We thus modulated the zebrafish bile salt levels by disrupting the hepatic synthesis or ileal uptake of bile salts and monitored the impacts on Fxr activity using the $T g(-1.7 f a b p 6: G F P)$ reporter. To reduce hepatic bile salt synthesis, we generated a new cyp7al mutant zebrafish (cyp7al ${ }^{-16 /-16}$, designated as 
cyp $7 a 1^{-/-}$) which exhibited a significant reduction in the total bile salt levels as compared to its wt counterparts (Fig S1C-F, Supplementary Results). Using the reporter assay, we observed a over $50 \%$ decrease in GFP fluorescence in cyp $7 a 1$ mutant zebrafish as compared to wt, suggesting that Fxr activity was reduced as a result of bile salt deficiency in zebrafish (Fig 1D). To reduce bile salt uptake in the ileum, we utilized slc10a2 mutant (slc10a2sa2486/sa2486, designated as slc10a2 $2^{-/}$) zebrafish (Fig S1G) (25), which also showed significantly decreased ileal GFP fluorescence, consistent with compromised Fxr activity due to insufficient bile salt uptake (Fig 1E). Together, these results suggest that despite the compositional differences in bile salts between zebrafish and mammals, bile salts still activate Fxr and the downstream signaling in the ileal epithelium of zebrafish.

\section{Fish microbiota modulate bile salt diversity in vivo and in vitro}

Primary bile salts can be modified by intestinal microbiota into various unconjugated or secondary bile salts and then cycled back to the liver through enterohepatic circulation (5). Our findings on zebrafish biliary bile salt diversity demonstrated the presence of a dehydrogenated $5 \alpha \mathrm{CS}$ (Fig 2A). However, it is not clear if this modified $5 \alpha \mathrm{CS}$ is an intermediate derived from de novo $5 \alpha \mathrm{CS}$ biosynthesis or a recycled bile salt that has been modified by gut microbiota. Further, biliary bile salts do not accurately reflect the full spectrum of microbial modification that occur in the intestine. We therefore examined bile salt diversity in the intestinal contents of adult zebrafish, aiming to determine if microbial modifications of bile salts occur. $5 \alpha \mathrm{CS}$ and TCA were present in zebrafish intestinal contents (Fig S2B); however, the low biomass of the zebrafish luminal contents limited our ability to accurately detect and/or quantify these bile salts and their derivatives. Thus, we turned to a larger cyprinid fish species closely related to zebrafish, the Asian grass carp (Ctenopharyngodon idella), and compared the bile salt diversity between the carp biliary bile and gut contents to determine if bile salts are modified by carp gut microbiota (Fig 2B, 2C). Carp possess a similar biliary bile salt profile to zebrafish, as all major peaks found in zebrafish were also present in carp (Fig 2A, 2B), except that it produces a different tetrahydroxy bile alcohol sulfate (Fig 2B, peak d), likely a $5 \beta$-isomer of the cholestane$3 \alpha, 7 \alpha, 12 \alpha, 26$-tetrolsulfate $(1,26)$. Notably, in the bile salts isolated from carp intestinal contents, we observed a new peak sharing the same mass ratio but a different retention time with $5 \alpha \mathrm{CS}$, indicative of an epimerized $5 \alpha \mathrm{CS}$. This suggests that carp microbiota can oxidize and epimerize an $\alpha$ - to a $\beta$-hydroxyl group of the primary bile alcohol $5 \alpha \mathrm{CS}$ (Fig 2C). To our knowledge, this is the first evidence demonstrating the ability of microbes to metabolize bile alcohols in vertebrates.

To test if similar and/or additional microbial modifications might be present in the zebrafish gut, we developed an in vitro bile salt modification assay using LC/MS (Fig 3A). Complex microbiota or individual microbes isolated from the zebrafish intestine were first enriched under aerobic or anaerobic conditions and then incubated with the bile salts of interest. This assay system was validated through successful detection of common modifications of primary bile salts 
upon treating with microbes known to perform these modifications (Fig S3A-B). We then used this system to test if zebrafish microbiota modify $5 \alpha \mathrm{CS}$ and TCA, the primary bile alcohol and acid in zebrafish. For $5 \alpha \mathrm{CS}$ cultured with zebrafish microbiota, two newly emerged peaks, representing the microbial metabolites of $5 \alpha \mathrm{CS}$, were detected in both aerobic and anaerobic conditions. One peak showed a mass ion of $529.3 \mathrm{~m} / \mathrm{z}$ with an elution time of $7.4 \mathrm{~min}$, suggesting a keto-5 $\alpha \mathrm{CS}$ variant (Fig 3B). The loss of two mass units observed in this product is consistent with bacterial hydroxysteroid dehydrogenase activity found in human gut microbiota (27, 28). The other peak, with a mass ion of $531.3 \mathrm{~m} / \mathrm{z}$ and elution time of $6.4 \mathrm{~min}$, corresponded to an epimerized $5 \alpha \mathrm{CS}$, a downstream product of the keto-5 $\alpha \mathrm{CS}$ variant, therefore further confirming the presence of hydroxysteroid dehydrogenases in zebrafish microbiota (Fig 3B). Interestingly, both peaks were also present in carp intestinal content (Fig 2C), suggesting that microbiota-mediated $5 \alpha \mathrm{CS}$ dehydrogenation and epimerization are conserved in these cyprinid fishes.

Cultures incubated with TCA resulted in a new peak corresponding to cholic acid (CA), the deconjugated product of TCA, in several zebrafish microbiota, though the extent of deconjugation varied (Fig 3C). For example, aerobic microbiota \#1 exhibited a complete deconjugation of TCA to CA whereas aerobic microbiota \#3 showed no sign of deconjugation. This likely indicates the variable distribution of microbes containing bile salt hydrolase (BSH), the enzyme catalyzing the deconjugation of TCA, among zebrafish. Interestingly, the presence or absence of BSH activity in a given zebrafish microbial community does not always match between aerobic and anaerobic conditions. For instance, zebrafish microbiota \#3 deconjugated TCA only under anaerobic conditions, whereas microbiota \#1 catalyzed deconjugation only under aerobic conditions. This suggests that the bacteria responsible for deconjugation are likely different among distinct zebrafish microbiota and that more than one deconjugating bacterium is present in zebrafish. No other transformations of $5 \alpha \mathrm{CS}$ or CA were detected in cultures.

Collectively, our results indicate that microbial modification of bile salts is a conserved feature between zebrafish and mammals.

Having shown that zebrafish microbiota modify both $5 \alpha \mathrm{CS}$ and TCA, we sought to determine the bacterial specificity of bile salt modification in zebrafish. We screened a panel of zebrafish gut isolates representing several major bacterial taxa in the zebrafish gut towards $5 \alpha \mathrm{CS}$ and TCA (Fig 4A, S3C). None of the tested strains modified $5 \alpha \mathrm{CS}$. Yet, we identified one Gammaproteobacteria strain, Acinetobacter sp. ZOR0008, capable of deconjugating TCA (Fig 4A). After overnight incubation with Acinetobacter sp., we observed complete conversion of 25 $\mu \mathrm{M}$ TCA to CA, suggesting robust BSH activity (Fig 4A). To our knowledge, this the first zebrafish gut bacterium confirmed to have bile salt metabolizing activity.

\section{Microbial modifications of bile salt in zebrafish modulate Fxr activity}


In mammals, microbial modification of bile salts can alter the signaling property of bile salts and modulate host physiology. Given that the primary bile acid TCA can be metabolized into CA by gut microbes in zebrafish, we investigated the potential impact of that modification on Fxr signaling in vivo by monitoring $T g(-1.7 f a b p 6: G F P)$ zebrafish treated with exogenous TCA or CA. To reduce the influences of Fxr activity caused by endogenous bile salts, we performed the reporter assay in the $c y p 7 a 1^{-/}$background. Physiological concentrations of TCA or CA were supplemented to larval zebrafish and GFP fluorescence was monitored after 4 days (23). Zebrafish larvae treated with CA exhibited increased GFP fluorescence as compared to those with TCA, and both showed higher fluorescence than the non-treated controls (Fig 4B). This suggests that both TCA and CA activate Fxr and that CA is more potent than TCA, consistent with observations in mammals (29). We further validated these findings under a more stringent setting using wt germ-free zebrafish, which permit competition between endogenous versus exogenous bile salts and eliminate potential influences of microbiota on metabolizing the supplemented bile salts. Quantitative RT-PCR (qRT-PCR) results suggested that CA treatment increased expression of Fxr targets, such as fabp6 and fgf19, as compared to TCA, confirming that CA displays higher potency than TCA in activating Fxr (Fig 4C). Together, our observations suggest that zebrafish gut microbiota have the potential to regulate Fxr-mediated signaling through modification of primary bile salts.

\section{Fxr regulates diverse cell types identified in zebrafish intestine by single-cell RNA-seq} Having established that bile salts and gut microbes interactively regulate Fxr activity, we next sought to discern how Fxr in turn contributes to intestinal functions. Gross intestinal morphology appeared normal in zebrafish and mice lacking Fxr function (Fig 1B) (30), but strong attenuation of the fabp6 reporter in $f x r$ mutant zebrafish (Fig 1B) suggested potential effects of $f x r$ mutation on functional specification of intestinal epithelial cells (IECs). To test this possibility, we performed single-cell RNA sequencing (scRNA-seq) on 12,543 IECs sorted from $6 \mathrm{dpf} f x r^{+/+}$or $\mathrm{fxr}^{-/-}$zebrafish larvae on a $\mathrm{TgBAC}(\mathrm{cldn15la-GFP})$ transgenic background that expresses GFP in all IECs (31). After quality control, 4,710 cells from $f x r^{+/+}$and 5,208 cells from $f x r^{-/}$samples were used for downstream analyses (Fig S4A-E). Twenty-seven distinct clusters were generated by unsupervised clustering of these cells using the Seurat R package as described previously (Fig 5A, S4A-E) (32). The cell types represented by these clusters were inferred through integrative analysis of published expression data of previously identified gene markers, novel markers of each cluster identified in this study by differential gene expression, and functional predictions from the gene expression data generated in this study (Datasets S1-3, and Supplementary Results). The resulting annotation revealed a range of IEC types including absorptive enterocytes, goblet cells (including those that resemble mammalian tuft cells and microfold cells), enteroendocrine cells, secretory precursors, ionocytes (including those that resemble mammalian BEST4/OTOP2 cells) (33), and foregut epithelial cells, as well as low levels of several other apparent contaminating cell types (e.g., exocrine pancreas cells, epidermis cells, mesenchymal cells, leukocytes, red blood cells) (Fig 5A, Table S1, and Supplementary Results). 
These results combined with our extended annotation of this scRNA-seq dataset provided in Supplementary Materials provide a useful new resource for zebrafish intestinal biology.

We next leveraged our scRNA-seq data to test the requirement for $f x r$ in different IEC types. Supporting the notion that Fxr regulates diverse aspects of intestinal physiology, we found that nearly one-third of all clusters exhibited over $50 \%$ change in cell abundance with an average of $\sim 500$ genes displaying over 1.5-fold changes in expression in response to Fxr mutation (Fig S5A, $\mathrm{B}$, Dataset S4). To further evaluate conservation of Fxr-mediated gene expression between zebrafish and mammals, we compared these results to an existing dataset of 489 mouse genes differentially regulated in the ileum or colon in response to intestinal Fxr agonism (34). We identified 583 zebrafish genes that were determined by BioMart to be homologous to those 489 mouse genes and also detected in our zebrafish dataset. Of the 583 zebrafish genes, 213 of them were differentially expressed in response to $f x r$ mutation in at least one cluster (Dataset S5). In those instances where one of those 213 genes was differentially expressed in a cluster, the directionality of change due to Fxr function was consist with mouse ileum in 59.5\% (72/121) of cases and with mouse colon in $49.7 \%$ (251/499) of cases. Though it remains unknown if these gene expression changes are due to direct or indirect effects of Fxr activity, these results do suggest substantial differences between the gene regulons influenced by Fxr activity in the zebrafish and mouse intestines. This further underscores the importance of using multiple animal models to gain complementary insights into bile salt-Fxr signaling pathways. Although we already showed that loss of $f x r$ function in zebrafish results in reduction of several conserved Fxr target genes (Fig 1C), this comparative functional genomic analysis identified potential additional targets of Fxr regulation that are conserved between zebrafish and mice such as $P c k 1$ (35), Akrlb7 (36), and Apoal (37) (Dataset S5). Collectively, our scRNA-seq results unveil extensive cellular diversity in the larval zebrafish intestine and highlight the broad impacts of Fxr on cell abundance and gene expression in diverse cell types.

\section{Fxr regulates functional specialization of ileal epithelial cells}

Given the striking attenuation of the ileal fabp6 reporter in fxr mutant zebrafish (Fig 1B), we next examined how Fxr impacts zebrafish ileal epithelial cells in our scRNA-seq analysis. We discerned cluster 17 as enriched for zebrafish ileal epithelial cells based on the abundant expression of bile transporters fabp6, slc10a2, and slc5la (Fig 5B). This cluster exhibited a higher level of $f x r$ expression as compared to all other clusters, consistent with the notion that $f x r$ displays spatially patterned expression along the intestine with highest levels in the ileal epithelium $(38,39)$. We also observed heterogeneity in the expression of these bile transporter genes in cluster 17, raising the possibility that multiple sub-cell types are present in this cluster (Fig S6A). For clarity, we operationally defined cells located in cluster 17 as "ileal epithelial cells" and the subset that expresses one or more bile transporters as "ileocytes". 
Mutation of $f x r$ drastically impacted gene expression in cluster 17 cells (Fig S5B, Dataset S4). As expected, many downregulated genes in cluster $17 \mathrm{fxr}$ mutant cells were related to bile salt metabolism, such as fabp6, slc10a2, and slc51a, consistent with the strong reduction in the fabp6 reporter activity upon Fxr mutation (Fig 6A, 1B). On the other hand, among the upregulated cluster 17-enriched markers, lysosome process (dre: 04142) was the most enriched pathway in fxr mutant cells (Fig 6A, S6B). Lysosome mediated degradation is a hallmark function of a specific type of vacuolated enterocytes named lysosome-rich enterocytes (LRE) (40). LREs are found in the ileum of fishes and suckling mammals and are known to internalize dietary macronutrients for intracellular digestion $(41,42)$. Therefore, our data confirm that LREs compose a key type of ileal epithelial cell, and further suggest that Fxr normally represses LRE gene expression. Indeed, we observed increased expression of many known LRE makers in $f x r$ mutant cells in cluster 17. This includes multiple classes of digestive enzymes involved in macromolecule degradation and transporters responsible for dietary protein uptake in LREs (Fig 6A) (40). To confirm these results, we used qRT-PCR to examine expression of several LRE markers including amn, which encodes Amnionless, the major component of the multi-ligand endocytic machinery in LREs, and $c t s b b$, which encodes Cathepsin B commonly found in lysosomes. Both genes exhibited higher expression in the zebrafish intestine upon $f x r$ mutation, validating our scRNA-seq observations (Fig 6B). To identify potential transcriptional regulatory pathways involved in the induction of LRE genes upon $f x r$ mutation, we searched for transcription factor binding sites (TFBS) that are over-represented within accessible chromatin regions (17) near genes upregulated in $f x r$ mutant cells in cluster 17. The top 3 enriched TFBS were ZBTB33, Atf2, and TATA-box, raising the possibility that Fxr may interact with TFs that bind at these TFBSs to regulate LRE functions such as lysosomal mediated degradation (Fig S6C). Collectively, these results establish that Fxr promotes expression of bile absorption genes and represses expression of lysosomal degradation genes in ileal epithelial cells in zebrafish.

The altered gene expression seen in $f x r$ mutant cells in cluster 17 could be explained by Fxr regulating the relative abundance of different ileal cell types such as ileocytes and LREs, or regulating expression of genes characteristic of those cell types in cluster 17 . We therefore carried out subclustering of cluster 17, aiming to distinguish ileocytes from LREs and to delineate the heterogeneity within these ileal epithelial cells (Fig S6D). To our surprise, we could not cleanly separate these two subtypes as many cluster 17 cells expressed both bile transporter genes and LRE makers (Fig S6D-F). This indicates an overlap between the bile salt absorption and lysosomal degradation programs in some cluster 17 ileal epithelial cells, and is in agreement with previous bulk RNA-seq studies showing that LREs can also express ileocyte markers such as fabp6 and slc10a2 (40). To test this overlap in vivo, we took advantage of the high endocytotic property of LREs and labeled them in $T g(-1.7 f a b p 6: G F P)$ zebrafish by gavaging with fluorescent dextran which is internalized by LREs (Fig 6C) (40). Indeed, some ileal epithelial cells were labeled by both GFP and dextran, whereas cells anterior to this region were only GFP+ and cells posterior to this region were only dextran+. This was confirmed with a second 
LRE reporter $T g B A C$ (lamp2:RFP) (Fig 6D), further establishing the partial overlap of these two functionally distinct transcriptional programs. Collectively, these findings demonstrate that cluster 17 represent cells located in the zebrafish ileum that include at least three subtypes that we operationally define as (1) ileocytes, which express bile metabolism genes and are responsible for bile salt absorption; (2) LREs, which express lysosomal enzymes and are responsible for macromolecule degradation; and (3) bi-functional cells exhibiting both of those programs.

We next sought to determine if Fxr regulates the abundance or location of these ileal cell types. In contrast to the striking changes in the gene expression of cluster 17 cells upon $f x r$ mutation (Fig 6A, S5B), the relative abundance of this cluster remained similar between $f x r$ mutant and wt (Fig S5A), suggesting that Fxr deficiency does not prevent the establishment of a zebrafish ileum. To validate this observation in vivo, we measured the length and the spatial location of the ileal epithelium, including ileocytes and LREs, in fxr wt or mutant zebrafish. The LRE region was evaluated by gavaging dextran into $f x r$ wt and mutant zebrafish followed with in vivo imaging. No significant difference was observed in the length of the dextran positive region or the intensity of the absorbed dextran after gavaging, suggesting that the abundance of LREs remain unchanged in the absence of Fxr (Fig 6E, F). To assess ileocyte abundance and positioning, we gavaged dextran into the double transgenic reporter $\operatorname{Tg}(-4.5 \mathrm{fabp} 2: \mathrm{DsRed}$, 1.7fabp6:GFP) in either $f x r$ wt or mutant background (43). The proximal intestinal region, labeled by DsRed, demarcates the anterior boundary of the ileocytes, while the LRE region, labeled by dextran, demarcates the posterior boundary. The anterior boundary remained intact in the $f x r$ mutant zebrafish, as the DsRed region did not expand or contract (Fig 6E, G). We did observe a nearly complete loss of GFP fluorescence in the $f x r$ mutant animals, consistent with the findings that fabp6 is under strong regulation by Fxr (Fig 6E, 1A). However, this non-fluorescent region, flanked by the anterior enterocytes and LREs in the fxr mutant, shares similar length and spatial position as the GFP positive region in the $f x r$ wt zebrafish (Fig 6E-G). These findings are in agreement with our scRNA-seq data and confirm that Fxr impacts the gene expression program of the ileal epithelial cells without overtly affecting the proportion of those cells, nor the segmental boundaries that organize that region of the intestine. Together, our data suggest that Fxr is not required for developmental organization of the ileal region, instead it is involved in distinct physiological aspects of the cell types in this region.

\section{Fxr promotes differentiation of anterior absorptive enterocytes}

Since $f x r$ is expressed along the length of the intestine in zebrafish and mammals (Fig 5B) (38), we next examined how Fxr contributes to the functions of absorptive enterocytes other than the ileal epithelial cells. We focused on cluster 4, which represents mature enterocytes in the anterior intestine based on their expression of known jejunal markers such as fabplb.1 and $r b p 2 a$, as well as genes involved in lipid metabolism, a hallmark function of mammalian jejunum (Fig 5B, Table S1, Datasets S2-3) (44). Our scRNA-seq data suggested increased cell abundance of 
cluster 4 in response to Fxr mutation (Fig S5A). To validate this in vivo, we performed fluorescence-activated cell sorting of anterior enterocytes collected from double transgenic $f x r$ wt or mutant fish harboring the anterior enterocyte reporter $T g(-4.5 f a b p 2: D s R e d)$ and the pan-IEC reporter $T g B A C(c l d n 15 l a-G F P)$. Consistent with our scRNA-seq data, we observed a significant increase in the relative abundance of anterior enterocytes in the $f x r$ mutant compared to wt (Fig 7A), confirming the role of Fxr in regulating the abundance of these cells in zebrafish. Fxr mutation also led to altered expression of over 250 genes in cluster 4 cells (Fig S5B, Dateset S4). Interestingly, the majority ( $\sim 86 \%$ ) of these differentially expressed genes were downregulated. Functional categorization analysis revealed that these downregulated genes in $f x r$ mutant cells in cluster 4 were enriched for pathways involved in energy metabolism of diverse substrates (Fig S7). This includes aspects of lipid metabolism such as lipid biosynthesis (GO term: sterol biosynthetic process), trafficking (GO term: plasma lipoprotein particle assembly), and regulation (dre: PPAR signaling pathway), amino acid metabolism (GO terms: peptide metabolic process; cellular modified amino acid metabolic process; creatine metabolism), and xenobiotic metabolism (GO terms: drug metabolic process; response to xenobiotic stimulus). Since these pathways represent key functions of differentiated anterior enterocytes, we speculated these gene expression differences in $f x r$ mutant cells in cluster 4 may be due to reduced differentiation of these enterocytes. We therefore compared the zebrafish genes differentially regulated in $f x r$ mutant cells in cluster 4 against defined sets of signature genes for intestinal stem cells (ISCs) and differentiated enterocytes in the small intestinal epithelium of adult mice (Fig 7B) (45). This revealed an overlap of 102 one-to-one gene orthologs between the downregulated genes of the fxr mutant cells in cluster 4 in this study and the genes preferentially expressed in either ISCs or differentiated enterocytes in mice. Approximately two-thirds of these genes (64 out of 102) are preferentially expressed in differentiated enterocytes, suggesting that Fxr inactivation in cluster 4 preferentially attenuates enterocyte differentiation programs. In support, we observed that the most enriched TFBS within accessible chromatin near the genes downregulated in $f x r$ mutant anterior enterocytes is $\mathrm{Hnf} 4 \alpha$, a TF known to promote enterocyte differentiation (Fig 7C) (46, 47). Collectively, these results reveal a novel role of Fxr in promoting differentiation programs of anterior enterocytes.

\section{Discussion}

The ability to synthesize bile salts and the bile salt-regulated transcription factor Fxr are common features of all vertebrate classes, yet our knowledge of bile salt metabolism and bile salt-Fxr signaling is largely derived from mammals. Here, we characterize the bile salt-Fxr signaling axis in zebrafish by determining the bile salt composition and the key genetic components of Fxr signaling pathways. Further, we elucidate the microbiota-bile salt-Fxr relationships in zebrafish and highlight the importance of these interactions as they have been conserved over 420 million years since the last shared common ancestor between mammals and fishes. Collectively, we establish zebrafish as a valuable non-mammalian vertebrate model to study the bile salt-Fxr signaling axis and host-microbe coevolution. Using this model, we uncover novel functions of 
Fxr in modulating transcriptional programs controlling regional metabolic activities in the zebrafish intestine, including its role in repressing genes important for LRE functions in the ileum and promoting genes involved in enterocyte differentiation in the anterior intestine.

Our data show that zebrafish bile salts are composed predominantly of the evolutionarily "ancestral" $\mathrm{C}_{27}$ bile alcohol $5 \alpha \mathrm{CS}$, with only a small proportion of the evolutionarily recent $\mathrm{C}_{24}$ bile acid TCA that are commonly found in mammals (Fig 2A). To our surprise, zebrafish $5 \alpha \mathrm{CS}$ was not observed to undergo $7 \alpha$-dehydroxylation, a common microbial modification of bile acids in mammals (Fig 3B, S3B-C) (48). Further, we did not observe $7 \alpha$-dehydroxylation of CA by the zebrafish or carp microbiota, even though $\mathrm{CA}$ is a suitable substrate for this modification in the mammalian gut environment (Fig 2C, 3C). Interestingly, although mammalian gut microbes have evolved numerous sulfatases that recognize and hydrolyze bile acid-sulfates $(49,50)$, we did not detect sulfatase activity towards $5 \alpha \mathrm{CS}$ in zebrafish microbiota (Fig 3B). Oxidation and epimerization of bile acids by microbial hydroxysteroid dehydrogenase enzymes is well documented in mammalian gut microbiota $(27,51,52)$ and is now confirmed to occur in zebrafish (Fig 3C). Deconjugation of TCA by bacterial BSHs was also observed in the present study (Fig 3C, 4A), a function widespread among mammalian microbial taxa (53), and important for regulation of lipid and cholesterol metabolism in diverse vertebrates (54). Together, these findings indicate that there may be top-down selection pressure in zebrafish to prevent evolution or acquisition of microbial enzymes that would recognize the side-chain sulfate and/or the $7 \alpha-$ hydroxyl group, therefore limiting secondary bile alcohol/acids production. Future study on how these primary and secondary bile salts contribute to digestive physiology and host-microbe interactions in different animals will shed light on understanding the evolutionary biology of vertebrate bile salts.

The binding pocket of FXR and the bile salt structures within a given vertebrate species are thought to have a co-evolutionary relationship $(7,19)$. For example, $\mathrm{C}_{27}$ bile alcohol $5 \alpha \mathrm{CS}$, the major bile salt species in zebrafish, specifically binds and activates zebrafish Fxr but not mammalian FXR (7). Here, we show that the $\mathrm{C}_{24}$ bile acids TCA, a minor zebrafish bile salt, along with its derivative CA, can both stimulate zebrafish Fxr activity in vivo (Fig 4B-C). This raises the possibility that zebrafish Fxr structure is able to bind both the ancestral bile alcohols and the modern bile acids, thereby representing an evolutionary transitional state. Additionally, we find that key aspects of the Fxr signaling pathways remain conserved between zebrafish and mammals including Fxr-mediated induction of fabp6 and $f g f 19$ (Fig 1C). We further show that these zebrafish Fxr-dependent genes, like their mammalian homologs, are more potently induced by the microbially-derived deconjugated bile acid CA compared to its primary bile acid precursor TCA (Fig 4B, C) (29). Beyond these similarities, our analysis of intestinal genes regulated by Fxr function in zebrafish and mice also revealed significant differences. An important example is the directionality of Fxr regulation of slc10a2. Unlike in humans and mice where FXR represses Slc10a2, Fxr in zebrafish appears to induce slc10a2, as both the fxr and 
cyp7a1 mutants displayed reduced slc10a2 expression (Fig 1C, S1F). This suggests divergence of regulation of slc10a2 by Fxr since the common ancestor of fish and mammals. In fact, Fxrmediated regulation of Slc10a2 homologs differs considerably even within mammals (55). For example, FXR negatively regulates intestinal Slc10a2 in mice but not in rats $(56,57)$. Further, although Slc10a2 is repressed by FXR in both mice and humans, the underlying mechanisms are different (58). Future structure-function analyses are warranted to dissect the regulatory mechanisms responsible for such differential control of slc10a2 as well as the physiological consequences.

The zebrafish intestinal epithelial cell scRNA-seq dataset reported here provides a useful new resource for zebrafish intestinal biology. The perspectives afforded by this scRNA-seq dataset allowed us to evaluate distinct regulatory roles of Fxr across different intestinal cell types. For example, we found that ileal epithelium (identified as cluster 17 in this dataset) is composed of multiple cell subtypes including ileocytes, LREs, and bifunctional cells expressing both bile transporter genes and lysosomal degradation markers (Fig 6, S6E-F). Close relationships between ileocytes and LREs have also been defined in mammals, suggesting they are ancient cellular features of the vertebrate ileum. LREs develop in the mammalian ileum only during suckling stages before being replaced by ileocytes post-weaning (40,59). Expression of genes involved in lysosomal degradation declines during this transition, whereas the expression of genes associated with bile salt absorption increases, suggesting an inverse correlation between these two functions (40). Our results provide potential mechanistic insight into the regulation of these two functions by demonstrating that Fxr promotes the expression of bile salt absorption genes and concomitantly reduces lysosomal degradation genes in the zebrafish ileum (Fig 6A, B). In support, similar suppression of lysosomal genes by Fxr has been implicated in mouse studies examining Fxr influence in hepatic autophagy. In mice, Fxr trans-represses autophagyrelated genes by competing for binding sites with transcriptional activators of these genes, such as CREB $(60,61)$. The binding motif of CREB ("TGACGT") identified in the mouse study was the second most enriched binding motif near genes repressed by Fxr in zebrafish ileal epithelial cells (Fig S6C) (61), suggesting that Fxr may interact with a conserved transcriptional pathway to repress lysosomal functions across these vertebrate lineages. Whereas our data establish roles for zebrafish Fxr on ileocyte and LRE gene expression, we find that Fxr is not required for morphology of the ileal region similar to the observations from Fxr knockout mice (30). Loss of Fxr function did not overtly affect the relative abundance of ileal epithelial cells (cluster 17) cells, nor the spatial boundaries separating the typical ileocyte region from the adjacent LRE and anterior enterocyte regions (Fig 6C-G). The abundance of LREs also appears unaffected in $f x r$ mutants, indicating the observed impacts on LRE gene expression represent altered physiology in those cells (Fig 6A, F). The impacts of $f x r$ mutation on ileocyte fate is less clear. Ileocytes are stereotypically defined by their expression of bile salt transport genes, which are markedly reduced in $f x r$ mutants as expected (Fig 6A). The differentiation and physiology of the cells that develop in $f x r$ mutants within the typical ileocyte region remain unclear, and were not resolved 
by our scRNA-seq dataset due to the relatively small number of cells located in cluster 17 as well as their substantial heterogeneity (Fig S6). Our results do show that Fxr is involved in tuning distinct transcriptional and physiologic programs of these ileal epithelial cell types while other transcriptional pathways likely determine ileal organization and differentiation. This is consistent with the notion that multiple TFs regulate the same intestinal enterocytes but target distinct cellular processes $(47,62)$.

In contrast to our grasp on Fxr regulation of ileal epithelial cell functions, relatively little is known about the impacts of Fxr on other intestinal cell types. Using scRNA-seq, we show that Fxr exhibits different regulatory effects in anterior enterocytes compared to ileal epithelial cells. Mutation of Fxr led to a significant increase in the abundance of the anterior enterocyte population (Fig 7A, S5A). This is consistent with the observations from intestinal tumorigenesis studies, which show that FXR restricts abnormal stem cell expansion thereby balancing the epithelial proliferative and apoptotic pathways $(30,63,64)$. It is therefore possible that Fxr similarly affects stem cell dynamics in the zebrafish intestinal epithelium, however such studies await the establishment of markers and tools to study intestinal epithelial stem cells in the zebrafish. Along with the abundance, we also found that the differentiation status of the anterior enterocytes in zebrafish is regulated by Fxr (Fig 7B). Similar roles of Fxr in promoting cell differentiation programs have been reported in other cell types in mammals, including mesenchymal stem cells, adipocytes, and osteoblasts (65-67). While the mechanism underlying Fxr's regulation of cell differentiation remains unclear, we speculate that Fxr may coordinate with $\mathrm{Hnf} 4 \alpha$ to elicit such regulatory effects in zebrafish anterior enterocytes, as Hnf $4 \alpha$ binding motif was highly enriched near Fxr-dependent genes (Fig 7C). Indeed, Fxr and Hnf4 $\alpha$ can directly interact and cooperatively modulate gene transcription $(68,69)$, and Fxr positively regulates Hnf $4 \alpha$ protein levels in mouse liver (68). Therefore, it is possible that Fxr increases $\mathrm{Hnf} 4 \alpha$ protein expression or activity to promote enterocyte differentiation in the zebrafish intestine. Nonetheless, our findings reveal novel roles of Fxr in modulating the abundance and differentiation of zebrafish anterior enterocytes.

The molecular and physiologic mechanisms by which Fxr mediates these effects on distinct intestinal epithelial cell types warrant further investigation. Fxr function affects hundreds of genes in the zebrafish (this study) and mouse intestine (34), but it remains unclear how many of those are due to primary autonomous roles for Fxr interacting with those gene loci as opposed to secondary systemic effects caused by Fxr mutation. For example, Fxr mutation in the intestine can disrupt endocrine hormone Fgf19 signaling and bile salt homeostasis, therefore producing systemic impacts on energy metabolism, tissue regeneration, and control of inflammation (70). Further, Fxr also has critical autonomous roles other organ systems (71) which may be impaired in the whole-animal fxr mutant zebrafish that we used here. The resulting extra-intestinal and systemic changes may in turn feedback to the intestine to elicit secondary effects on intestinal 
gene expression and physiology. Tissue-specific and conditional mutant alleles could help distinguish between these different possibilities in the future.

\section{Materials and Methods}

\section{Zebrafish lines and husbandry}

All zebrafish experiments were performed following protocols approved by the Duke University Medical Center Institutional Animal Care and Use Committee (protocol number A115-16-05). Zebrafish stocks were maintained on EK, TL, or a mixed EK/TL background on a 14/10-h light/dark cycle at $28.5^{\circ} \mathrm{C}$ in a recirculating system. From $5 \mathrm{dpf}$ to $14 \mathrm{dpf}$, larval zebrafish were fed Zeigler AP100 larval diet (Pentair, LD50-AQ) twice per day and Skretting Gemma Micro 75 (Bio-Oregon, B5676) powder once per day. From $14 \mathrm{dpf}$ to $28 \mathrm{dpf}$, larval zebrafish were fed Artemia (Brine Shrimp Direct, BSEACASE) twice per day and Skretting Gemma Micro 75 powder once per day. From $28 \mathrm{dpf}$ to the onset of sexual maturity, Gemma Micro 75 diet was replaced with Gemma Micro 300 (Bio-Oregon, B2809) to feed juvenile zebrafish. After reaching sexual maturity, adult fish were fed Artemia twice per day and a 1:1 mixture of Skretting Gemma Micro 500 and Wean 0.5 (Bio-Oregon, B1473 and B2818) once per day. Male and female adult zebrafish of 3-12 months of age were used for breeding for fish used in this study.

Zebrafish embryos were collected from natural matings and maintained in the corresponding media at a density of $<1$ larva/mL at $28.5^{\circ} \mathrm{C}$ on a $14 / 10$-h light/dark cycle, and were of indeterminate sex. Generation, colonization, maintenance, and sterility test of the germ-free zebrafish larvae were performed as described previously with the exception that an additional 50 $\mu \mathrm{g} / \mathrm{mL}$ gentamycin (Sigma, G1264) was supplemented in the antibiotic-containing gnotobiotic zebrafish medium (AB-GZM) (72). Conventionally raised zebrafish larvae were maintained in embryo media $\left(0.3 \%\right.$ (w/v) crystal sea salt, $0.75 \mathrm{mM} \mathrm{CaCO}_{3}, 0.45 \mathrm{mM} \mathrm{NaHCO}_{3}$, methylene blue). The following engineered zebrafish lines were used in this study: $f x r^{-10 /-10}$ (generated in this study), cyp7a1 ${ }^{-16 /-16}$ (generated in this study), Tg(-1.7fabp6:EGFP-pA-cryaa:mCherry) (generated in this study), slc10a2 ${ }^{\text {sa2486 }}$ (25), Tg(-4.5fabp2:DsRed) (43), TgBAC(cldn15la-GFP) (31), TgBAC(lamp2:RFP) (73), and Tg(-0.258fabp6-cfos:GFP) (17).

\section{Genotyping}

For genotyping of larval zebrafish, whole larvae were euthanized and placed in PCR tubes containing $50 \mu \mathrm{L}$ of $50 \mathrm{mM} \mathrm{NaOH}$ and denatured at $95^{\circ} \mathrm{C}$ for 20 minutes, after which $5 \mu \mathrm{L}$ of $1 \mathrm{M}$ Tris- $\mathrm{HCl}$ ( $\mathrm{pH}$ 8.0) was added. PCR was performed with 2x GoTaq Green master mix using 1 $\mu \mathrm{L}$ template and the corresponding primers (Table S2). For genotyping of adult zebrafish, the tail fin was clipped from anesthetized fish and used to generate the PCR template.

\section{Construction of mutant zebrafish lines}

Mutant zebrafish lines were generated using CRISPR/Cas9 as described previously (74). Briefly, the guide RNAs (gRNAs) were designed using the "CRISPRscan" tool 
(https://www.crisprscan.org/) (75) and synthesized using oligo-based in vitro transcription method (Table S2). At the one cell stage, wt zebrafish embryos (TL or EK strain) were injected with 1-2 nL of a cocktail consisting of $150 \mathrm{ng} / \mu \mathrm{L}$ of Cas $9 \mathrm{mRNA}, 120 \mathrm{ng} / \mu \mathrm{L}$ of $\mathrm{gRNA}, 0.05 \%$ phenol red, $120 \mathrm{mM} \mathrm{KCl}$, and $20 \mathrm{mM}$ HEPES (pH 7.0). Injected embryos were screened for mutagenesis with the corresponding primers (Table S2) using Melt Doctor High Resolution Melting Assay (HRMA, ThermoFisher, 4409535) following manufacturer's specifications. The mutations were further determined through Sanger sequencing of the region encompassing the gRNA targeting sites. The $f x r$ mutants were generated through targeted deletion at the exon 4 encoding the DNA binding domain of Fxr. We identified two independent deletion alleles, $f x r^{-10 /-~}$ 10 and $f x r^{-11 /-11}$ (allele designations $r d u 81$ and $r d u 82$ respectively), that each resulted in frameshift mutations and displayed significantly reduced $f x r$ mRNA (Fig S1A-B). Likewise, the cyp7al mutants, $c y p 7 a 1^{-7-/ 7}$ and $c y p 7 a 1^{-16 /-16}$ (allele designations $r d u 83$ and $r d u 84$ respectively), were generated by targeting the exon 2 encoding the cytochrome P450 domain and were validated via phenotypic assessment and/or qRT-PCR (Fig S1C-F). Only the $f x r^{-10 /-10}(r d u 81)$ and the cyp7al16/-16 (rdu84) mutants were used in this study.

\section{Construction of transgenic zebrafish line}

The $1.7 \mathrm{~kb}$ promoter fragment of the fabp6 gene was PCR amplified from the genomic DNA of wild type Tübingen zebrafish and cloned into p5E-Fse-Asc plasmid (Table S2). The resulting clone (p5E-1.7fabp6), along with the pME-EGFP and p3E-polyA plasmids were further recombined into pDestTol2pACrymCherry through multisite Gateway recombination to generate the pDestTol2-1.7fabp6:EGFPpACrymCherry $(76,77)$. This recombinant plasmid carries two linked fluorescent marker genes, a GFP and a mCherry. The expression of GFP is driven by the $1.7 \mathrm{~kb}$ fabp6 promoter fragment and reflects the expression of fabp6, whereas the expression of mCherry is driven by the lens marker cryaa and serves as a constitutive transgene marker. At the one-cell stage, wt zebrafish embryos (EK strain) were injected with 1-2 nL of a cocktail containing $50 \mathrm{ng} / \mu \mathrm{L}$ pDestTol2-1.7fabp6:EGFPpACrymCherry, $25 \mathrm{ng} / \mu \mathrm{L}$ transposase mRNA, $0.3 \%$ phenol red and $1 \mathrm{x}$ Tango buffer (ThermoFisher, BY5). Two mosaic germline founders were identified, raised to adulthood, and screened to isolate lines with the transgene inserted at a single locus. Stable Tg(-1.7fabp6:EGFP-pA-cryaa:mCherry) (allele designations $r d u 80$ ) lines were generated by outcross the founder to wt EK for at least three generations (abbreviated as $T g(-1.7 f a b p 6: G F P)$ in the rest of the article). This $T g(-1.7 f a b p 6: G F P)$ reporter line displayed a pattern of GFP expression in the ileocyte region and the LRE region similar to our previous transgenic line $T g(-0.258 f a b p 6$-cfos:GFP) (17) which expresses GFP under control of a smaller 258 bp fabp6 promoter region and a mouse Cfos minimal promoter. Compared to that line, the new $T g(-1.7 f a b p 6: G F P)$ line using the larger $1.7 \mathrm{~kb}$ fabp6 promoter region expresses GFP more distally into the LRE region and also in rare cells within the anterior regions of the intestine.

\section{Quantitative RT-PCR analysis}


RNA was isolated from samples using TRIzol (ThermoFisher, 15596026), DNase-treated using TURBO $^{\text {TM }}$ DNase (ThermoFisher, AM2238), and reverse transcribed using iScript cDNA synthesis kit (Bio-Rad, 1708891) following manufacturer's specifications. Quantitative PCR was performed with gene-specific primers (Table S2) and SYBR Green PCR Master Mix with ROX (PerfeCta, Quanta Bio) on an Applied Biosystems StepOnePlus ${ }^{\text {TM }}$ Real-Time PCR System. Data were analyzed with the $\Delta \Delta \mathrm{Ct}$ method. For whole larvae samples, 6-7 dpf larvae were collected for RNA isolation (15-30 larvae/replicate; 4-8 replicates/condition). For larval digestive tissue samples, 6-7 dpf larval zebrafish digestive tracts were dissected under a stereomicroscope and pooled for RNA isolation (25-35 guts/replicate; 4-6 replicates/condition). For adult digestive tissue samples, 3-month-old gender and size matched adult zebrafish livers or guts were used (1 gut or liver/replicate; 5-8 replicates/condition).

\section{In vivo imaging and densitometry}

To quantify the GFP fluorescence of the $T g(-1.7 f a b p 6: G F P)$ lines, live zebrafish larvae were anesthetized, embedded in 3\% methylcellulose (w/v in GZM), and imaged using a Leica M205 FA stereomicroscope with identical exposure time and magnification in the same experiment. GFP densitometry analysis was performed using Fiji software (78). For each experiment, the areas of interest were selected using the shape tools, recorded using the ROI manager, and applied to all images. The background was calculated as the average fluorescence from 3-5 nontransgenic siblings of the transgenic zebrafish lines from the same experiment and was subtracted from all images using the threshold tools. The mean fluorescence intensity values of each image were determined and plotted using GraphPad Prism software.

\section{Bile salts collection in zebrafish}

Twenty wild-type adult zebrafish of 6-9-month-old from 4 different stocks were starved for $48 \mathrm{~h}$ to eliminate the potential contribution of exogenous bile salt from the zebrafish diet on zebrafish de novo bile salts. The gallbladders were dissected using autoclaved forceps and immediately placed in $1 \mathrm{~mL}$ of pre-chilled isopropanol. The suspension was vortexed and centrifuged (13,000 rpm for $10 \mathrm{~min}$ ), and the supernatant was evaporated under a stream of nitrogen at room temperature. The residues were resuspended in $1 \mathrm{~mL}$ of $100 \%$ methanol. For thin layer chromatography (TLC), $20 \mu \mathrm{L}$ of the methanol extract was spotted on to a silica TLC plate. The butanol: acetic acid: water $(85: 10: 15$, BAW) mobile phase system was used to separate the bile components. Additionally, a diluted (1:100) sample was subjected for LC/MS analysis. For bile salt analysis of zebrafish intestinal contents, 10 pooled wt adult zebrafish intestines were subjected to the same procedures as gallbladders above and diluted (1:100) for LC/MS.

\section{Flash column chromatography of crude carp bile}

Asian grass carp gallbladders $(n=3)$ were collected from a local supermarket in Champaign, IL. Bile was collected from each gallbladder and pooled for extraction $(45 \mathrm{~mL})$. Crude bile was extracted using 9x isopropanol, and the isopropanol-soluble portion was collected for analysis. 
The isopropanol layer was concentrated to approximately $20 \mathrm{~mL}$ under nitrogen. Diluted (1:100) crude bile samples were used for TLC analysis with the BAW mobile phase. Purification of carp bile acids and alcohols was performed using flash column chromatography as described previously (23). The flash column (80 cm x $2 \mathrm{~cm} ; 100 \mathrm{~mL})$ was packed $2 / 3$ full with $40 \mu \mathrm{M}$ silica gel. It was assembled using chloroform: methanol (80:20; v/v) mobile phase. The concentrated isopropanol-bile mixture was placed on top of the packed silica for purification. The eluates of crude bile were collected in $50 \mathrm{~mL}$ fractions using a gradient of chloroform:methanol (80:20; $500 \mathrm{~mL}, 75: 25 ; 500 \mathrm{~mL}, 70: 30 ; 1000 \mathrm{~mL}, 65: 35 ; 500 \mathrm{~mL})$. The fractions were evaporated under nitrogen and resuspended in $100 \%$ methanol. A dilute sample of each fraction was spotted $(30 \mu \mathrm{L})$ and examined on a TLC plate using BAW mobile phase. Select fractions were chosen for LC/MS analysis.

\section{TLC visualization and extraction of bile compounds from TLC}

Zebrafish and carp bile in methanol were examined using silica gel TLC plate (JT Baker, JT4449-4). Two mobile phases were used to separate bile alcohols and bile acids. BAW mobile phase consisted of butanol: acetic acid: water (85:10:15) mobile phase. Solvent 25 mobile phase used was n-propanol: isoamyl acetate: acetic acid: water (4:3:2:1). Plates were sprayed with $10 \%$ phosphomolybdic acid (w/v) in ethanol and plates were baked at $100{ }^{\circ} \mathrm{C}$ for $10 \mathrm{~min}$. To extract bile compounds from the TLC plate, silica from replicate plates was extracted twice with $3 \mathrm{~mL}$ butanol and $3 \mathrm{~mL}$ water. The butanol layer was removed after each extraction, combined, and evaporated under nitrogen gas.

\section{Extraction of carp intestinal contents}

Whole intestines were removed from Asian carp and collected in $50 \mathrm{~mL}$ conical tubes. The contents were placed in a $-80{ }^{\circ} \mathrm{C}$ freezer overnight and lyophilized to remove all liquid. For LC/MS analysis, dry intestinal contents $(0.14 \mathrm{~g})$ were resuspended in $1 \mathrm{~mL}$ of $90 \%$ ethanol and sonicated for $30 \mathrm{~min}$ to completely dissolve soluble compounds. Furthermore, the intestinal content was centrifuged (10,000 rpm for $15 \mathrm{~min})$ and the supernatant was filtered $(0.45 \mu \mathrm{m})$ to remove additional precipitates. Diluted samples (1:100) of the filtered supernatant were spotted $(30 \mu \mathrm{L})$ on to a TLC using BAW mobile phase and also injected on to LC/MS in untargeted full scan mode to analyze metabolites.

\section{NMR analysis of purified zebrafish bile alcohol}

Pure flash column chromatography fractions and TLC spots matching the Rf value for $5 \alpha \mathrm{CS}$ were validated using mass spectrometry in negative ion mode. $1 \mathrm{mg}$ of pure bile alcohol in methanol was used on a Waters SynaptG2-Si ESI MS. The MS data was analyzed using Waters MassLynx 4.1 software. Additionally, a $4 \mathrm{mg}$ sample of the evaporated bile alcohol was resuspended in $750 \mu \mathrm{L}$ of deuterated methanol and analyzed by nuclear magnetic resonance spectroscopy using an Agilent $600 \mathrm{MHz}$ with a 14.1 Tesla $54 \mathrm{~mm}$ bore Agilent Premium 
Compact Shield Superconducting Magnet. Data was visualized at the University of Illinois using MNova.

\section{Liquid chromatography/mass spectrometry (LC/MS)}

LC/MS for all samples was performed using a Waters Aquity UPLC coupled with a Waters Synapt G2-Si ESI MS. Chromatography was performed using a Waters Cortecs UPLC C18 column $(1.6 \mu \mathrm{m}$ particle size $)(2.5 \mathrm{~mm}$ x $50 \mathrm{~mm})$ with a column temperature of $40^{\circ} \mathrm{C}$. Samples were injected at $1 \mu \mathrm{L}$. Solvent A consisted of $95 \%$ water, $5 \%$ acetonitrile, and $0.1 \%$ formic acid. Solvent B consisted of $95 \%$ acetonitrile, $5 \%$ water, and $0.1 \%$ formic acid. The initial mobile phase was $90 \%$ Solvent A, 10\% Solvent B and increased linearly until the gradient reached 50\% Solvent A and 50\% Solvent B at $7.5 \mathrm{~min}$. Solvent B was increased linearly again until it was briefly $100 \%$ at 8.0 min until returning to the initial mobile phase $(90 \%$ Solvent A, $10 \%$ Solvent B) over the next $2 \mathrm{~min}$. The total run was $10 \mathrm{~min}$ with a flow rate of $10 \mu \mathrm{L} / \mathrm{min}$. MS was performed in negative ion mode. Nebulizer gas pressure was maintained at $400{ }^{\circ} \mathrm{C}$ and gas flow was $800 \mathrm{~L} /$ hour. The capillary voltage was set at 2,000 V in negative mode. MassLynx was used to analyze chromatographs and mass spectrometry data. The limit of detection (LOD) was defined as a 3:1 signal to noise ratio using the LC peak data. The limit of quantification was defined as the 10:1 signal to noise ratio using the LC peak data. A mixture containing $10 \mu \mathrm{M}$ of the following bile standards were injected onto LC/MS for analysis: D4-Glycocholic acid (Internal Standard), TCA, 5 $\alpha \mathrm{CS}$, and allocholic acid (ACA). The LC/MS method was validated once a single peak for each compound was identified with the respective $\mathrm{m} / \mathrm{z}$ value in negative mode.

To test the bile salt metabolism activity of complex zebrafish microbiota, the contents from the dissected intestines of $6 \mathrm{wt}$ adult zebrafish from 4 different stocks were pooled into 4 samples as representatives of distinct zebrafish microbial communities. Each sample was homogenized in $500 \mu \mathrm{L}$ PBS with $1 \mathrm{mM}$ DTT. The resulting intestinal homogenate was split into both aerobic and anaerobic vials containing modified TSB (1:10 dilution). Aerobic cultures were incubated with $200 \mathrm{rpm}$ shaking while anaerobic cultures were incubated statically. Both aerobic and anaerobic cultures were incubated at $30^{\circ} \mathrm{C}$ for $24 \mathrm{~h}$, after which they were subcultured (1:10 dilution) into different substrate testing media and allowed to grow at $30{ }^{\circ} \mathrm{C}$ for an additional 48 $\mathrm{h}$ before being subjected to solid phase extraction.

To test the bile salt metabolism activity of individual microbial strains, Pseudomonas sp. ZWU0006, Acinetobacter sp. ZOR0008, Shewanella sp. ZOR0012, Exiguobacterium acetylicum ZWU0009, and Chryseobacterium sp. ZOR0023 were grown at $30{ }^{\circ} \mathrm{C}$ for $24 \mathrm{~h}$ and were subcultured (1:10 dilution) into different substrate testing media, respectively. The subcultures were grown under the same condition for an additional $48 \mathrm{~h}$ and were subjected to solid phase extraction. 


\section{Solid phase extraction of bacterial culture}

Culture medium $(1 \mathrm{~mL})$ containing $50 \mu \mathrm{M}$ bile salt substrate was used for further SPE. Once grown, the culture was centrifuged (10,000 rpm for 5mins) to remove bacterial cells and conditioned medium was removed. A $10 \mu \mathrm{M}$ spike of D4-GCA internal standard was added to each sample before SPE. Waters tC18 vacuum cartridges (3 mL reservoir, $500 \mathrm{mg}$ sorbent) were used for SPE. The method was adapted from Abdel-Khalik, et al as follows (79). Cartridges were preconditioned with $100 \%$ hexanes $(6 \mathrm{~mL}), 100 \%$ acetone $(3 \mathrm{~mL}), 100 \%$ methanol $(6 \mathrm{~mL})$, and water adjusted to $\mathrm{pH} 3.0(6 \mathrm{~mL})$. Conditioned medium was adjusted to $\mathrm{pH} 3.0$, applied to the cartridge, and pulled through dropwise using a vacuum chamber. The cartridge was washed with water adjusted to $\mathrm{pH} 3.0(6 \mathrm{~mL})$ and allowed to air dry for $30 \mathrm{~min}$ before being washed with 3 $\mathrm{mL}$ of $40 \%$ methanol. The $40 \%$ methanol fraction was tested on TLC to ensure no substrates were being washed off of the column. Products were eluted using $3 \mathrm{~mL}$ of $100 \%$ methanol. Final eluates were evaporated under a stream of nitrogen and resuspended in $200 \mu \mathrm{L}$ of $100 \%$ methanol for analysis on TLC (using solvent 25) or LC/MS.

\section{Serial bile salt exposure}

For serial bile salt exposure in conventionally raised larvae, embryos were collected from natural matings between $c y p 7 a 1^{+/-16}$ and cyp $7 a 1^{+/-16} ; \mathrm{Tg}(-1.7 f a b p 6: G F P)$ and incubated in GZM at 28.5 ${ }^{\circ} \mathrm{C}$. At $3 \mathrm{dpf}$, larvae were randomly assigned into untreated group or groups treated with either 1 $\mathrm{mM}$ TCA or CA in GZM in 6-well plates. The density of larvae in each well is maintained as 10 larvae in $10 \mathrm{~mL}$ media and the media in each well were changed daily $(80 \% \mathrm{v} / \mathrm{v})$ with fresh GZM or GZM supplemented with either $1 \mathrm{mM}$ TCA or CA. At $7 \mathrm{dpf}$, larvae were sorted for mCherry under a fluorescence microscope, after which positive larvae were subjected to in vivo imaging and genotyping. Serial bile salt exposure in GF larvae was performed similarly except that GF larvae were maintained in T25 tissue flasks and that sterile TCA or CA was used for treatment.

\section{Fluorescence-activated cell sorting (FACS)}

Approximately 600-700 $6 \mathrm{dpf}$ TgBAC(cldn15la-GFP) zebrafish larvae of the $f x r^{+/+}$and the $f x r^{-/}$ genotypes were collected for the FACS experiment, respectively. The parental zebrafish used to generate the wt or the mutant embryos were stock-matched siblings from heterozygous incrosses. Dissociation of the larvae was performed as previously described (80), after which the $f x r^{+/+}$; TgBAC(cldn15la-GFP) and $f x r^{--} ; \mathrm{TgBAC}(\mathrm{cldn15la-GFP})$ cells were immediately subjected to FACS at the Duke Cancer Institute Flow Cytometry Shared Resource and were sorted side by side with two identical Beckman Coulter Astrios instruments. Non-transgenic and single transgenic controls (pools of 50 fish/genotype) were prepared as above and used for gating and compensation. Approximately $120 \mathrm{k}$ GFP positive 7-AAD negative cells per genotype were collected in $1.5 \mathrm{~mL}$ of DMEM/F12 supplemented with $10 \%$ heat-inactivated FBS and $10 \mu \mathrm{M}$ Y27632 ROCK1 inhibitor and were immediately subjected to the downstream experiments. 


\section{Single-cell RNA sequencing}

Each single-cell RNA sequencing library was generated from 10,000 FACS sorted TgBAC(cldn15la-GFP) IECs of the indicated genotype following the 10x Genomics Single-cell 3' protocol by the Duke Molecular Genomics Core. The sequencing ready libraries were cleaned with both Silane Dynabeads and SPRI beads, and quality controlled for size distribution and yield with the Agilent D5000 screenTape assays using the Agilent 4200 TapeStation system. Illumina P5 and P7 sequences, a sample index, and TruSeq read 2 primer sequence were ligated for Illumina bridge amplification. Sequence was generated using paired-end sequencing on the Novaseq SP flow cell sequencing platform at a minimum of $40 \mathrm{k}$ reads/cell.

Cell barcodes and unique molecular identifier (UMI) barcodes were demultiplexed and reads were aligned to the reference genome, danRer11, following the CellRanger pipeline recommended by $10 \mathrm{X}$ Genomics. For quality control, we first performed UMI filtering by only including UMIs with $<3000$ detected genes. Next, we removed low quality cells which we define as cells that contain $>25 \%$ transcript counts derived from mitochondrial genes. Further, we removed the putative doublets by excluding cells that contain more than 30,000 UMIs. Through these steps, a total of 2,625 low-quality or potential doublet cells were removed, after which 9,918 cells passed the requirement, including 4,710 cells from $f x r$ wt and 5,208 cells from $f x r$ mutant samples. The genotype of $f x r$ wt and mutant samples was confirmed by visualization of reads spanning the $-10 /-10$ lesion (Fig. S4A).

Clustering and statistical analysis of the single-cell RNA-sequencing data was performed using the $\mathrm{R}$ package Seurat (version 3.1). Count matrices from both the fxr wt and mutant libraries were log-normalized and highly variable genes were found in each library using the FindVariableFeatures() function. Afterwards, these data were integrated together using the wt library as the reference dataset through the FindIntegrationAnchors (dims $=1: 35)$ and IntegrateData (dims $=1: 35$ ) functions. The integrated expression matrix was then re-normalized using the NormalizeData() function for visualization purposes. To mitigate the effects of unwanted sources of cell-to-cell variation in the integrated dataset, we used the ScaleData() function prior to running a principal component analysis. Jackstraw analysis revealed that the first 54 principal components significantly accounted for the variation in our data, and were thus used as input to the FindClusters() function with the resolution parameter set to 0.82 . Using the shared nearest neighbor algorithm (SNN) within the FindNeighbors() function, cells were grouped into 27 distinct clusters and were visualized by uniform manifold approximation and projection (UMAP), which reduces the information captured in the selected significant principal components to two dimensions. The UMAP visualization was generated using the RunUMAP() function with the "n_neighbors" parameter set to 30 .

To resolve putative distinct functional cell types in cluster 17 cells in $f x r$ wt zebrafish, we performed sub-clustering of the cluster 17 using a similar strategy as described above with the 
exception that we used 8 principal components following JackStraw analysis and a resolution of 0.5 in the FindClusters() function. This resulted in two sub-clusters: 17_0 and 17_1 (Fig S6D).

To identify marker genes of $f x r$ wt cells in each cluster, we used two methods with different stringency standards. First, we employed the FindAllMarkers() function using a Wilcox Rank Sum Test to determine genes that are significantly upregulated in each cluster compared to all other clusters combined as one group. These genes were further filtered based on an adjusted pvalue below 0.05 and an absolute $\log _{10}$ fold-change value over 0.25 , resulting in a set of marker genes that we designated as "cluster markers" (Dataset 2). Second, we performed pairwise comparisons between the cluster of interest and each and every other clusters using FindMarkers() function and only selected genes that showed higher expression, defined as an absolute $\log _{10}$ fold-change value over 0.25 , in the cluster of interest in all comparisons. This pairwise comparison-based filtering step resulted in a set of more stringent marker genes, designated as "cluster-enriched markers", that represented the most highly expressed genes in the cluster of interest (Dataset 3). The expression and the distribution of relevant cluster markers or any gene of interest were visualized using FeaturePlot(), DotPlot(), and VlnPlot() functions.

To identify genes that were differentially expressed between the $f x r$ wt and mutant cells in each cluster, we used the FindMarkers() function using a Wilcox Rank Sum Test. Differentially expressed genes were arbitrarily defined as those that showed an absolute $\log _{10}$ fold-change value over 0.25 .

\section{Transcription factor binding motif enrichment analysis}

We used FAIRE-Seq data from adult zebrafish intestinal epithelium (17) to identify accessible chromatin regions at genes that are differentially regulated in either cluster 17 or 4 . Using GALAXY, each FAIRE-Seq peak was associated with the nearest gene, including its surrounding regulatory regions (including $10 \mathrm{~kb}$ from the gene transcription start site, the gene body, and $10 \mathrm{~kb}$ from transcription termination sequence). We generated a BED file containing this information for every gene, that could be filtered based on gene symbol identifier later based on whether or not a particular gene was differentially expressed in clusters 17 or 4 . To identify enriched transcription factor binding sites, we used "findMotifsGenome.pl" function of the HOMER software (http://homer.ucsd.edu/homer/) with foreground and background set of genomic coordinates. Specifically, genes that were differentially expressed between $f x r$ wt and mutant cells in the cluster of interest were used as the foreground, and the ones that were not differentially expressed in the cluster of interest but exhibited expression in at least one of the IEC clusters were used as background.

\section{Statistical Analysis}

For the scRNA-seq experiment, statistical analyses for determination of the cluster markers, cluster-enriched markers, and differentially expressed genes of each clusters were calculated 
using the FindMarkers() function of the Seurat package in R with a Wilcox Rank Sum Test. For all other experiments, statistical analysis was performed using unpaired t-test, or one-way or two-way ANOVA with Turkey's multiple comparisons test with GraphPad Prism. A P<0.05 was defined as statistically significant.

\section{References}

1. A. F. Hofmann, L. R. Hagey, M. D. Krasowski, Bile salts of vertebrates: structural variation and possible evolutionary significance. J Lipid Res 51, 226-246 (2010).

2. F. G. Schaap, M. Trauner, P. L. Jansen, Bile acid receptors as targets for drug development. Nat Rev Gastroenterol Hepatol 11, 55-67 (2014).

3. D. J. Parks, S. G. Blanchard, R. K. Bledsoe, G. Chandra, T. G. Consler, S. A. Kliewer, J. B. Stimmel, T. M. Willson, A. M. Zavacki, D. D. Moore, J. M. Lehmann, Bile acids: natural ligands for an orphan nuclear receptor. Science 284, 1365-1368 (1999).

4. P. Lefebvre, B. Cariou, F. Lien, F. Kuipers, B. Staels, Role of bile acids and bile acid receptors in metabolic regulation. Physiol Rev 89, 147-191 (2009).

5. J. M. Ridlon, D. J. Kang, P. B. Hylemon, J. S. Bajaj, Bile acids and the gut microbiome. Curr Opin Gastroenterol 30, 332-338 (2014).

6. J. A. Winston, C. M. Theriot, Diversification of host bile acids by members of the gut microbiota. Gut Microbes 11, 158-171 (2020).

7. E. J. Reschly, N. Ai, S. Ekins, W. J. Welsh, L. R. Hagey, A. F. Hofmann, M. D. Krasowski, Evolution of the bile salt nuclear receptor FXR in vertebrates. J Lipid Res 49, 1577-1587 (2008).

8. K. Frisch, A. K. O. Alstrup, On the Evolution of Bile Salts and the Farnesoid X Receptor in Vertebrates. Physiol Biochem Zool 91, 797-813 (2018).

9. G. L. Guo, J. Y. L. Chiang, Is CYP2C70 the key to new mouse models to understand bile acids in humans? J Lipid Res 61, 269-271 (2020).

10. E. R. McGlone, T. Tan, S. R. Bloom, J. R. F. Walters, What Can We Learn From Mouse Models About Bile Acid-Mediated Changes After Bariatric Surgery? Gastroenterology 157, 4-8 (2019).

11. J. D. Carten, M. K. Bradford, S. A. Farber, Visualizing digestive organ morphology and function using differential fatty acid metabolism in live zebrafish. Dev Biol 360, 276-285 (2011).

12. J. L. Ellis, K. E. Bove, E. G. Schuetz, D. Leino, C. A. Valencia, J. D. Schuetz, A. Miethke, C. Yin, Zebrafish abcb11b mutant reveals strategies to restore bile excretion impaired by bile salt export pump deficiency. Hepatology 67, 1531-1545 (2018).

13. S. Wang, S. R. Miller, E. A. Ober, K. C. Sadler, Making It New Again: Insight Into Liver Development, Regeneration, and Disease From Zebrafish Research. Curr Top Dev Biol 124, 161-195 (2017).

14. D. H. Pham, C. Yin, Zebrafish as a Model to Study Cholestatic Liver Diseases. Methods Mol Biol 1981, 273-289 (2019). 
15. F. A. Alves-Costa, E. M. Denovan-Wright, C. Thisse, B. Thisse, J. M. Wright, Spatiotemporal distribution of fatty acid-binding protein 6 (fabp6) gene transcripts in the developing and adult zebrafish (Danio rerio). FEBS J 275, 3325-3334 (2008).

16. S. Enya, K. Kawakami, Y. Suzuki, S. Kawaoka, A novel zebrafish intestinal tumor model reveals a role for cyp7a1-dependent tumor-liver crosstalk in causing adverse effects on the host. Dis Model Mech 11, (2018).

17. C. R. Lickwar, J. G. Camp, M. Weiser, J. L. Cocchiaro, D. M. Kingsley, T. S. Furey, S. Z. Sheikh, J. F. Rawls, Genomic dissection of conserved transcriptional regulation in intestinal epithelial cells. PLoS Biol 15, e2002054 (2017).

18. S. A. Farber, M. Pack, S. Y. Ho, I. D. Johnson, D. S. Wagner, R. Dosch, M. C. Mullins, H. S. Hendrickson, E. K. Hendrickson, M. E. Halpern, Genetic analysis of digestive physiology using fluorescent phospholipid reporters. Science 292, 1385-1388 (2001).

19. L. R. Hagey, P. R. Moller, A. F. Hofmann, M. D. Krasowski, Diversity of bile salts in fish and amphibians: evolution of a complex biochemical pathway. Physiol Biochem Zool 83, 308-321 (2010).

20. C. J. Sinal, M. Tohkin, M. Miyata, J. M. Ward, G. Lambert, F. J. Gonzalez, Targeted disruption of the nuclear receptor FXR/BAR impairs bile acid and lipid homeostasis. Cell 102, 731-744 (2000).

21. J. R. Plass, O. Mol, J. Heegsma, M. Geuken, K. N. Faber, P. L. Jansen, M. Muller, Farnesoid $\mathrm{X}$ receptor and bile salts are involved in transcriptional regulation of the gene encoding the human bile salt export pump. Hepatology 35, 589-596 (2002).

22. T. Inagaki, M. Choi, A. Moschetta, L. Peng, C. L. Cummins, J. G. McDonald, G. Luo, S. A. Jones, B. Goodwin, J. A. Richardson, R. D. Gerard, J. J. Repa, D. J. Mangelsdorf, S. A. Kliewer, Fibroblast growth factor 15 functions as an enterohepatic signal to regulate bile acid homeostasis. Cell Metab 2, 217-225 (2005).

23. T. Goto, F. Holzinger, L. R. Hagey, C. Cerre, H. T. Ton-Nu, C. D. Schteingart, J. H. Steinbach, B. L. Shneider, A. F. Hofmann, Physicochemical and physiological properties of 5alpha-cyprinol sulfate, the toxic bile salt of cyprinid fish. J Lipid Res 44, 1643-1651 (2003).

24. M. D. Krasowski, K. Yasuda, L. R. Hagey, E. G. Schuetz, Evolution of the pregnane x receptor: adaptation to cross-species differences in biliary bile salts. Mol Endocrinol 19, 1720-1739 (2005).

25. R. N. Kettleborough, E. M. Busch-Nentwich, S. A. Harvey, C. M. Dooley, E. de Bruijn, F. van Eeden, I. Sealy, R. J. White, C. Herd, I. J. Nijman, F. Fenyes, S. Mehroke, C. Scahill, R. Gibbons, N. Wali, S. Carruthers, A. Hall, J. Yen, E. Cuppen, D. L. Stemple, A systematic genome-wide analysis of zebrafish protein-coding gene function. Nature 496, 494-497 (2013).

26. M. Une, N. Matsumoto, K. Kihira, M. Yasuhara, T. Kuramoto, T. Hoshita, Bile salts of frogs: a new higher bile acid, 3 alpha, 7 alpha, 12 alpha, 26-tetrahydroxy-5 betacholestanoic acid from the bile Rana plancyi. J Lipid Res 21, 269-276 (1980). 
27. H. Doden, L. A. Sallam, S. Devendran, L. Ly, G. Doden, S. L. Daniel, J. M. P. Alves, J. M. Ridlon, Metabolism of Oxo-Bile Acids and Characterization of Recombinant 12alphaHydroxysteroid Dehydrogenases from Bile Acid 7alpha-Dehydroxylating Human Gut Bacteria. Appl Environ Microbiol 84, (2018).

28. S. M. Mythen, S. Devendran, C. Mendez-Garcia, I. Cann, J. M. Ridlon, Targeted Synthesis and Characterization of a Gene Cluster Encoding NAD(P)H-Dependent 3alpha-, 3beta-, and 12alpha-Hydroxysteroid Dehydrogenases from Eggerthella CAG:298, a Gut Metagenomic Sequence. Appl Environ Microbiol 84, (2018).

29. J. Y. Chiang, R. Kimmel, C. Weinberger, D. Stroup, Farnesoid X receptor responds to bile acids and represses cholesterol 7alpha-hydroxylase gene (CYP7A1) transcription. $J$ Biol Chem 275, 10918-10924 (2000).

30. R. R. Maran, A. Thomas, M. Roth, Z. Sheng, N. Esterly, D. Pinson, X. Gao, Y. Zhang, V. Ganapathy, F. J. Gonzalez, G. L. Guo, Farnesoid X receptor deficiency in mice leads to increased intestinal epithelial cell proliferation and tumor development. J Pharmacol Exp Ther 328, 469-477 (2009).

31. A. L. Alvers, S. Ryan, P. J. Scherz, J. Huisken, M. Bagnat, Single continuous lumen formation in the zebrafish gut is mediated by smoothened-dependent tissue remodeling. Development 141, 1110-1119 (2014).

32. T. Stuart, A. Butler, P. Hoffman, C. Hafemeister, E. Papalexi, W. M. Mauck, 3rd, Y. Hao, M. Stoeckius, P. Smibert, R. Satija, Comprehensive Integration of Single-Cell Data. Cell 177, 1888-1902 e1821 (2019).

33. K. Parikh, A. Antanaviciute, D. Fawkner-Corbett, M. Jagielowicz, A. Aulicino, C. Lagerholm, S. Davis, J. Kinchen, H. H. Chen, N. K. Alham, N. Ashley, E. Johnson, P. Hublitz, L. Bao, J. Lukomska, R. S. Andev, E. Bjorklund, B. M. Kessler, R. Fischer, R. Goldin, H. Koohy, A. Simmons, Colonic epithelial cell diversity in health and inflammatory bowel disease. Nature 567, 49-55 (2019).

34. S. Fang, J. M. Suh, S. M. Reilly, E. Yu, O. Osborn, D. Lackey, E. Yoshihara, A. Perino, S. Jacinto, Y. Lukasheva, A. R. Atkins, A. Khvat, B. Schnabl, R. T. Yu, D. A. Brenner, S. Coulter, C. Liddle, K. Schoonjans, J. M. Olefsky, A. R. Saltiel, M. Downes, R. M. Evans, Intestinal FXR agonism promotes adipose tissue browning and reduces obesity and insulin resistance. Nat Med 21, 159-165 (2015).

35. K. Jadhav, Y. Xu, Y. Xu, Y. Li, J. Xu, Y. Zhu, L. Adorini, Y. K. Lee, T. Kasumov, L. Yin, Y. Zhang, Reversal of metabolic disorders by pharmacological activation of bile acid receptors TGR5 and FXR. Mol Metab 9, 131-140 (2018).

36. D. R. Schmidt, S. Schmidt, S. R. Holmstrom, M. Makishima, R. T. Yu, C. L. Cummins, D. J. Mangelsdorf, S. A. Kliewer, AKR1B7 is induced by the farnesoid X receptor and metabolizes bile acids. J Biol Chem 286, 2425-2432 (2011).

37. T. Claudel, E. Sturm, H. Duez, I. P. Torra, A. Sirvent, V. Kosykh, J. C. Fruchart, J. Dallongeville, D. W. Hum, F. Kuipers, B. Staels, Bile acid-activated nuclear receptor 
FXR suppresses apolipoprotein A-I transcription via a negative FXR response element. $J$ Clin Invest 109, 961-971 (2002).

38. I. Kim, S. H. Ahn, T. Inagaki, M. Choi, S. Ito, G. L. Guo, S. A. Kliewer, F. J. Gonzalez, Differential regulation of bile acid homeostasis by the farnesoid $\mathrm{X}$ receptor in liver and intestine. J Lipid Res 48, 2664-2672 (2007).

39. Z. Wang, J. Du, S. H. Lam, S. Mathavan, P. Matsudaira, Z. Gong, Morphological and molecular evidence for functional organization along the rostrocaudal axis of the adult zebrafish intestine. BMC Genomics 11, 392 (2010).

40. J. Park, D. S. Levic, K. D. Sumigray, J. Bagwell, O. Eroglu, C. L. Block, C. Eroglu, R. Barry, C. R. Lickwar, J. F. Rawls, S. A. Watts, T. Lechler, M. Bagnat, Lysosome-Rich Enterocytes Mediate Protein Absorption in the Vertebrate Gut. Dev Cell 51, 7-20 e26 (2019).

41. K. N. Wallace, S. Akhter, E. M. Smith, K. Lorent, M. Pack, Intestinal growth and differentiation in zebrafish. Mech Dev 122, 157-173 (2005).

42. J. Harper, A. Mould, R. M. Andrews, E. K. Bikoff, E. J. Robertson, The transcriptional repressor Blimp1/Prdm1 regulates postnatal reprogramming of intestinal enterocytes. Proc Natl Acad Sci U S A 108, 10585-10590 (2011).

43. M. Kanther, X. Sun, M. Muhlbauer, L. C. Mackey, E. J. Flynn, 3rd, M. Bagnat, C. Jobin, J. F. Rawls, Microbial colonization induces dynamic temporal and spatial patterns of NFkappaB activation in the zebrafish digestive tract. Gastroenterology 141, 197-207 (2011).

44. A. L. Haber, M. Biton, N. Rogel, R. H. Herbst, K. Shekhar, C. Smillie, G. Burgin, T. M. Delorey, M. R. Howitt, Y. Katz, I. Tirosh, S. Beyaz, D. Dionne, M. Zhang, R. Raychowdhury, W. S. Garrett, O. Rozenblatt-Rosen, H. N. Shi, O. Yilmaz, R. J. Xavier, A. Regev, A single-cell survey of the small intestinal epithelium. Nature 551, 333-339 (2017).

45. J. Kazakevych, S. Sayols, B. Messner, C. Krienke, N. Soshnikova, Dynamic changes in chromatin states during specification and differentiation of adult intestinal stem cells. Nucleic Acids Res 45, 5770-5784 (2017).

46. J. P. Babeu, M. Darsigny, C. R. Lussier, F. Boudreau, Hepatocyte nuclear factor 4alpha contributes to an intestinal epithelial phenotype in vitro and plays a partial role in mouse intestinal epithelium differentiation. Am J Physiol Gastrointest Liver Physiol 297, G124134 (2009).

47. A. K. San Roman, B. E. Aronson, S. D. Krasinski, R. A. Shivdasani, M. P. Verzi, Transcription factors GATA4 and HNF4A control distinct aspects of intestinal homeostasis in conjunction with transcription factor CDX2. J Biol Chem 290, 1850-1860 (2015).

48. J. M. Ridlon, S. C. Harris, S. Bhowmik, D. J. Kang, P. B. Hylemon, Consequences of bile salt biotransformations by intestinal bacteria. Gut Microbes 7, 22-39 (2016). 
49. J. Robben, G. Parmentier, H. Eyssen, Isolation of a rat intestinal Clostridium strain producing 5 alpha- and 5 beta-bile salt 3 alpha-sulfatase activity. Appl Environ Microbiol 51, 32-38 (1986).

50. Y. Tazuke, K. Matsuda, K. Adachi, Y. Tsukada, Purification and properties of a novel sulfatase from Pseudomonas testosteroni that hydrolyzed 3 beta-hydroxy-5-cholenoic acid 3-sulfate. Biosci Biotechnol Biochem 62, 1739-1744 (1998).

51. J. P. Hamilton, G. Xie, J. P. Raufman, S. Hogan, T. L. Griffin, C. A. Packard, D. A. Chatfield, L. R. Hagey, J. H. Steinbach, A. F. Hofmann, Human cecal bile acids: concentration and spectrum. Am J Physiol Gastrointest Liver Physiol 293, G256-263 (2007).

52. C. Song, B. Wang, J. Tan, L. Zhu, D. Lou, Discovery of tauroursodeoxycholic acid biotransformation enzymes from the gut microbiome of black bears using metagenomics. Sci Rep 7, 45495 (2017).

53. B. V. Jones, M. Begley, C. Hill, C. G. Gahan, J. R. Marchesi, Functional and comparative metagenomic analysis of bile salt hydrolase activity in the human gut microbiome. Proc Natl Acad Sci U S A 105, 13580-13585 (2008).

54. S. A. Joyce, J. MacSharry, P. G. Casey, M. Kinsella, E. F. Murphy, F. Shanahan, C. Hill, C. G. Gahan, Regulation of host weight gain and lipid metabolism by bacterial bile acid modification in the gut. Proc Natl Acad Sci U S A 111, 7421-7426 (2014).

55. T. Matsubara, F. Li, F. J. Gonzalez, FXR signaling in the enterohepatic system. Mol Cell Endocrinol 368, 17-29 (2013).

56. M. Arrese, M. Trauner, R. J. Sacchiero, M. W. Crossman, B. L. Shneider, Neither intestinal sequestration of bile acids nor common bile duct ligation modulate the expression and function of the rat ileal bile acid transporter. Hepatology 28, 1081-1087 (1998).

57. F. Chen, L. Ma, P. A. Dawson, C. J. Sinal, E. Sehayek, F. J. Gonzalez, J. Breslow, M. Ananthanarayanan, B. L. Shneider, Liver receptor homologue-1 mediates species- and cell line-specific bile acid-dependent negative feedback regulation of the apical sodiumdependent bile acid transporter. J Biol Chem 278, 19909-19916 (2003).

58. E. Neimark, F. Chen, X. Li, B. L. Shneider, Bile acid-induced negative feedback regulation of the human ileal bile acid transporter. Hepatology 40, 149-156 (2004).

59. V. Muncan, J. Heijmans, S. D. Krasinski, N. V. Buller, M. E. Wildenberg, S. Meisner, M. Radonjic, K. A. Stapleton, W. H. Lamers, I. Biemond, M. A. van den Bergh Weerman, D. O'Carroll, J. C. Hardwick, D. W. Hommes, G. R. van den Brink, Blimp1 regulates the transition of neonatal to adult intestinal epithelium. Nat Commun 2, 452 (2011).

60. J. M. Lee, M. Wagner, R. Xiao, K. H. Kim, D. Feng, M. A. Lazar, D. D. Moore, Nutrient-sensing nuclear receptors coordinate autophagy. Nature 516, 112-115 (2014).

61. S. Seok, T. Fu, S. E. Choi, Y. Li, R. Zhu, S. Kumar, X. Sun, G. Yoon, Y. Kang, W. Zhong, J. Ma, B. Kemper, J. K. Kemper, Transcriptional regulation of autophagy by an FXR-CREB axis. Nature 516, 108-111 (2014). 
62. Y. D. Benoit, F. Pare, C. Francoeur, D. Jean, E. Tremblay, F. Boudreau, F. Escaffit, J. F. Beaulieu, Cooperation between HNF-1alpha, Cdx2, and GATA-4 in initiating an enterocytic differentiation program in a normal human intestinal epithelial progenitor cell line. Am J Physiol Gastrointest Liver Physiol 298, G504-517 (2010).

63. S. Modica, S. Murzilli, L. Salvatore, D. R. Schmidt, A. Moschetta, Nuclear bile acid receptor FXR protects against intestinal tumorigenesis. Cancer Res 68, 9589-9594 (2008).

64. T. Fu, S. Coulter, E. Yoshihara, T. G. Oh, S. Fang, F. Cayabyab, Q. Zhu, T. Zhang, M. Leblanc, S. Liu, M. He, W. Waizenegger, E. Gasser, B. Schnabl, A. R. Atkins, R. T. Yu, R. Knight, C. Liddle, M. Downes, R. M. Evans, FXR Regulates Intestinal Cancer Stem Cell Proliferation. Cell 176, 1098-1112 e1018 (2019).

65. G. Rizzo, M. Disante, A. Mencarelli, B. Renga, A. Gioiello, R. Pellicciari, S. Fiorucci, The farnesoid $\mathrm{X}$ receptor promotes adipocyte differentiation and regulates adipose cell function in vivo. Mol Pharmacol 70, 1164-1173 (2006).

66. H. Id Boufker, L. Lagneaux, H. Fayyad-Kazan, B. Badran, M. Najar, M. Wiedig, G. Ghanem, G. Laurent, J. J. Body, F. Journe, Role of farnesoid X receptor (FXR) in the process of differentiation of bone marrow stromal cells into osteoblasts. Bone 49, 12191231 (2011).

67. I. Sawitza, C. Kordes, S. Gotze, D. Herebian, D. Haussinger, Bile acids induce hepatic differentiation of mesenchymal stem cells. Sci Rep 5, 13320 (2015).

68. Y. Zhang, L. Yin, J. Anderson, H. Ma, F. J. Gonzalez, T. M. Willson, P. A. Edwards, Identification of novel pathways that control farnesoid $\mathrm{X}$ receptor-mediated hypocholesterolemia. J Biol Chem 285, 3035-3043 (2010).

69. A. M. Thomas, S. N. Hart, G. Li, H. Lu, Y. Fang, J. Fang, X. B. Zhong, G. L. Guo, Hepatocyte nuclear factor 4 alpha and farnesoid $X$ receptor co-regulates gene transcription in mouse livers on a genome-wide scale. Pharm Res 30, 2188-2198 (2013).

70. E. Somm, F. R. Jornayvaz, Fibroblast Growth Factor 15/19: From Basic Functions to Therapeutic Perspectives. Endocr Rev 39, 960-989 (2018).

71. M. Cariello, E. Piccinin, O. Garcia-Irigoyen, C. Sabba, A. Moschetta, Nuclear receptor FXR, bile acids and liver damage: Introducing the progressive familial intrahepatic cholestasis with FXR mutations. Biochim Biophys Acta Mol Basis Dis 1864, 1308-1318 (2018).

72. L. N. Pham, M. Kanther, I. Semova, J. F. Rawls, Methods for generating and colonizing gnotobiotic zebrafish. Nat Protoc 3, 1862-1875 (2008).

73. A. E. Rodriguez-Fraticelli, J. Bagwell, M. Bosch-Fortea, G. Boncompain, N. RegleroReal, M. J. Garcia-Leon, G. Andres, M. L. Toribio, M. A. Alonso, J. Millan, F. Perez, M. Bagnat, F. Martin-Belmonte, Developmental regulation of apical endocytosis controls epithelial patterning in vertebrate tubular organs. Nat Cell Biol 17, 241-250 (2015).

74. L. Yin, L. E. Jao, W. Chen, Generation of Targeted Mutations in Zebrafish Using the CRISPR/Cas System. Methods Mol Biol 1332, 205-217 (2015). 
75. M. A. Moreno-Mateos, C. E. Vejnar, J. D. Beaudoin, J. P. Fernandez, E. K. Mis, M. K. Khokha, A. J. Giraldez, CRISPRscan: designing highly efficient sgRNAs for CRISPRCas9 targeting in vivo. Nat Methods 12, 982-988 (2015).

76. K. M. Kwan, E. Fujimoto, C. Grabher, B. D. Mangum, M. E. Hardy, D. S. Campbell, J. M. Parant, H. J. Yost, J. P. Kanki, C. B. Chien, The Tol2kit: a multisite gateway-based construction kit for Tol2 transposon transgenesis constructs. Dev Dyn 236, 3088-3099 (2007).

77. J. Berger, P. D. Currie, 503unc, a small and muscle-specific zebrafish promoter. Genesis 51, 443-447 (2013).

78. J. Schindelin, I. Arganda-Carreras, E. Frise, V. Kaynig, M. Longair, T. Pietzsch, S. Preibisch, C. Rueden, S. Saalfeld, B. Schmid, J. Y. Tinevez, D. J. White, V. Hartenstein, K. Eliceiri, P. Tomancak, A. Cardona, Fiji: an open-source platform for biological-image analysis. Nat Methods 9, 676-682 (2012).

79. J. Abdel-Khalik, E. Bjorklund, M. Hansen, Development of a solid phase extraction method for the simultaneous determination of steroid hormones in H295R cell line using liquid chromatography-tandem mass spectrometry. J Chromatogr B Analyt Technol Biomed Life Sci 935, 61-69 (2013).

80. C. C. Murdoch, S. T. Espenschied, M. A. Matty, O. Mueller, D. M. Tobin, J. F. Rawls, Intestinal Serum amyloid A suppresses systemic neutrophil activation and bactericidal activity in response to microbiota colonization. PLoS Pathog 15, e1007381 (2019).

81. C. J. Hall, R. H. Boyle, X. Sun, S. M. Wicker, J. P. Misa, G. W. Krissansen, C. G. Print, K. E. Crosier, P. S. Crosier, Epidermal cells help coordinate leukocyte migration during inflammation through fatty acid-fuelled matrix metalloproteinase production. Nat Commun 5, 3880 (2014).

82. R. A. Phelps, S. Chidester, S. Dehghanizadeh, J. Phelps, I. T. Sandoval, K. Rai, T. Broadbent, S. Sarkar, R. W. Burt, D. A. Jones, A two-step model for colon adenoma initiation and progression caused by APC loss. Cell 137, 623-634 (2009).

83. V. M. Bedell, A. D. Person, J. D. Larson, A. McLoon, D. Balciunas, K. J. Clark, K. I. Neff, K. E. Nelson, B. R. Bill, L. A. Schimmenti, S. Beiraghi, S. C. Ekker, The lineagespecific gene ponzr1 is essential for zebrafish pronephric and pharyngeal arch development. Development 139, 793-804 (2012).

84. Y. Shu, Q. Lou, Z. Dai, X. Dai, J. He, W. Hu, Z. Yin, The basal function of teleost prolactin as a key regulator on ion uptake identified with zebrafish knockout models. Sci Rep 6, 18597 (2016).

85. R. A. Wingert, R. Selleck, J. Yu, H. D. Song, Z. Chen, A. Song, Y. Zhou, B. Thisse, C. Thisse, A. P. McMahon, A. J. Davidson, The cdx genes and retinoic acid control the positioning and segmentation of the zebrafish pronephros. PLoS Genet 3, 1922-1938 (2007). 
86. L. J. Shih, Y. F. Lu, Y. H. Chen, C. C. Lin, J. A. Chen, S. P. Hwang, Characterization of the agr2 gene, a homologue of $\mathrm{X}$. laevis anterior gradient 2, from the zebrafish, Danio rerio. Gene Expr Patterns 7, 452-460 (2007).

87. Y. C. Chen, Y. F. Lu, I. C. Li, S. P. Hwang, Zebrafish Agr2 is required for terminal differentiation of intestinal goblet cells. PLoS One 7, e34408 (2012).

88. S. W. Park, G. Zhen, C. Verhaeghe, Y. Nakagami, L. T. Nguyenvu, A. J. Barczak, N. Killeen, D. J. Erle, The protein disulfide isomerase AGR2 is essential for production of intestinal mucus. Proc Natl Acad Sci U S A 106, 6950-6955 (2009).

89. F. Zhao, R. Edwards, D. Dizon, K. Afrasiabi, J. R. Mastroianni, M. Geyfman, A. J. Ouellette, B. Andersen, S. M. Lipkin, Disruption of Paneth and goblet cell homeostasis and increased endoplasmic reticulum stress in Agr2-/- mice. Dev Biol 338, 270-279 (2010).

90. T. K. Noah, A. Kazanjian, J. Whitsett, N. F. Shroyer, SAM pointed domain ETS factor (SPDEF) regulates terminal differentiation and maturation of intestinal goblet cells. Exp Cell Res 316, 452-465 (2010).

91. A. Gregorieff, D. E. Stange, P. Kujala, H. Begthel, M. van den Born, J. Korving, P. J. Peters, H. Clevers, The ets-domain transcription factor Spdef promotes maturation of goblet and paneth cells in the intestinal epithelium. Gastroenterology 137, 1333-1345 e1331-1333 (2009).

92. F. Gerbe, E. Sidot, D. J. Smyth, M. Ohmoto, I. Matsumoto, V. Dardalhon, P. Cesses, L. Garnier, M. Pouzolles, B. Brulin, M. Bruschi, Y. Harcus, V. S. Zimmermann, N. Taylor, R. M. Maizels, P. Jay, Intestinal epithelial tuft cells initiate type 2 mucosal immunity to helminth parasites. Nature 529, 226-230 (2016).

93. M. A. Schumacher, J. J. Hsieh, C. Y. Liu, K. L. Appel, A. Waddell, D. Almohazey, K. Katada, J. K. Bernard, E. B. Bucar, S. Gadeock, K. M. Maselli, M. K. Washington, T. C. Grikscheit, D. Warburton, M. J. Rosen, M. R. Frey, Sprouty2 limits intestinal tuft and goblet cell numbers through GSK3ß-mediated restriction of epithelial IL-33. bioRxiv, 2020.2003.2009.984369 (2020).

94. S. Kimura, N. Kobayashi, Y. Nakamura, T. Kanaya, D. Takahashi, R. Fujiki, M. Mutoh, Y. Obata, T. Iwanaga, T. Nakagawa, N. Kato, S. Sato, T. Kaisho, H. Ohno, K. Hase, Sox 8 is essential for $\mathrm{M}$ cell maturation to accelerate IgA response at the early stage after weaning in mice. J Exp Med 216, 831-846 (2019).

95. K. A. Knoop, N. Kumar, B. R. Butler, S. K. Sakthivel, R. T. Taylor, T. Nochi, H. Akiba, H. Yagita, H. Kiyono, I. R. Williams, RANKL is necessary and sufficient to initiate development of antigen-sampling $M$ cells in the intestinal epithelium. J Immunol 183, 5738-5747 (2009).

96. S. Kimura, Y. Nakamura, N. Kobayashi, K. Shiroguchi, E. Kawakami, M. Mutoh, H. Takahashi-Iwanaga, T. Yamada, M. Hisamoto, M. Nakamura, N. Udagawa, S. Sato, T. Kaisho, T. Iwanaga, K. Hase, Osteoprotegerin-dependent M cell self-regulation balances gut infection and immunity. Nat Commun 11, 234 (2020). 
97. L. Ye, O. Mueller, J. Bagwell, M. Bagnat, R. A. Liddle, J. F. Rawls, High fat diet induces microbiota-dependent silencing of enteroendocrine cells. Elife 8, (2019).

98. F. M. Delporte, V. Pasque, N. Devos, I. Manfroid, M. L. Voz, P. Motte, F. Biemar, J. A. Martial, B. Peers, Expression of zebrafish pax6b in pancreas is regulated by two enhancers containing highly conserved cis-elements bound by PDX1, PBX and PREP factors. BMC Dev Biol 8, 53 (2008).

99. A. N. Ng, T. A. de Jong-Curtain, D. J. Mawdsley, S. J. White, J. Shin, B. Appel, P. D. Dong, D. Y. Stainier, J. K. Heath, Formation of the digestive system in zebrafish: III. Intestinal epithelium morphogenesis. Dev Biol 286, 114-135 (2005).

100. J. J. Worthington, F. Reimann, F. M. Gribble, Enteroendocrine cells-sensory sentinels of the intestinal environment and orchestrators of mucosal immunity. Mucosal Immunol 11, 3-20 (2018).

101. S. Gross, D. C. Garofalo, D. A. Balderes, T. L. Mastracci, J. M. Dias, T. Perlmann, J. Ericson, L. Sussel, The novel enterochromaffin marker Lmx1a regulates serotonin biosynthesis in enteroendocrine cell lineages downstream of Nkx2.2. Development 143, 2616-2628 (2016).

102. F. M. Gribble, F. Reimann, Enteroendocrine Cells: Chemosensors in the Intestinal Epithelium. Annu Rev Physiol 78, 277-299 (2016).

103. S. Moran-Ramos, A. R. Tovar, N. Torres, Diet: friend or foe of enteroendocrine cells-how it interacts with enteroendocrine cells. Adv Nutr 3, 8-20 (2012).

104. L. Ye, M. Bae, C. D. Cassilly, S. V. Jabba, H.-Y. Lu, J. Wang, J. D. Thompson, C. R. Lickwar, K. D. Poss, S.-E. Jordt, J. Clardy, R. A. Liddle, J. F. Rawls, Enteroendocrine cells sense bacterial tryptophan catabolites to activate enteric and vagal neuronal pathways. bioRxiv, 2020.2006.2009.142133 (2020).

105. M. P. Verzi, R. A. Shivdasani, Epigenetic regulation of intestinal stem cell differentiation. Am J Physiol Gastrointest Liver Physiol 319, G189-G196 (2020).

106. C. Wang, U. T. Meier, Architecture and assembly of mammalian H/ACA small nucleolar and telomerase ribonucleoproteins. EMBO J 23, 1857-1867 (2004).

107. M. C. Rao, Physiology of Electrolyte Transport in the Gut: Implications for Disease. Compr Physiol 9, 947-1023 (2019).

108. L. W. Plasschaert, R. Zilionis, R. Choo-Wing, V. Savova, J. Knehr, G. Roma, A. M. Klein, A. B. Jaffe, A single-cell atlas of the airway epithelium reveals the CFTR-rich pulmonary ionocyte. Nature 560, 377-381 (2018).

109. D. T. Montoro, A. L. Haber, M. Biton, V. Vinarsky, B. Lin, S. E. Birket, F. Yuan, S. Chen, H. M. Leung, J. Villoria, N. Rogel, G. Burgin, A. M. Tsankov, A. Waghray, M. Slyper, J. Waldman, L. Nguyen, D. Dionne, O. Rozenblatt-Rosen, P. R. Tata, H. Mou, M. Shivaraju, H. Bihler, M. Mense, G. J. Tearney, S. M. Rowe, J. F. Engelhardt, A. Regev, J. Rajagopal, A revised airway epithelial hierarchy includes CFTR-expressing ionocytes. Nature 560, 319-324 (2018). 
110. E. Dubaissi, K. Rousseau, R. Lea, X. Soto, S. Nardeosingh, A. Schweickert, E. Amaya, D. J. Thornton, N. Papalopulu, A secretory cell type develops alongside multiciliated cells, ionocytes and goblet cells, and provides a protective, anti-infective function in the frog embryonic mucociliary epidermis. Development 141, 1514-1525 (2014).

111. S. Varsamos, C. Nebel, G. Charmantier, Ontogeny of osmoregulation in postembryonic fish: a review. Comp Biochem Physiol A Mol Integr Physiol 141, 401-429 (2005).

112. D. H. Evans, Teleost fish osmoregulation: what have we learned since August Krogh, Homer Smith, and Ancel Keys. Am J Physiol Regul Integr Comp Physiol 295, R704-713 (2008).

113. N. A. Ameen, T. Ardito, M. Kashgarian, C. R. Marino, A unique subset of rat and human intestinal villus cells express the cystic fibrosis transmembrane conductance regulator. Gastroenterology 108, 1016-1023 (1995).

114. R. L. Jakab, A. M. Collaco, N. A. Ameen, Characterization of CFTR High Expresser cells in the intestine. Am J Physiol Gastrointest Liver Physiol 305, G453-465 (2013).

115. J. K. Gustafsson, A. Ermund, D. Ambort, M. E. Johansson, H. E. Nilsson, K. Thorell, H. Hebert, H. Sjovall, G. C. Hansson, Bicarbonate and functional CFTR channel are required for proper mucin secretion and link cystic fibrosis with its mucus phenotype. $J$ Exp Med 209, 1263-1272 (2012).

116. T. Kayahara, M. Sawada, S. Takaishi, H. Fukui, H. Seno, H. Fukuzawa, K. Suzuki, H. Hiai, R. Kageyama, H. Okano, T. Chiba, Candidate markers for stem and early progenitor cells, Musashi-1 and Hes1, are expressed in crypt base columnar cells of mouse small intestine. FEBS Lett 535, 131-135 (2003).

117. S. Fre, E. Hannezo, S. Sale, M. Huyghe, D. Lafkas, H. Kissel, A. Louvi, J. Greve, D. Louvard, S. Artavanis-Tsakonas, Notch lineages and activity in intestinal stem cells determined by a new set of knock-in mice. PLoS One 6, e25785 (2011).

118. J. Yang, C. Y. Chan, B. Jiang, X. Yu, G. Z. Zhu, Y. Chen, J. Barnard, W. Mei, hnRNP I inhibits Notch signaling and regulates intestinal epithelial homeostasis in the zebrafish. PLoS Genet 5, e1000363 (2009).

119. J. Que, T. Okubo, J. R. Goldenring, K. T. Nam, R. Kurotani, E. E. Morrisey, O. Taranova, L. H. Pevny, B. L. Hogan, Multiple dose-dependent roles for Sox 2 in the patterning and differentiation of anterior foregut endoderm. Development 134, 2521-2531 (2007).

120. V. Muncan, A. Faro, A. P. Haramis, A. F. Hurlstone, E. Wienholds, J. van Es, J. Korving, H. Begthel, D. Zivkovic, H. Clevers, T-cell factor 4 (Tcf712) maintains proliferative compartments in zebrafish intestine. EMBO Rep 8, 966-973 (2007).

121. Y. Ito, S. Kobayashi, N. Nakamura, H. Miyagi, M. Esaki, K. Hoshijima, S. Hirose, Close Association of Carbonic Anhydrase (CA2a and CA15a), $\mathrm{Na}(+) / \mathrm{H}(+)$ Exchanger (Nhe3b), and Ammonia Transporter Rhcg1 in Zebrafish Ionocytes Responsible for $\mathrm{Na}(+)$ Uptake. Front Physiol 4, 59 (2013).

122. B. T. Thisse, C, in ZFIN Direct Data Submission. (http://zfin.org, 2004). 
123. N. Sharp, National Health Service Corps = free tuition to school. Nurs Manage 22, 18-19 (1991).

124. G. J. Rauch, Lyons, D.A., Middendorf, I., Friedlander, B., Arana, N., Reyes, T., and Talbot, W.S. , in ZFIN Direct Data Submission. (http://zfin.org, 2003).

125. B. Thisse, Pflumio, S., Fürthauer, M., Loppin, B., Heyer, V., Degrave, A., Woehl, R., Lux, A., Steffan, T., Charbonnier, X.Q. and Thisse, C, in ZFIN Direct Data Submission. (http://zfin.org, 2001).

126. T. P. Wilm, L. Solnica-Krezel, Essential roles of a zebrafish prdm1/blimp1 homolog in embryo patterning and organogenesis. Development 132, 393-404 (2005).

127. C. A. Parkin, C. E. Allen, P. W. Ingham, Hedgehog signalling is required for cloacal development in the zebrafish embryo. Int J Dev Biol 53, 45-57 (2009).

128. X. J. Sun, P. F. Xu, T. Zhou, M. Hu, C. T. Fu, Y. Zhang, Y. Jin, Y. Chen, S. J. Chen, Q. H. Huang, T. X. Liu, Z. Chen, Genome-wide survey and developmental expression mapping of zebrafish SET domain-containing genes. PLoS One 3, e1499 (2008).

129. B. Thisse, Wright, G.J., Thisse, C., in ZFIN Direct Data Submission. (http://zfin.org, 2008).

130. S. E. Lepage, A. E. Bruce, Characterization and comparative expression of zebrafish calpain system genes during early development. Dev Dyn 237, 819-829 (2008).

131. I. Jevtov, T. Samuelsson, G. Yao, A. Amsterdam, K. Ribbeck, Zebrafish as a model to study live mucus physiology. Sci Rep 4, 6653 (2014).

132. K. Laue, S. Daujat, J. G. Crump, N. Plaster, H. H. Roehl, C. Tubingen Screen, C. B. Kimmel, R. Schneider, M. Hammerschmidt, The multidomain protein Brpf1 binds histones and is required for Hox gene expression and segmental identity. Development 135, 1935-1946 (2008).

133. S. M. Sperber, I. B. Dawid, barx1 is necessary for ectomesenchyme proliferation and osteochondroprogenitor condensation in the zebrafish pharyngeal arches. Dev Biol 321, 101-110 (2008).

134. J. Bakkers, M. Hild, C. Kramer, M. Furutani-Seiki, M. Hammerschmidt, Zebrafish DeltaNp63 is a direct target of Bmp signaling and encodes a transcriptional repressor blocking neural specification in the ventral ectoderm. Dev Cell 2, 617-627 (2002).

135. H. Lee, D. Kimelman, A dominant-negative form of p63 is required for epidermal proliferation in zebrafish. Dev Cell 2, 607-616 (2002).

136. M. E. Dodd, J. Hatzold, J. R. Mathias, K. B. Walters, D. A. Bennin, J. Rhodes, J. P. Kanki, A. T. Look, M. Hammerschmidt, A. Huttenlocher, The ENTH domain protein Clint 1 is required for epidermal homeostasis in zebrafish. Development 136, 2591-2600 (2009).

137. D. Kimelman, N. L. Smith, J. K. H. Lai, D. Y. Stainier, Regulation of posterior body and epidermal morphogenesis in zebrafish by localized Yap1 and Wwtr1. Elife 6, (2017). 
138. S. Reischauer, M. P. Levesque, C. Nusslein-Volhard, M. Sonawane, Lg12 executes its function as a tumor suppressor by regulating ErbB signaling in the zebrafish epidermis. PLoS Genet 5, e1000720 (2009).

139. C. Thisse, and Thisse, B, in ZFIN Direct Data Submission. (http://zfin.org, 2005).

140. V. F. Oliver, K. A. van Bysterveldt, M. Cadzow, B. Steger, V. Romano, D. Markie, A. W. Hewitt, D. A. Mackey, C. E. Willoughby, T. Sherwin, P. S. Crosier, C. N. McGhee, A. L. Vincent, A COL17A1 Splice-Altering Mutation Is Prevalent in Inherited Recurrent Corneal Erosions. Ophthalmology 123, 709-722 (2016).

141. G. T. Eisenhoffer, G. Slattum, O. E. Ruiz, H. Otsuna, C. D. Bryan, J. Lopez, D. S. Wagner, J. L. Bonkowsky, C. B. Chien, R. I. Dorsky, J. Rosenblatt, A toolbox to study epidermal cell types in zebrafish. J Cell Sci 130, 269-277 (2017).

142. M. Siddiqui, H. Sheikh, C. Tran, A. E. Bruce, The tight junction component Claudin E is required for zebrafish epiboly. Dev Dyn 239, 715-722 (2010).

143. R. T. Lee, P. V. Asharani, T. J. Carney, Basal keratinocytes contribute to all strata of the adult zebrafish epidermis. PLoS One 9, e84858 (2014).

144. P. J. Lyons, L. H. Ma, R. Baker, L. D. Fricker, Carboxypeptidase A6 in zebrafish development and implications for VIth cranial nerve pathfinding. PLoS One 5, e12967 (2010).

145. L. Tao, A. M. DeRosa, T. W. White, G. Valdimarsson, Zebrafish cx30.3: identification and characterization of a gap junction gene highly expressed in the skin. Dev Dyn 239, 2627-2636 (2010).

146. L. Abbas, T. T. Whitfield, Nkcc1 (Slc12a2) is required for the regulation of endolymph volume in the otic vesicle and swim bladder volume in the zebrafish larva. Development 136, 2837-2848 (2009).

147. C. L. Winata, S. Korzh, I. Kondrychyn, W. Zheng, V. Korzh, Z. Gong, Development of zebrafish swimbladder: The requirement of Hedgehog signaling in specification and organization of the three tissue layers. Dev Biol 331, 222-236 (2009).

148. F. Fang, Y. Li, M. Bumann, E. J. Raftis, P. G. Casey, J. C. Cooney, M. A. Walsh, P. W. O'Toole, Allelic variation of bile salt hydrolase genes in Lactobacillus salivarius does not determine bile resistance levels. J Bacteriol 191, 5743-5757 (2009).

149. S. Marion, N. Studer, L. Desharnais, L. Menin, S. Escrig, A. Meibom, S. Hapfelmeier, R. Bernier-Latmani, In vitro and in vivo characterization of Clostridium scindens bile acid transformations. Gut Microbes 10, 481-503 (2019).

150. S. Ishibashi, M. Schwarz, P. K. Frykman, J. Herz, D. W. Russell, Disruption of cholesterol 7alpha-hydroxylase gene in mice. I. Postnatal lethality reversed by bile acid and vitamin supplementation. J Biol Chem 271, 18017-18023 (1996).

151. E. J. Raftis, B. M. Forde, M. J. Claesson, P. W. O'Toole, Unusual genome complexity in Lactobacillus salivarius JCM1046. BMC Genomics 15, 771 (2014). 
152. N. A. Jacques, L. Hardy, K. W. Knox, A. J. Wicken, Effect of Tween 80 on the morphology and physiology of Lactobacillus salivarius strain IV CL-37 grown in a chemostat under glucose limitation. J Gen Microbiol 119, 195-201 (1980).

\section{Acknowledgments}

General: We thank Dr. Jieun Esther Park, Dr. Daniel Levic, and Laura Childers for their technical assistance. We extend our gratitude to Dr. Furong Sun, director of the Illinois Mass Spectrometry Core for providing assistance with LC/MS analysis. We would like to acknowledge the assistance of the Duke Molecular Physiology Institute Molecular Genomics Core for the generation of scRNA-seq data.

Funding: We gratefully acknowledge support for this work to J.M.R. from USDA Hatch ILLU538-916, and to J.F.R. from NIH grants R01-DK093399, R01-DK081426, and R01-DK121007, and an Innovation Grant from the Pew Charitable Trusts. H.D. is supported by the David H. and Norraine A. Baker Graduate Fellowship in Animal Sciences. C.K. was supported by NIH Ruth L. Kirschstein National Research Service Award Individual Predoctoral Fellowship F31DK121392. J.L.C. was supported by NIH Ruth L. Kirschstein National Research Service Award Individual Postdoctoral Fellowship F32-DK094592.

Author contributions: J.W., J.M.R., and J.F.R. designed research; J.W. and A.V. performed research; G.K., C. K., and J.L.C contributed new reagents/analytic tools; J.W., G.P.M., A.V., H.L.D., C.R.L., T.C., G.K., J.M.R, and J.F.R. analyzed data; and J.W., G.P.M., A.V., H.L.D., C.R.L., J.M.R., and J.F.R. drafted and revised paper.

Competing interests: The authors declare no competing interests.

Data and materials availability: All data needed to evaluate the conclusions in the paper are present in the paper and/or the Supplementary Materials. 


\section{Figures and Tables}

\section{Figure 1}
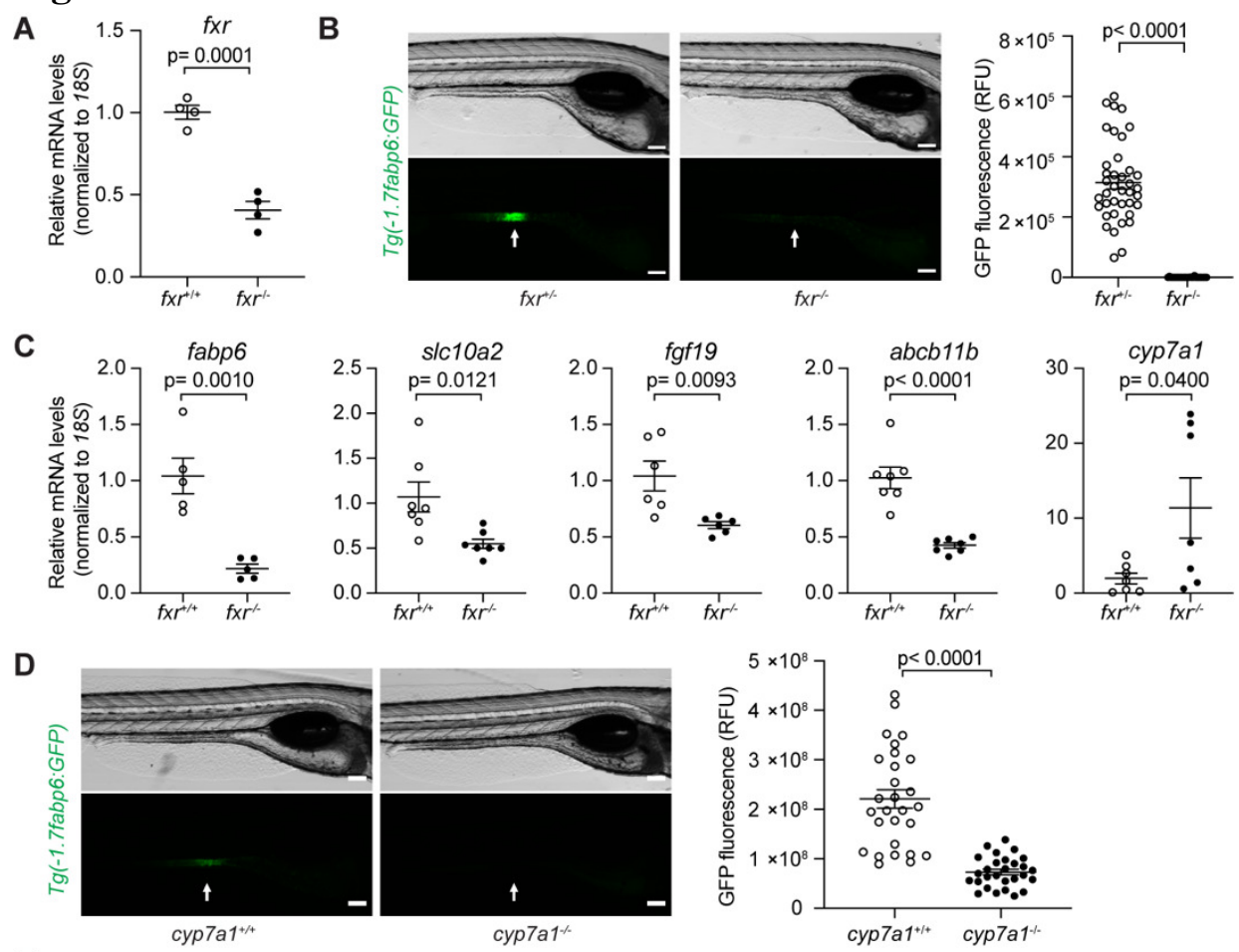

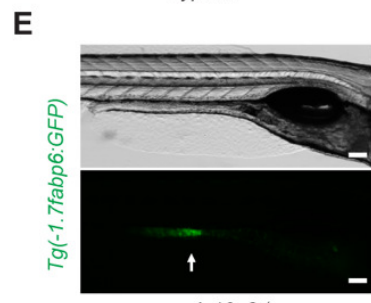

slc10a2 $2^{+/ 2}$

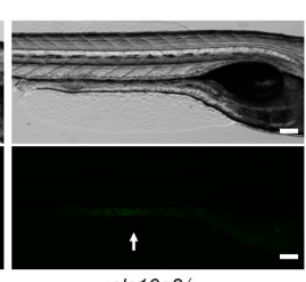

slc10a2

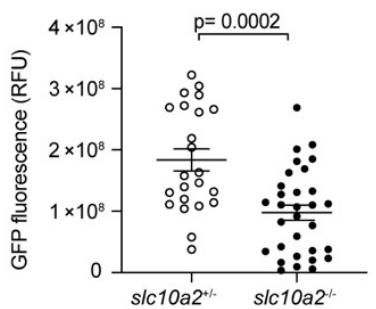

Figure 1. Genetic analyses reveal conserved key components of the bile salt-Fxr signaling axis in zebrafish.

A. qRT-PCR comparing $f x r$ expression in whole $7 \mathrm{dpf} f x r$ wild type $\left(f x r^{+/+}\right)$or $f x r$ homozygous mutant $\left(f \mathrm{xr}^{-/-}\right)$zebrafish larvae. B. Imaging and quantification of GFP fluorescence of the ileal region of $7 \mathrm{dpf} f x r^{+/+}$and $f x r^{-/} T g(-1.7 f a b p 6: G F P)$ larvae. The ileal region is indicated by arrows. C. qRT-PCR comparing expression of genes related to bile salt metabolism in dissected digestive tracts (including intestine, liver, pancreas, and gall bladder) of $7 \mathrm{dpf} f \mathrm{xr}^{+/+}$or $f x r^{-/-}$larvae (for fabp6, slc10a2, and $f g f 19$ ) or dissected liver of gender and size-matched adult $f x r^{+/+}$or $f x r^{-/-}$ zebrafish (for $a b c b 11 b$ and cyp7a1). The results are represented as relative expression levels normalized $18 S$ (Mean \pm SEM). D and E. Imaging and quantification of GFP fluorescence of the ileal region of $7 \mathrm{dpf} T g(-1.7 f a b p 6: G F P) c y p 7 a 1^{+/+}$and $c y p 7 a 1^{-/-}$larvae (D) or $s l c 10 a 2^{+/-}$and slc10a2 $2^{-/-}$larvae (E). The zebrafish ileal region is indicated by arrows. Scale bar $=100 \mu \mathrm{m}$ in (B, D, E). Statistical significance was calculated by unpaired t-test. Shown are representative data from at least three independent experiments. 


\section{Figure 2}
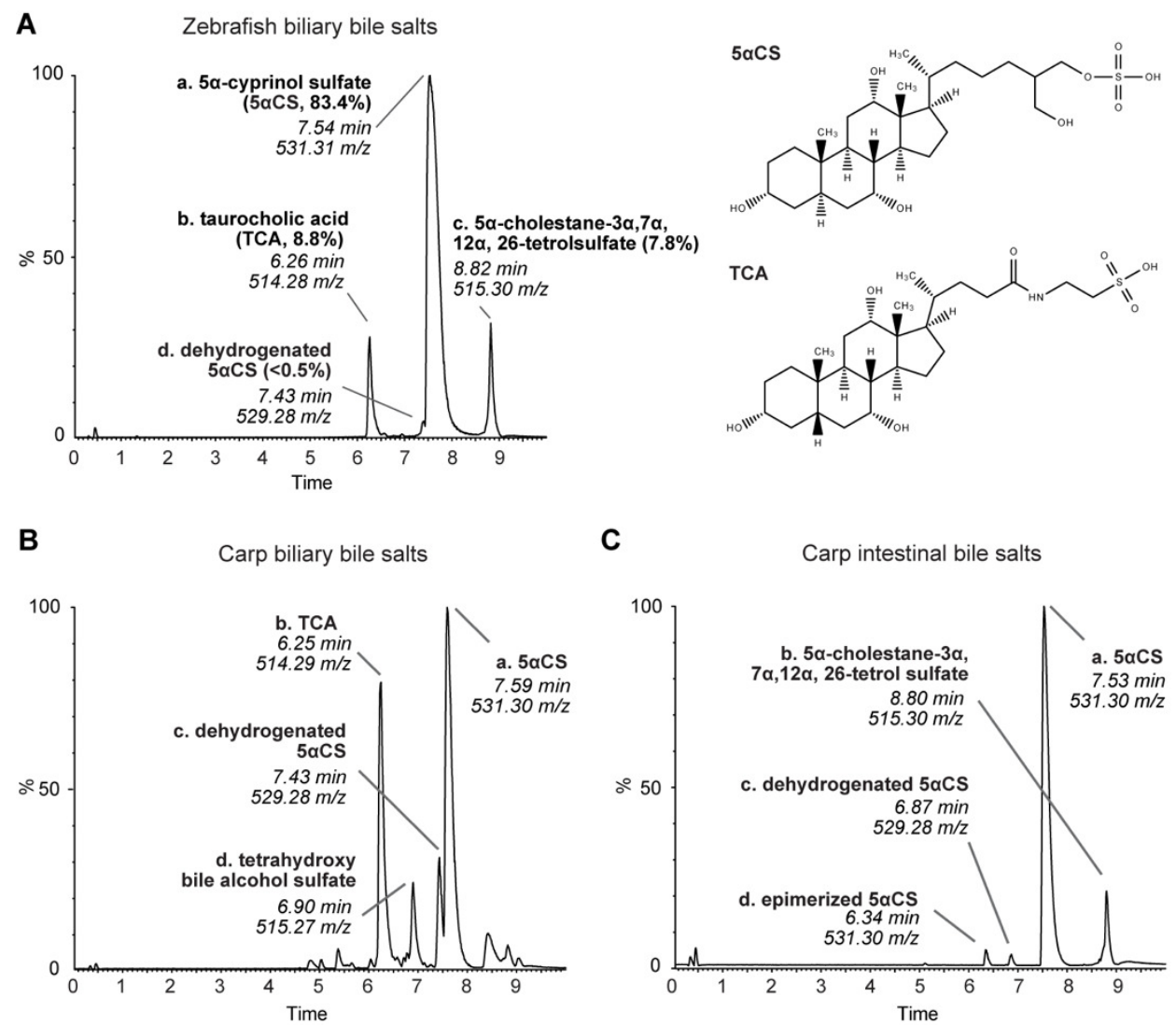

Figure 2. Zebrafish and carp bile salts consist of both $\mathbf{C}_{24}$ bile alcohols and $\mathbf{C}_{27}$ bile acids.

A. Mass spectrometry chromatograms of the bile salts extracted from adult zebrafish gallbladders. The identity and proportion of major peaks are listed. The height of each peak is shown as the relative percentage that was normalized to the highest peak of the metabolites detected. Structures of $5 \alpha \mathrm{CS}$ and TCA are shown. B and C. Mass spectrometry chromatograms of the bile salts extracted from adult carp gallbladders (B) or adult carp intestinal contents (C). The identities of major peaks are listed accordingly. 
bioRxiv preprint doi: https://doi.org/10.1101/2020.12.13.422569; this version posted December 13, 2020. The copyright holder for this preprint (which was not certified by peer review) is the author/funder, who has granted bioRxiv a license to display the preprint in perpetuity. It is made available under aCC-BY-NC 4.0 International license.

\section{Figure 3}

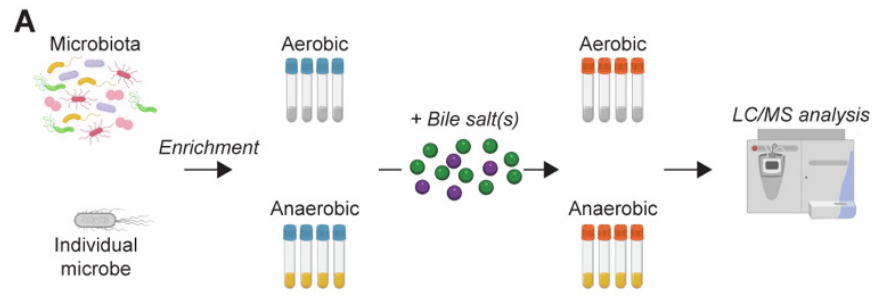

B
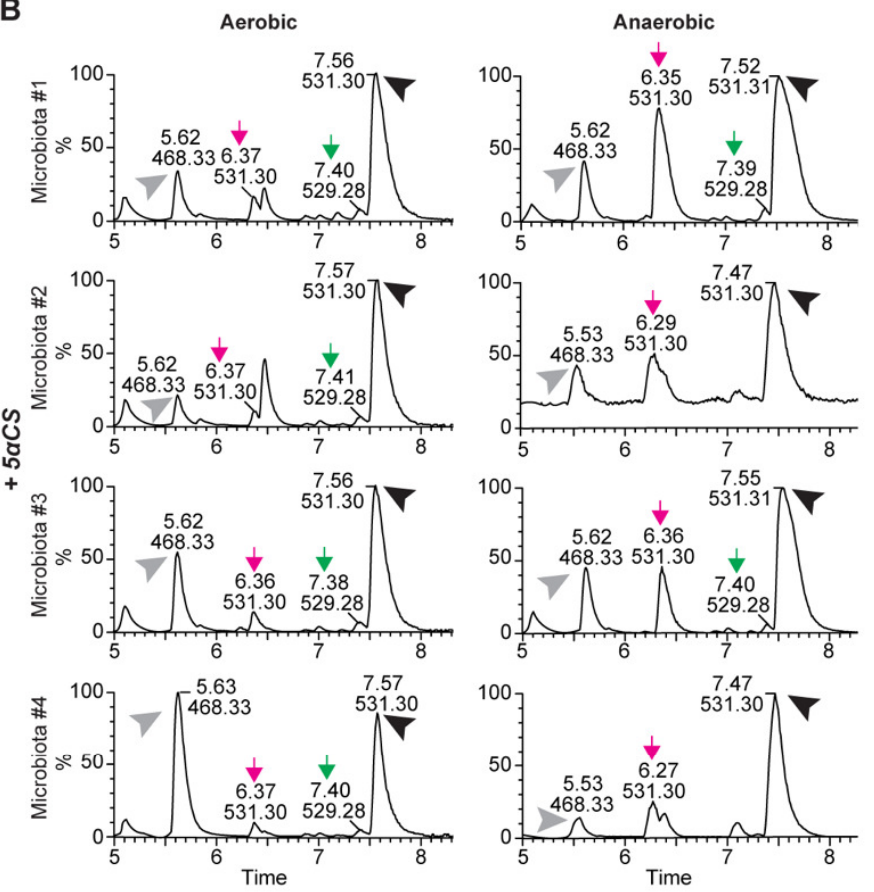

C
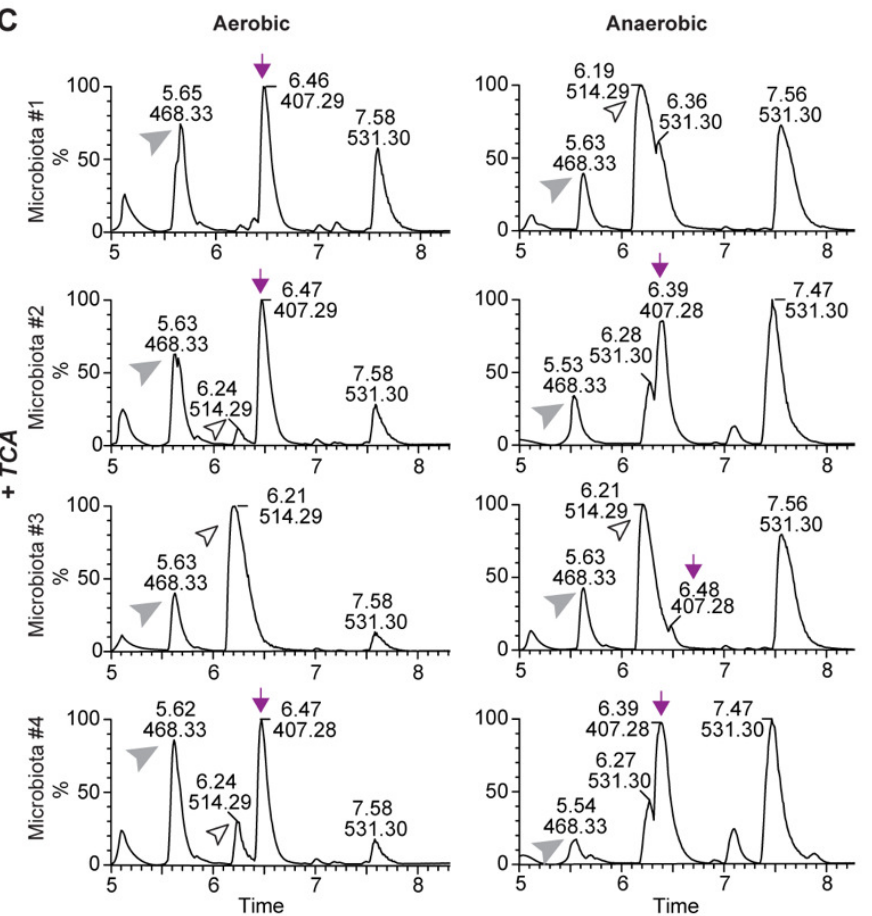

Figure 3. Microbiota modulate bile salt diversity in zebrafish. 
A. Schematic diagram of the in vitro bile salt metabolism assay. Complex microbiota or individual bacterial strains were enriched in modified TSB media under both aerobic and anaerobic conditions, and then incubated with $50 \mu \mathrm{M}$ of bile salts of interest, after which the total bile salts were extracted from individual bacterial cultures and subjected to LC/MS to identify modification of the supplemented bile salts. B and C. LC/MS chromatographs of bile salt metabolites extracted from enriched zebrafish microbiota cultures supplemented with $50 \mu \mathrm{M}$ $5 \alpha \mathrm{CS}(\mathrm{B})$ or TCA (C) under aerobic (left) or anaerobic (right) conditions. The arrowheads indicate the supplemented bile salts and internal control: black arrowhead: $5 \alpha \mathrm{CS}$; white arrowhead: TCA; grey arrowhead: internal standard D4-GCA. The arrows indicate bile salt metabolites resulted from microbial modification of the supplemented bile salts: green arrow: dehydrogenated $5 \alpha \mathrm{CS}$; magenta arrow: epimerized $5 \alpha \mathrm{CS}$; purple arrow: CA. The height of each peak is shown as the relative percentage that was normalized to the highest peak of the metabolites detected. Shown are representative chromatographs of zebrafish microbiota from four independent experiments. 
Figure 4
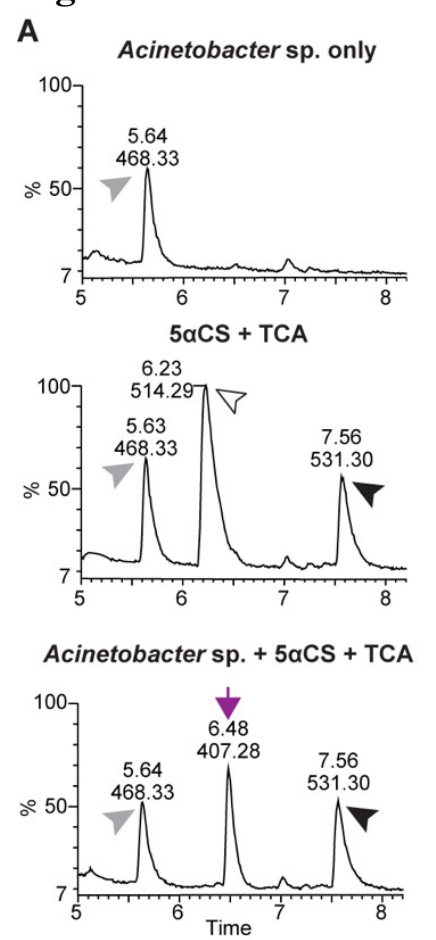
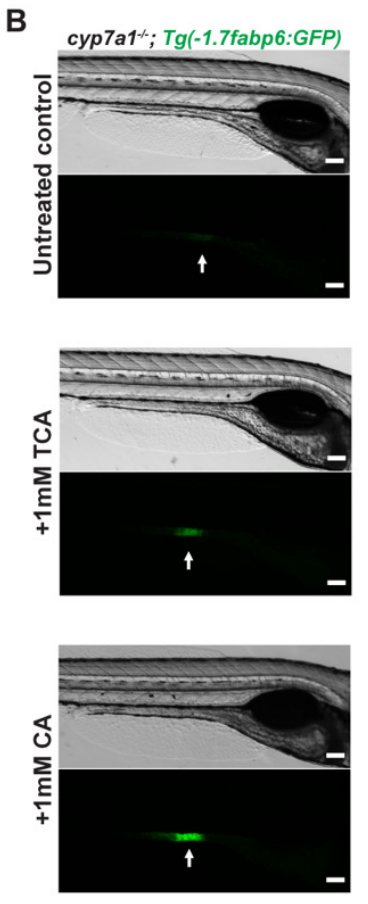
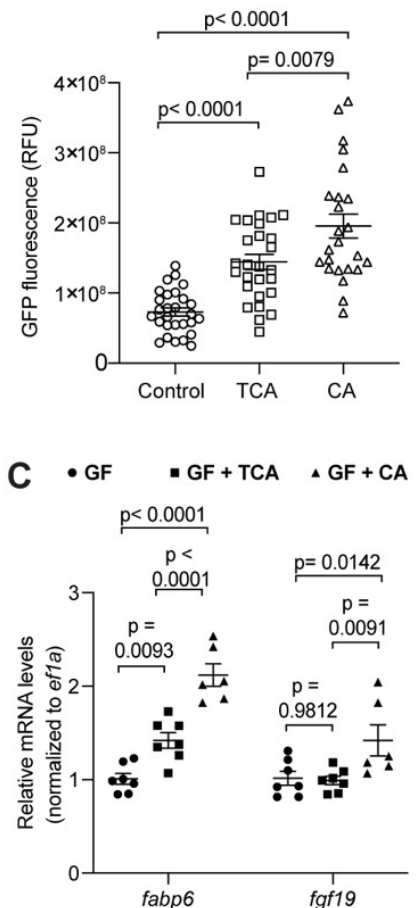

Figure 4. A zebrafish gut bacterium modifies primary bile acid producing a metabolite that augments Fxr signaling in zebrafish.

A. LC/MS chromatographs of medium only control (upper), bile salts only control (middle), and Acinetobacter sp. ZOR0008 culture supplemented with bile salts (bottom) under aerobic conditions. The arrowheads indicate the supplemented bile salts and internal control: black arrowhead: $5 \alpha \mathrm{CS}$; white arrowhead: TCA; grey arrowhead: internal standard D4-GCA. The purple arrow indicates the liberated CA resulted from bacterial deconjugation of TCA. Results from other bacterial strains are shown in Fig S3C. B. Imaging and quantification of GFP fluorescence of the ileal region of $7 \mathrm{dpf} T g(-1.7 f a b p 6: G F P)$ cyp $7 a 1^{-/-}$larvae that were untreated or treated with either $1 \mathrm{mM}$ TCA or CA for 4 days. The zebrafish ileal region is indicated by arrows. Scale bar $=100 \mu \mathrm{m}$. C. qRT-PCR comparing the expression of Fxr target genes in $7 \mathrm{dpf}$ wt germ free larvae that were untreated or treated with either $1 \mathrm{mM}$ TCA or CA for 4 days. The results are represented as relative expression levels normalized to the housekeeping gene efla (Mean+SEM). Statistical significance was calculated by one-way (B) and two-way (C) ANOVA with Turkey's multiple comparisons test. Shown are representative data from at least three independent experiments. 


\section{Figure 5}

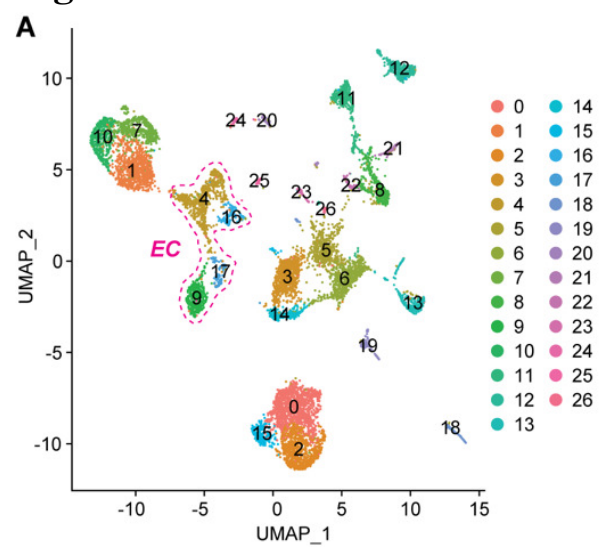

B

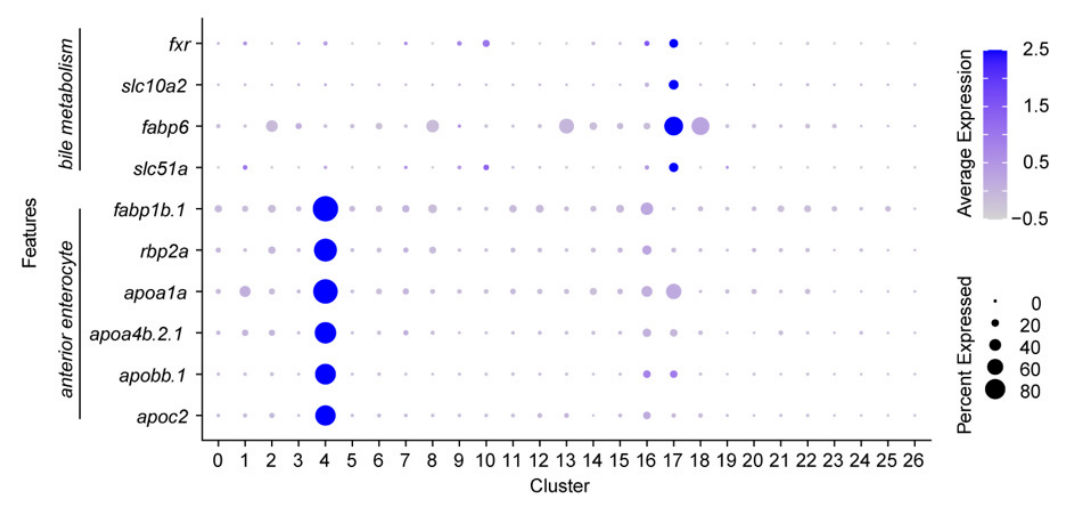

Figure 5. ScRNA-seq reveals extensive cellular diversity in the larval zebrafish intestinal epithelium.

A. UMAP visualization of cell-type clusters using combined $f x r^{+/+}$and $f x r^{-/-}$single-cell transcriptomes $\left(4,710\right.$ cells from $f x r^{+/+}$and 5,208 cells from $\left.f x r^{-/-}\right)$. Clusters were hierarchically ordered in PCA spaces and were numbered accordingly. Detailed annotations of each cluster are shown in Table S1 and Supplementary Results. Clusters 4, 16, 17, and 9 are absorptive enterocytes (EC). B. Dot plots showing relative expression of bile salt metabolism genes and anterior enterocyte markers in $\mathrm{xxr}^{+/+}$cells throughout all clusters. 


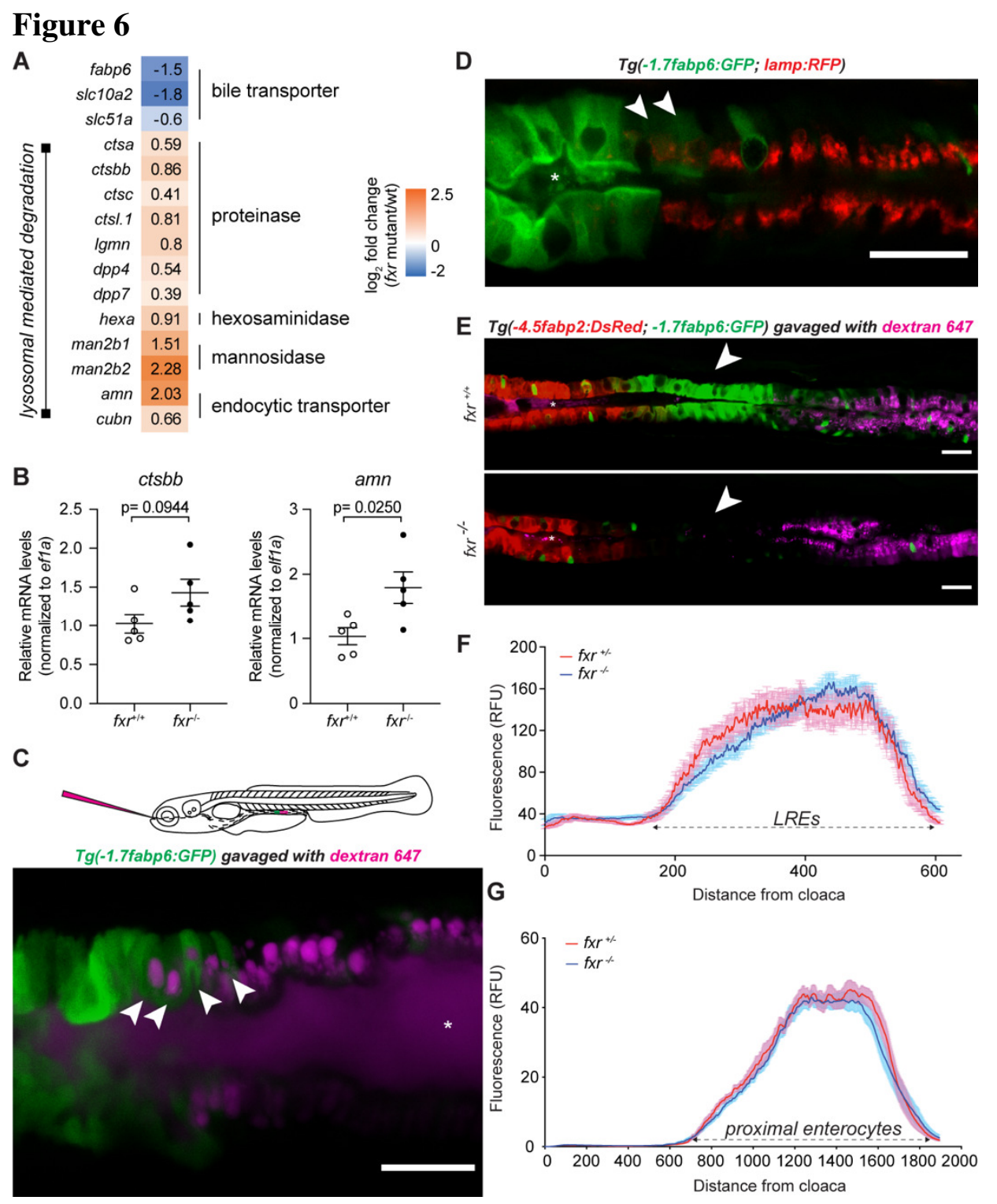

Figure 6. Fxr determines specific cell functions of ileal epithelial cells but is not required for establishment of regional boundaries.

A. Differential expression of genes related to bile metabolism and lysosomal functions in $f x r^{-1-}$ cells as compared to $f x r^{+/+}$cells in cluster 17. B. qRT-PCR comparing expression of LRE markers in dissected intestines of gender and size-matched adult $f x r^{+/+}$or $f x r^{-/-}$zebrafish. The results are represented as relative expression levels normalized to the housekeeping gene efla (Mean \pm SEM). Statistical significance was calculated by unpaired t-test. Shown are representative data from 2 independent experiments. C. Confocal single-plane image of the intestinal epithelium in $7 \mathrm{dpf}$ live larvae expressing the $\mathrm{Tg}(-1.7 \mathrm{fabp} 6: G F P$ ) transgene (green) following gavage with Alexa Fluor 647 Dextran (magenta). White arrowheads mark GFPexpressing cells that uptake dextran. The schematic diagram depicting gavage approach for labeling lysosome rich enterocytes (LREs) in the larval zebrafish intestine using fluorescent luminal cargo is shown in the top panel. Image is representative of 6 larvae examined. D. 
Confocal three-dimensional projections of the intestinal epithelium of $7 \mathrm{dpf}$ larvae expressing the $T g(-1.7 f a b p 6: G F P)$ (green) and the $T g B A C(\operatorname{lamp} 2: R F P)$ (red) transgenes. White arrowheads mark cells showing both GFP and RFP expression. Image is representative of 5 larvae examined. E. Confocal single-plane image of the intestinal epithelium in $7 \mathrm{dpf} f x r^{+/+}$(top) and $f \mathrm{xr}^{-/-}$(bottom) larvae expressing the $T g(-4.5 f a b p 2: D s R e d)$ (red) and $T g(-1.7 f a b p 6: G F P)$ (green) transgenes following gavage with Alexa Fluor 647 Dextran (magenta). White arrowheads mark the ileocyte region, which persists in $f x r^{-/}$larvae despite loss of GFP expression. Images are representative of $5 \mathrm{fxr}^{+/+}$and $5 \mathrm{frr}^{-/-}$larvae examined. Asteroids mark zebrafish lumen in $(\mathrm{C}, \mathrm{D}, \mathrm{E})$. Scale bar $=25$ $\mu \mathrm{m}$. F. Uptake profiles along LRE region following gavage with $1.25 \mathrm{mg} / \mathrm{mL}$ Alexa Fluor 647 Dextran in $7 \mathrm{dpf} f x r^{+/-}(\mathrm{n}=14)$ and $f x r^{-/-}(\mathrm{n}=22)$ larvae. G. DsRed fluorescence along the intestine of $7 \mathrm{dpf} f x r^{+/-}(\mathrm{n}=18)$ and $f x r^{-/-}(\mathrm{n}=24) \mathrm{Tg}(-4.5 f a b p 2: D s R e d)$ larvae. 


\section{Figure 7}

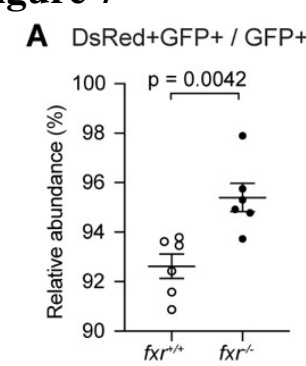

B

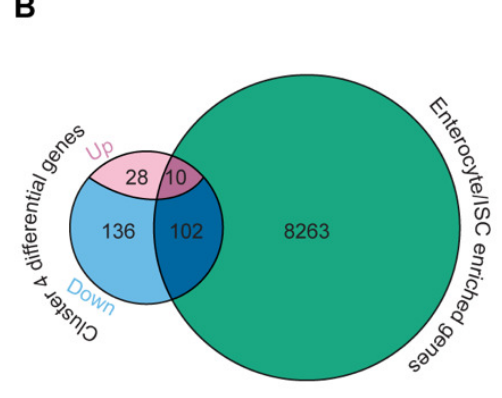

Figure 7. Fxr regulates differentiation and functions of anterior absorptive enterocytes in zebrafish.

A. FACS analysis comparing the relative abundance of anterior enterocytes in $7 \mathrm{dpf} f x r^{+/+}$and $f x r^{-/}$larvae expressing the $T g(-4.5 f a b p 2: D s R e d)$ and $T g B A C($ cldn15la-GFP) transgenes. The relative abundance was calculated by dividing the cell counts of DsRed+GFP+ double positive cells by the cell counts of GFP+ single positive cells (Mean \pm SEM). Statistical significance was calculated by unpaired t-test. Shown are representative data from two independent experiments. B. Comparisons between the genes that were differentially expressed in $f x r^{-/-}$cells relative to $\mathrm{fxr}^{+/+}$cells in cluster 4 and the mouse genes enriched in jejunal enterocytes/intestinal stem cells (ISC) (45). Left: Venn diagram showing the number of overlapped genes between the two gene sets, of which the differentially expressed genes in $f x r^{-/-}$cells were further classified based on the changes in their expression (up- or down-regulated) upon $f x r$ mutation. Middle: The distributions of enterocyte- and ISC-enriched genes from the enterocyte/ISC dataset used in the current comparison. Right: The distribution of overlapped genes resulting from the comparison. C. The top 3 HOMER-identified motifs enriched within accessible chromatin regions near genes that were down regulated in the $f \mathrm{xr}^{-/-}$cells relative to $f \mathrm{xr}^{+/+}$cells in cluster 4 . Shown are the position weight matrices (PWMs) of the enriched nucleotide sequences. The TF family that most closely matches the motif is indicated above the PWM. 


\section{SUPPLEMENTARY MATERIALS}

\section{Supplementary Results \\ Annotation of single-cell RNA-seq data identifies cell types within the larval zebrafish intestinal epithelium}

We generated scRNA-seq data on GFP+ cells sorted from wild-type (wt) and $f x^{-/-}$ $T g B A C$ (cldn15la-GFP) zebrafish larvae at $6 \mathrm{dpf}$. The $T g B A C($ cldn15la-GFP) transgenic line was chosen for this study because it is reported to express GFP throughout the intestinal epithelium (31). After quality control filtering, a total of 9,918 cells from both genotypes combined were subjected to unsupervised clustering using the Seurat R package yielding a total of 27 clusters (Fig 5A). As expected, the vast majority of cells and clusters expressed cldn15la and displayed gene expression patterns consistent with known gut epithelial cell types. Below we provide a working annotation of each cluster as a resource for the field. For this annotation, we focus on data derived from wild-type zebrafish intestinal epithelial cells. Our general approach was to study the genes we found to be enriched in each cluster or set of related clusters, along with UMAP visualization of the gene expression patterns in the current scRNA-seq dataset, the primary literature, and gene expression patterns reported on ZFIN. Due to limited previous studies of the zebrafish digestive tract, we acknowledge that some of these annotations may be found to be inaccurate in future studies. In addition to the annotation below, we provide average expression of genes in individual cell clusters (Data set 1), cluster markers of individual cell clusters identified (Data set 2), and cluster-enriched markers of individual cell clusters identified (Data set 3).

Enterocytes: The principal function of the intestinal epithelium is absorption of dietary nutrients, provided primarily by enterocytes. As described in further detail in the Results section, we identified clusters 4, 9, 16, and 17 as enterocytes based on their expression of known enterocyte markers. We tentatively assigned these clusters as enterocytes in the anterior intestine (also called the intestinal bulb or segment 1; clusters 4 and 16), ileal/mid-intestine (also called segment 2; cluster 17), and distal intestine/cloaca/pronephric duct (also called segment 3; cluster 9). Clusters 4 and 16 were both enriched for known anterior enterocyte markers involved in metabolism and transport of lipids (e.g., rbp2a, fabp1b.1, apoala, apoa4b.2.1, apobb.1, scarb1), chitin (e.g., chia.1, chia.2), and other genes not previously implicated in anterior enterocyte biology (e.g., $m b l 2$, rida, gcshb). Despite these commonalities, these two anterior enterocyte clusters also displayed interesting differences. Metascape analysis of enriched markers in cluster 4 revealed overrepresentation in biological processes such as oxidation-reduction (e.g., fads2, agmo, aocl), gluconeogenesis ( $f b p l b, p c k l)$, and metabolism of lipids and other nutrients (e.g., apoalb, apoea, pla2g12b, elovl2, slc26a3.2, slc34a2a, slc37a4a, slc6a19b) (Fig S8). In contrast, markers enriched in cluster 16 include those involved in chromatin organization (e.g., hist $2 h 3 c$, si:ch211-113a14.18, zgc:110425, zgc:173585), and cell cycle and chromosomal segregation (e.g., mki67, cks1b, cks2, nuf2, aurkb, cdca8, birc5a, kif20bb, plk1, spc25, top2a, ube2c) (Fig 
S8). Based on these observations, we operationally define cluster 4 as differentiated anterior intestinal enterocytes and cluster 16 as proliferative anterior intestinal enterocytes.

Whereas clusters 4 and 16 appear to represent anterior enterocytes, clusters 17 and 9 appear to represent enterocytes from the mid and distal regions of the intestine. As described in detail in the Results, cluster 17 was identified as mid-intestinal enterocytes which include ileocytes and lysosome-rich enterocytes (LREs) (see Figs 6 and S6, Table S1, Dataset 1-2). Metascape analysis of cluster 17 revealed enrichment for bile acid and bile salt transport among other functions (Fig S8), Cluster 9 expresses known distal intestinal epithelial markers like saa (43), irgll (81), hoxal3a and evxl.1 (82). This cluster also expresses ponzrl and slc9a3.2 which are expressed not only in the intestine but also the pronephric duct, tubules, and nephrons ( 83 , 84). This raises the possibility that this cluster may include cells from the pronephric duct or tubule. However, we think this is unlikely since cluster 9 does not express several known markers of the pronephric duct and tubule epithelium like atplala.5 (84) and $c d h 17$, pax $2 a$, slc4a2a (85). Metascape analysis for cluster 9 was not particularly informative (Fig S8), but based on the above information we predict that cluster 9 represents enterocytes from the distal intestine and cloaca.

Absorptive enterocytes are typically the most common epithelial cell type in the intestine, so we were surprised that the relative abundance of cells in clusters $4,16,17$, and 9 was comparable to other cell types discussed below. We expect that these relative cell abundances are inaccurate and infer that our chosen methods for cell dissociation, sorting, processing, and/or data quality may have preferentially led to a reduced representation of enterocytes in this dataset. However, we think these four enterocyte clusters do represent the major enterocyte populations in the larval zebrafish intestine. Although cluster 16 appears to be a proliferative enterocyte population, additional studies are needed to identify absorptive lineage precursors that give rise to these different differentiated enterocyte types.

Goblet cells: Mucus provides an important physical and chemical barrier along the gut, and is primarily produced by secretory goblet cells. Anterior gradient 2 (agr2) is expressed in goblet cells within the zebrafish larval gut, as well as the pharynx and esophagus $(86,87)$, and Agr2 is required for goblet cell development and mucin production in zebrafish and mice (8789). SAM Pointed Domain Containing ETS Transcription Factor (Spdef) is expressed by and promotes differentiation of goblet cells and Paneth cells in the mouse intestine $(90,91)$, however fishes are not thought to develop Paneth cells. We found that clusters 3, 13, and 14 all express high levels of $a g r 2$, two of which (clusters 3 and 14) also displayed elevated expression of spdef. An additional shared marker for these three clusters was galnt 7 which is involved in mucin-type O-linked protein glycosylation. Goblet cells do produce mucins at this stage (41), but the mucin genes detected in our scRNA-seq dataset did not show enrichment in these three clusters. Cluster 13 displayed elevated expression of POU Class 2 Homeobox 3 (pou2f3), which is a lineagespecifying transcription factor for tuft cells in mice (92), as well as Sprouty 2 (spry2) which is regulates differentiation of goblet and tuft cells in mice (93). Interestingly, cells in cluster 13 also displayed elevated expression of genes known to be involved in the development of antigen- 
sampling microfold cells (M-cells) in the mammalian intestine including SRY-Box Transcription Factor 8 (sox8b) (94), TNF Receptor Superfamily Member 11a (tnfrsf11a; also known as RANK) (95), and its conserved paralog tnfrsf11b (also known as Osteoprotegerin) which acts as a decoy receptor for RANK ligand (96). Tuft cells and M-cells are considered to be distinct differentiated cell types in the mammalian gut, but these zebrafish cells in cluster 13 appear to display conserved markers of both cell types. Based on these criteria, we annotated these three clusters as goblet cells, with the possibility that cluster 13 represents zebrafish tuft cells or Mcells.

Enteroendocrine cells: The other major secretory cell lineage in the intestine is enteroendocrine cells (EECs) which serve as specialized sensory cells that respond to luminal and basolateral stimuli to release specific hormones and neurotransmitters. We identified five clusters of cells (clusters 8, 11, 12,21, and 22) as putative EEC subtypes based on their shared expression of known EEC markers neurod1 (97), pax6b (98), and $n k x 2.2 a$ (99). Those same five clusters expressed other known markers of EECs such as pcsk1, gck, and the Secretogranins $s c g 2 b, s c g 3$, and $s c g 5$. GO Term Enrichment analysis of each of these clusters revealed pathways associated with protein processing and transport, with some specific pathways linked to neurotransmitters and neuropeptides. As expected, each of these EEC subtypes was characterized by distinct gene expression signatures for transcription factors, hormones, and neurotransmitters. For example, EEC subtypes displayed distinct expression patterns for known EEC transcription factor homologs neurog3 and pax4 (cluster 11), isl1 (clusters 8, 21, and 22), pdx1 (cluster 22), and lmxlba (cluster 12) (100, 101). Genes involved in production of hormones, neurotransmitters, and other signaling molecules also showed elevated expression in clusters 8 ( hhrl, pyyb, sst2, mlnl), 11 (trhra), 12 (adcyapla, bdnf, hbegfb, il22, nmu, penka, tphlb, trpalb), 21 (calca), and 22 (gcga, insl5b, tac3a, galn, btc, vipb). Other hormones and neurotransmitters were expressed in multiple EEC clusters, such as $c c k a$ and $n m b b$ (clusters 11 and 12) and insl5a (clusters 21 and 22). Based on these gene expression patterns, potential homologies to known mammalian EEC subtypes were suggested. For example, cluster 11 may represent early differentiating EECs due to their expression of transcription factors involved in early EEC differentiation neurog3 and pax4, and their relative paucity of hormone or neurotransmitter expression. Like cluster 8 EECs, motilin-producing EECs (M-cells) in the mammalian gut also express Ghrl, Sst, and Mln. Like cluster 22, L-cells in the mammalian gut also express the proglucagon gene Gcg (the precursor to GLP-1 and GLP-2) as well as Ins15 (102, 103). Finally, zebrafish EEC cluster 12 and mammalian enterochromaffin cells (ECs) express respective homologs of Tph1 and Trpa1, as well as other shared markers Rab3c and Ddc $(44,104)$. We anticipate that some of these individual EEC clusters may represent multiple EEC cell types which could be further resolved by future studies. Together, these data reveal interesting functional diversity among EEC subtypes in larval zebrafish, including potential subtype conservation that has been conserved since the last common ancestor with mammals.

Putative secretory precursors: Studies in the mammalian intestine identify Math1/Atoh1, Dll1, and Gfi1 as markers of secretory lineage precursors (105). In our dataset, zebrafish 
math1/atoh1 and dll1 homologs were not detected, whereas gfilb was expressed in a subset of cells in cluster 13 (goblet/tuft cells) and gfilaa was expressed in a small fraction of cells across multiple secretory and absorptive cell clusters. Despite this paucity of clear conserved markers, two clusters presented as potential precursors of secretory cell lineages based on their location in the UMAP plot and their gene expression patterns. Clusters 5 and 6 both expressed agr 2 though at lower levels than the goblet cell clusters. Cluster 5 appeared to be either EEC precursors or perhaps another differentiated EEC subtype based on its strong expression of pyyb (similar to cluster 8 EECs), and expression of pax4, neurod1, scg2b, scg3, scg5, insl5a, and $m l n l$ in a subset of cells. Located adjacent to cluster 5 and the goblet cell clusters in the UMAP plot, cluster 6 was enriched for transcripts involved in the H/ACA small nucleolar ribonucleoprotein (H/ACA snoRNP) complex including $n h p 2$, nop 10, $d k c 1$, and garl (106). Additional cluster 6 markers include other ribonucleoproteins nop58, snu13b, hnrnpabb, and npmla, RNA processing and splicing factors like $s s b$, trmt61a, $d d x 39 a b, d d x 24$, and $c 1 q b p$, and other markers like the nucleolar G-protein $g n l 3$ and the dihydrolipoamide dehydrogenase $d l d$. Although the precise identity of cluster 6 remains unclear, their location on the UMAP plot combined with their enrichment for these markers for RNA processing and ribosomal biogenesis suggests they are likely secretory precursors at a stage of differentiation marked by elevated transcription and translation. Since the lineage relationships between intestinal epithelial cells and markers for intestinal epithelial stem cells remain unknown in the zebrafish, it is also possible that cells within cluster 6 represent common precursors of both secretory and absorptive lineages.

Ionocytes: Electrolyte secretion and ion balance are important aspects of epithelial biology in the intestine and other organs (107). Epithelial cells specialized to perform these functions, typically called ionocytes (sometimes called chloride cells), can be found in diverse organ systems including the human airway, frog epidermis, and fish epidermis and gills (108112). The chloride and bicarbonate ion channel Cftr is known to be a marker of ionocytes in the mouse and human airway as well as fish. In the small intestine of human and rat, Cftr is expressed at high levels in a distinct subset of cells $(113,114)$ though their function remains unclear. We found that a distinct group of three clusters 0,2 , and 15 were enriched for $c f t r$, as well as other markers conserved with mammalian ionocytes like tmem51a and stap2b $(108,109)$. These three clusters also express the carbonic anhydrases $c a 2$ and $c a 4 b$, which may function to produce bicarbonate for subsequent Cftr-mediated transport across the plasma membrane. A recent study identified a new population of epithelial cells in the human colon predicted to be involved in electrolyte transportation marked by the proton-conducting ion channel Otopetrin 2 (OTOP2), the calcium-sensitive chloride channel Bestrophin 4 (BEST4), and the paracrine hormone uroguanlylin (33). Strikingly, we found that clusters 0, 2, and 15 express otop2, best4, and the predicted receptors for uroguanylin $($ gucy $2 c)$ and atrial and brain natriuretic peptides (nprla). These data strongly suggest that these cells are specialized for regulated secretion of bicarbonate and other ions to control mucus secretion (115) and perhaps other processes. We therefore conclude that these clusters together represent intestinal ionocytes, with similarities to mammalian BEST4/OTOP2 cells. Interestingly, these three ionocyte clusters were also enriched 
for notch 2 and the Notch-responsive gene her6/hes1. In the mammalian intestine, Her6/Hes1 and Notch 2 are expressed in the crypt in stem cells and absorptive progenitors $(116,117)$. In accord, we previously identified a cis-regulatory element at zebrafish her6/hes 1 that drove expression in IECs near the base of intestinal folds that also activated a Notch reporter (17), in accord with previous studies of zebrafish Hes1 localization (118). These findings suggest a previously unappreciated relationship between Notch signaling and intestinal ionocytes in zebrafish. The significance of other genes enriched in all three ionocyte clusters (e.g., $c f d, o s r 2, s y t 7 b, f g f r 4$, abcc12, prdx1, hmoxla, syt7b, si:dkey-190j3.2, tmtops $2 b$ ) or individual clusters (e.g., hsp70.1, hsp70.2, hsp70.3, hsp70l, and hsp90aal.2 for cluster 15; osr2, gsto1, scpp8, and tpmt.1 for cluster 2; epb4la and MPRIP for cluster 0) remains unclear.

Foregut: The transcription factor Sox 2 in birds and mammals is expressed in foregut regions including pharynx, esophagus, and stomach (119). This expression domain is conserved in the stomachless zebrafish, with sox 2 expressed in pharyngeal and esophageal epithelium (120). This foregut marker was only expressed in the distinct group of clusters 1, 7 and 10 . Annotation of these individual clusters was more difficult than others due to a relatively low number of genes enriched specifically in those individual clusters. However, there were several genes enriched in all three clusters that support that these clusters represent epithelial cells from foregut regions such as pharynx and esophagus. For example, all three clusters expressed known markers of the pharyngeal epithelium such as cal5 (121), aqp3a (122), ptgs 2b, and ptgs2a (123). These three clusters were enriched for other known pharyngeal markers that were also expressed at lower levels in other non-pharyngeal clusters such as wu:fbl8f06 (124) and sult6bl (125). Notably, these three clusters and the anterior enterocyte clusters 4 and 16 shared expression of fabp2, which is typically considered to be a marker of anterior intestinal enterocytes (43). However, the absence of other known anterior intestinal enterocyte markers (e.g., $r b p 2 a$, fabplb.1, apoala; see above) in clusters 1, 7, and 10 lead us to conclude those three clusters do not represent anterior intestinal enterocytes. These three clusters were also enriched for other genes without available WISH data including si:ch73-288o11.5, sytl4, si:dkey-74k8.3, icn, ktn1, ARF5 (1 of many), cdxla, vill, vtcn1, and gstp2, which may represent new markers for these cell types. We observed that several of the genes enriched in clusters 1 and 10 were also enriched in cluster 9 which we annotate as enterocytes from the distal intestine and cloaca. These include prdmla which is a known marker of the cloaca (126-128), the pharyngeal marker bcam (129), and other genes that lack WISH data (CABZ01020840.1, BX908782.2, efnalb, lect $2 l$, si:cabz01007794.1, zgc:113314). It is notable also that agr2, which is expressed most highly in goblet cell clusters 3,13, and 14, is also expressed at lower levels in foregut clusters 1,7 , and 10 as well as distal enterocyte cluster 9 . As cells lining the entrance and exit of the intestinal tract, it is tempting to speculate these genes may represent unknown shared physiologic functions in those cells. We were unable to functionally distinguish these three individual clusters due to paucity of specifically enriched genes. Cluster 10 specifically expressed several interesting genes including the pharyngeal markers capn $2 a$ (130) and muc5.3 (131), mucin synthesis enzyme gcnt3, a cysteine-rich natrin-1-like venom protein (CABZ01068499.1), O-glycan processing 
enzyme si:dkey-202e17.1 as well as si:dkey-248g15.3 and $\operatorname{arrdc} 2$. Genes enriched in cluster 10 but also expressed appreciably by other clusters includes the pharyngeal marker rhpn2 (125), as well as aplp2, $c 7 b$, and tnfrsf9a. In contrast, clusters 1 and 7 revealed very few genes that were specific to these clusters with the nearest examples being neu3.3 and si:ch211-284d12.3 in cluster 7, and CU467905.1 and stoml3b in cluster 1. Based on these observations, we annotate clusters 1,7 , and 10 as foregut epithelial cells. Since publicly available WISH data provide more information about pharyngeal gene expression compared to esophagus, we are unable to confidently annotate these three clusters to specific regions of the foregut at this time. Cluster 10 seems likely to be mucus producing cells but the specific identities of clusters 1 and 7 remain unresolved. We note that known markers of the oral epithelium such as evplb (124), brpfl (132), and $\operatorname{barx} 2$ (133) were low or absent in our dataset. Therefore, while we annotate clusters 1, 7, and 10 as foregut epithelial cells, we do not exclude that the oral cavity or other foregut regions include cell types not captured in our dataset here.

Epidermis: Analysis of genes enriched in clusters 23 and 26 suggest they are integumentary cells. Cluster 23 expresses tp63, a known marker of the basal layer of the epidermis (134-136), as well as other genes with known expression in the epidermis such as ecrg4b (137), krt5, mmp9 (138), zgc:101810 (122), col4a5, col4a6 (139), and coll7ala (140). Another gene specifically enriched in cluster 23 specific for cluster 23, cldni, is reported to be expressed in epidermis as well as pharynx (122). Cluster 23 also uniquely expresses several other genes that lack WISH data but may represent new epidermal markers including ca6, cldn1, cxl34b.11, anxa2a, si:dkey-33c14.3, and mmp30.

Cluster 26 is enriched for genes known to be expressed in the outermost layer of the epidermis called the peridermis including krt4 (141) and anxalc (125). Several genes enriched in this cluster (dhrs13a.2, evpla, cldne, zgc:110333, zgc:111983) have known expression in the periderm or other epidermal cells as well as the pharynx $(122,125,142)$. Several other genes that lack available WISH data also showed strong expression in these cells including icn2, zgc:153665, krt17, scel, and si:dkey-247k7.2. Several genes were enriched in both clusters 23 and 26 including epidermal markers krttlc19e (143), cytl (124), and other genes like cyt 11 and spaca4l. Taken together, these data indicate that clusters 23 and 26 represent cell types within the epidermis, with cluster 23 potentially representing basal cells and cluster 26 potentially representing peridermal cells. Considering that several of these genes are known to be expressed in epidermis as well as pharynx, it is possible some of these cells are located in the pharynx.

Other cell types: Our dataset identified several clusters that appear to be contaminating cell types not derived from the intestinal epithelium. For example, we annotate cluster 18 as leukocytes based on their expression of myeloid leukocyte markers including spila, lcpl, mpeg1.1, and $n c f 1$. Cluster 19 we annotate as mesenchymal cells based on their expression of epithelial-mesenchymal transition genes like twistla and snaila, as well as vim and multiple collagen genes. Cluster 20 we annotate as exocrine pancreas based on expression of the pancreatic transcription factor ptfla and other pancreatic markers ela3l, pdia2, cpal, prss 1, amy $2 a(122,124,144)$. Cluster 25 we annotate as red blood cells based on their unique 
expression of multiple hemoglobin genes. We were not able to confidently annotate cluster 24 due to a paucity of specific markers for which previous in situ hybridization data was available. Genes specific for cluster 24 include $c x 30.3 / g j b 8$ which is expressed in the otic vesicle, skin, and swim bladder $(145,146)$, and si:dkey-96g2.1. However, a known marker for the swim bladder epithelium $m n x 1 / h b 9$ (147) was very low in our dataset, suggesting cluster 24 is not swim bladder. Several markers of cluster 24 were also shared with pharyngeal clusters 1,7 , and 10 (clic2, tnfb, noxola, and CR762483.1) suggesting some shared function between these cell types.

\section{In vitro bile salt metabolism assay detects common bile salt modifications mediated by mammalian gut microbes}

To test if complex gut microbiota or individual bacterial strains can modify bile salts, we developed an in vitro bile salt modification assay. Microbes of interest were first enriched in rich medium under aerobic or anaerobic conditions and were then incubated with known bile salts. Afterward, the metabolites from these cultures were extracted and subjected to LC/MS to examine potential modifications of the bile salts. To improve the detection sensitivity of the assay, we modified a previous extraction method used to extract cholesterol and other steroid hormones out of culture media for LC/MS analysis (79). Our extraction method was tested via extracting and quantifying $5 \alpha \mathrm{CS}$ and TCA as well as ACA, a $\mathrm{C}_{24}$ bile acid analog of $5 \alpha \mathrm{CS}$, from modified TSB medium (Fig S3A). As expected, the internal standard D4-GCA was eluted at 5.62 $\min$ at $468.33 \mathrm{~m} / \mathrm{z} ; 5 \alpha \mathrm{CS}$ was eluted at approximately $7.6 \mathrm{~min}$ at $531.3 \mathrm{~m} / \mathrm{z}$; TCA was eluted at approximately $6.2 \mathrm{~min}$ at $514.29 \mathrm{~m} / \mathrm{z}$; ACA was eluted at approximately $6.5 \mathrm{~min}$ at $407.29 \mathrm{~m} / \mathrm{z}$. These results confirmed that this method was appropriate for the extraction of $5 \alpha \mathrm{CS}$, TCA, and ACA from bacterial cultures. We next utilized several bacterial strains with known bile salt modification abilities as positive controls to validate the detection of bile salt modifications in our in vitro system. Lactobacillus salivarius JCM1046 encodes a bile salt hydrolase enzyme, which cleaves off the conjugated taurine in TCA, thus generating CA (148). Clostridium scindens ATCC 35704 is known to contain the bile acid $7 \alpha$-dehydroxylation pathway, which can transform CA and/or ACA into secondary bile acids deoxycholic acid (DCA) or allo-DCA, respectively (149). Indeed, the predicted modified bile salts were recovered from the culture medium after incubation with the corresponding bacterial strains under anaerobic conditions (Fig $\mathrm{S} 3 \mathrm{~B})$. Interestingly, we did not observe signs of $7 \alpha$-dehydroxylation of $5 \alpha \mathrm{CS}$ when supplementing this bile alcohol to $C$. scindens culture (Fig S3B). This suggests that $5 \alpha \mathrm{CS}$ is likely resistant to such modification. Nonetheless, these data confirmed that our in vitro bile salt modification assay is appropriate for detecting modified metabolites of primary bile salts in cultures.

\section{The Tg(-0.258fabp6-cfos:GFP) ${ }^{\text {rdu22 }}$ is physically linked with cyp7a1 locus}

To monitor Fxr activity in response to different levels of bile salts, we attempted to introduce the homozygous cyp $7 a 1^{-16 /-16}$ mutation into the previously reported $\mathrm{Tg}(-0.258 \mathrm{fabp} 6$ cfos:GFP $)^{r d u 22}$ transgenic line (17) by setting up breeding crosses between $c y p 7 a 1^{+/-16}$ zebrafish 
and $c y p 7 a 1^{+/-16} ; \operatorname{Tg}(-0.258 f a b p 6-c f o s: G F P)$ zebrafish. Following this cross, the progeny exhibited a normal Mendelian ratio with respect to the cyp7al genotype and the wt: heterozygous: homozygous ratio was approximately 1:2:1 (Fig S1E). The segregation of $g f p$ transgene also followed the Mendelian ratio, with only half of the progeny carrying the $g f p$ (Fig $\mathrm{S} 1 \mathrm{E})$. Interestingly, we found that 152 out of $153 \mathrm{gfp}$ positive offspring were either $c y p 7 \mathrm{al} \mathrm{I}^{+/+}$or $c y p 7 a 1^{+/-}$, whereas 158 out of 161 non-transgenic fish were either $c y p 7 a 1^{+/-16}$ or $c y p 7 a 1^{-16 /-16}$. In fact, of all 314 progeny sampled, only one cyp7a1 $16 /-16 ; T g(-0.258 f a b p 6-c f o s: G F P)$ fish and three $c y p 7 a 1^{+/+}$nontransgenic fish were identified. These genotypic frequencies suggested that the $g f p$ transgene and cyp $7 a 1$ gene were physically linked on chromosome 2 in the $T g(-$ 0.258fabp6-cfos:GFP) reporter line and therefore co-segregated following the cross. We therefore generated a new $\operatorname{Tg}(-1.7 f a b p 6: G F P)$ reporter line and used the new line instead to examine Fxr activity upon bile salt deficiency (Fig 1D).

\section{Validation of cyp7a1 mutant zebrafish}

The cyp 7al mutant zebrafish were generated by targeting exon 2 that encodes the cytochrome P450 domain using CRISPR-Cas9. We identified two independent deletion alleles resulting in frameshift mutations in exon 2 of the cyp $7 a 1$ gene, cyp $7 a 1^{-7 /-7}$ and cyp $7 a 1^{-16 /-16}$. Early mortality was observed in zebrafish homozygous for either of these cyp $7 a 1$ alleles. Specifically, both the $c y p 7 a 1^{-7 /-7}$ and $c y p 7 a 1^{-16 /-16}$ zebrafish showed exceptionally low survival rate past 1 month post-fertilization ( 1 out of $>300$ fish), consistent with the observations in Cyp7al null mice (150). One allele, the larger cyp7al deletion allele cyp $7 a 1^{-16 /-16}(r d u 84$, designated as $c y p 7 a 1^{-/}$) was selected for subsequent study. We validated this allele using two methods. First, we quantified the levels of bile salts in pooled cyp7al wt versus homozygous mutant larvae. This revealed a significant reduction of the total bile salts in cyp7al mutant zebrafish as compared to their wt counterparts, indicative of impaired bile salt synthesis in the cyp7al mutant zebrafish. Second, we compared the mRNA levels of cyp7al between larvae pools enriched for either cyp $7 a 1$ wt or mutant zebrafish. Specifically, we crossed the $c y p 7 a 1^{+/-}$ zebrafish with the cyp $7 a 1^{+-} ; \operatorname{Tg}(-0.258 f a b p 6-c f o s: G F P)$ zebrafish. As mentioned above, since the $g f p$ gene in the $T g(-0.258 f a b p 6$-cfos:GFP) reporter line is physically linked with the cyp7al gene, the GFP positive progeny produced by this cross will be either $c y p 7 a 1^{+/+}$or $c y p 7 a 1^{+/-}$ (designated as the wt enriched pool), whereas the GFP negative progeny will be either $c y p 7 a 1^{+/-}$ or $c y p 7 a 1^{-/-}$(designated as the mutant enriched pool). qPCR analysis of the GFP negative and negative populations revealed that the mutant enriched pool (GFP negative) exhibited a strong reduction of cyp7al transcript levels as compared to the wt enriched pool (GFP positive), suggesting efficient knockdown of the cyp7al gene in the mutants. We also observed decreased levels of fabp6 and slc10a2 RNA in the mutant enriched pool, consistent with the prediction that Fxr activity is reduced upon bile salt deficiency in the cyp7al mutant. 


\section{Supplementary Materials and Methods}

\section{Chemicals, reagents, and materials}

Corning polypropylene conical tubes $(15 \mathrm{~mL}$ and $50 \mathrm{~mL})$ were purchased from MilliporeSigma (San Jose, CA). Organic solvents and other chemicals were purchased from Fisher Scientific (Hampton, NH). JT Baker 20 x 20 thin layer chromatography (TLC) plates were purchased from Thomas Scientific (Swedesboro, NJ). Solid phase extraction cartridges were purchased from Waters (Milford, MA). Allocholic acid was purchased from Cayman Chemicals (Ann Arbor, MI), and deuterated-glycocholic acid was purchased from Toronto Research Chemicals (Ontario, Canada). All other bile standards were purchased from MilliporeSigma. Other materials were purchased from either MilliporeSigma or Fisher Scientific. Since we determined that animalbased peptones contained detectable bile acids, vegetable peptone and soy peptone both from BD Biosciences (San Jose, CA) were used in culture medium. Other ingredients include glucose, sodium chloride, dipotassium phosphate, Tween 80, and cysteine obtained from Fisher Scientific.

\section{Total bile salt quantification}

For whole larvae samples, $6 \mathrm{dpf}$ larvae were euthanized and rinsed with GZM for three times to remove carryover of food or debris (30 larvae/replicate; 4-6 replicates/condition). The pooled larvae were then placed in $1 \mathrm{~mL} \mathrm{1:1} \mathrm{chloroform:} \mathrm{methanol} \mathrm{and} \mathrm{sonicated} \mathrm{for} 3$ min with 2/1 ON/OFF cycle and 70\% amplitude using a QSONICA Q700-MPX-110 cup horn sonicator. The homogenate of each replicate was spun at room temperature at $20000 \mathrm{~g}$ for $30 \mathrm{~min}$. The supernatant was collected, air-dried in a fume hood overnight, and subjected to bile salt quantification using the enzyme-cycling method based bile acid detection kit (Diazyme, DZ042A) as described previously (14).

\section{In vitro bile salt modification assay}

Modified tryptic soy broth (TSB) at $\mathrm{pH}=7.0$ was prepared aerobically and anaerobically for experimental use with the composition as follows: vegetable peptone $(17.0 \mathrm{~g} / \mathrm{L})$, soy peptone $(3.0 \mathrm{~g} / \mathrm{L})$, glucose $(2.5 \mathrm{~g} / \mathrm{L})$, sodium chloride $(0.5 \mathrm{~g} / \mathrm{L})$, dipotassium phosphate $(2.5 \mathrm{~g} / \mathrm{L})$, and cysteine $(1.0 \mathrm{~g} / \mathrm{L})$. The substrate testing medium was generated by supplemented freshly made modified TSB medium with $50 \mu \mathrm{M}$ methanol vehicle, $5 \alpha \mathrm{CS}$, TCA, or ACA, respectively. Two microbes with known bile salt conversion activities were selected as reference controls for bile acid and bile alcohol conversion: Lactobacillus salivarius JCM1046 for the bile salt hydrolase activity (151), and Clostridium scindens ATCC 35704 for $7 \alpha$-dehydroxylation activity (149). Bacterial reference control tubes were also inoculated (1:10 dilution) in modified TSB medium with the selected strains of $L$. salivarius and $C$. scindens containing $50 \mu \mathrm{M}$ corresponding bile salt substrates and cultured at $37^{\circ} \mathrm{C}$ for $48 \mathrm{~h}$. For L. salivarius, $1 \%$ Tween 80 was supplemented to media for growth enrichment (152). 
bioRxiv preprint doi: https://doi.org/10.1101/2020.12.13.422569; this version posted December 13, 2020. The copyright holder for this preprint (which was not certified by peer review) is the author/funder, who has granted bioRxiv a license to display the preprint in perpetuity. It is made available under aCC-BY-NC 4.0 International license.

\section{Supplementary Figures and Tables}


bioRxiv preprint doi: https://doi.org/10.1101/2020.12.13.422569; this version posted December 13, 2020. The copyright holder for this preprint (which was not certified by peer review) is the author/funder, who has granted bioRxiv a license to display the preprint in perpetuity. It is made available under aCC-BY-NC 4.0 International license.

A

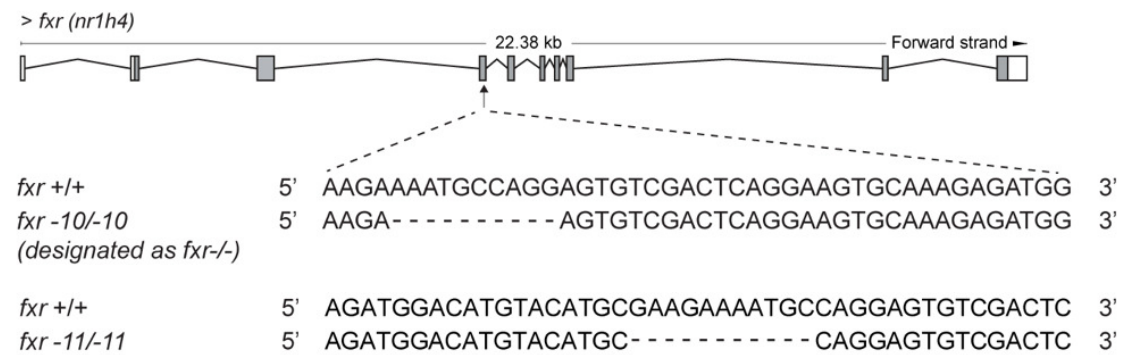

B

○ $f x r+/+$ - $f x r-10 /-10$
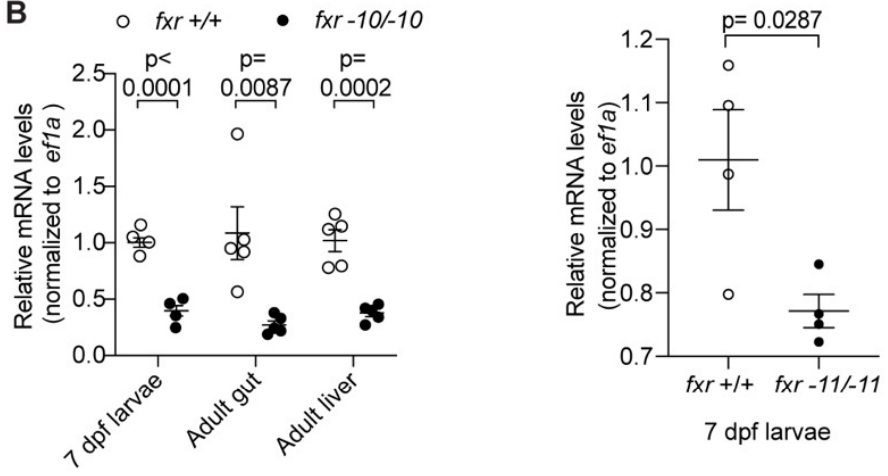

C
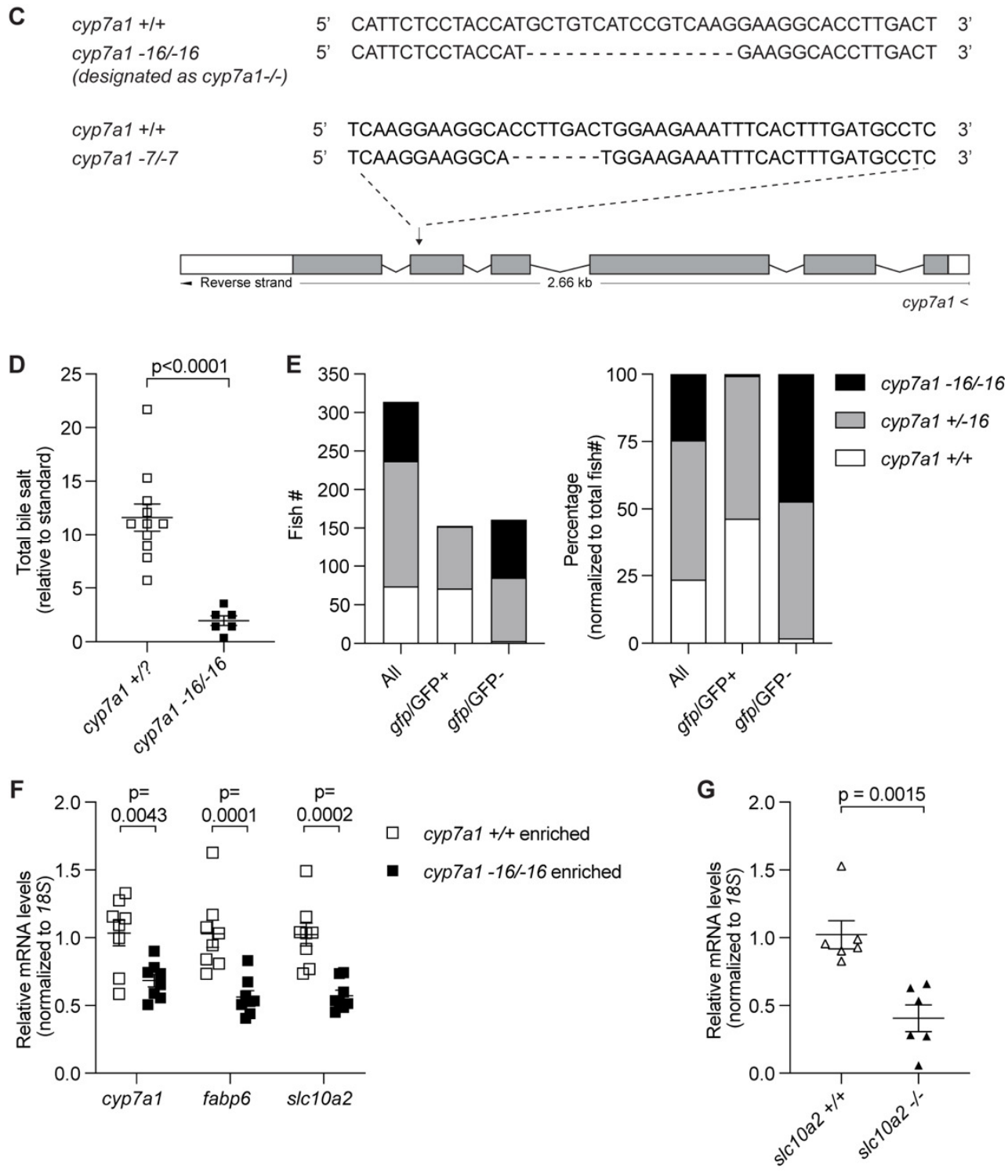


\section{Supplementary Figure 1. Zebrafish mutants with disrupted bile salt signaling pathways are validated by qRT-PCR and chemical assay.}

A. Schematic representation of the zebrafish $f x r$ locus along with the wt and the indel sequences from two independently identified alleles. Nucleotide changes are listed as dashes. B. qRT-PCR analysis comparing the expression of $f x r$ between $f x r^{+/+}$and $f x r^{-10 /-10}$ (left) or $f x r^{-11 /-11}$ (right) zebrafish at different developmental stages and in different tissues. The results are represented as relative expression levels that were normalized to efla (Mean \pm SEM). C. Schematic representation of the zebrafish cyp7al locus along with the wt and indel sequences from two independent alleles. Nucleotide changes are listed as dashes. D. Total bile salt levels in whole larvae of $6 \mathrm{dpf} c y p 7 a 1^{+/ ?}$ (WT or heterozygous) and cyp $7 a 1^{-16 /-16}$ (designated as cyp $7 a 1^{-/}$, homozygous) zebrafish. E. Distribution of cyp7al and $g f p$ genotypes in progeny from cross between $c y p 7 a 1^{+/-16}$ and cyp7a1 ${ }^{+/-16} ; \mathrm{Tg}(-0.258 f a b p 6$-cfos:GFP) zebrafish. Raw fish counts of the respective genotype are shown on the left. The percentage of each genotype relative to the total fish counts is shown on the right. F. qPCR analysis comparing the expression of the direct Fxr target genes in 6 dpf $c y p 7 a 1^{+/+}$enriched larvae and $c y p 7 a 1^{-16 /-16}$ enriched larvae. G. qPCR analysis comparing expression of slcl0a2 in $6 \mathrm{dpf}$ slcl0a2 ${ }^{+/+}$and slcloa2 $2^{\text {sa2486/sa2486 }}$ larvae. The results in $(\mathrm{B}, \mathrm{F}, \mathrm{G})$ are represented as relative expression levels normalized to $18 S$ (Mean $\pm \mathrm{SEM}$ ). Statistical significance in $(B, D, G)$ was calculated by unpaired t-test and in (F) was calculated by two-way ANOVA with Turkey's multiple comparisons test. Shown are representative data from at least two independent experiments. 
S2

A

${ }^{13} \mathrm{C} \delta \mathrm{ppm}$
$(1 \mathrm{H} \delta \mathrm{ppm})$$\quad$ a-cyprinol sulfate NMR

H-H COSY: $\longrightarrow$

27.9

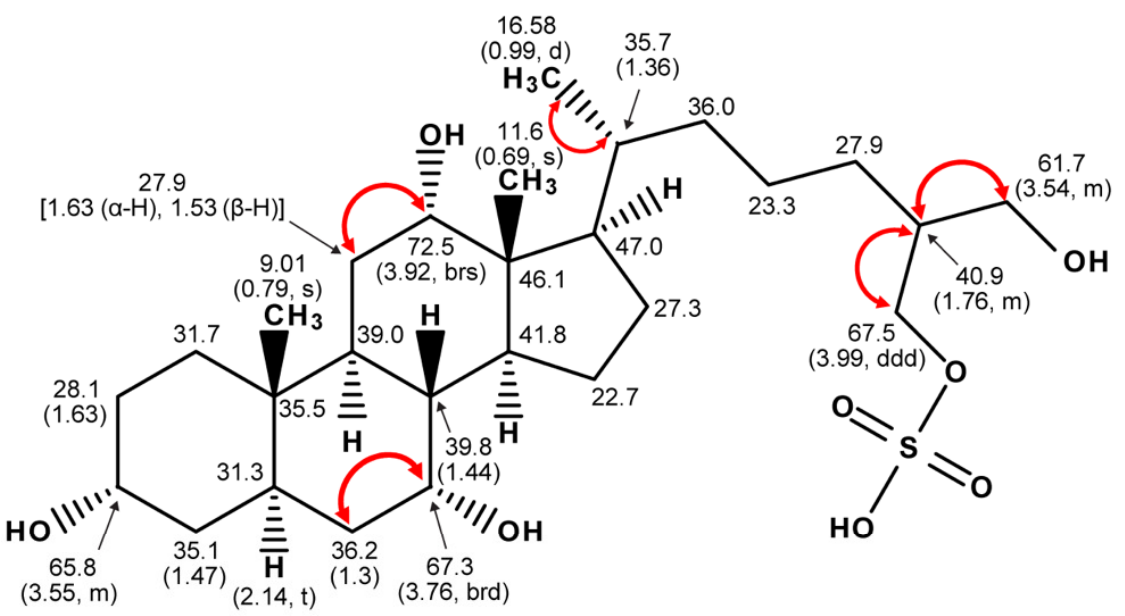

B
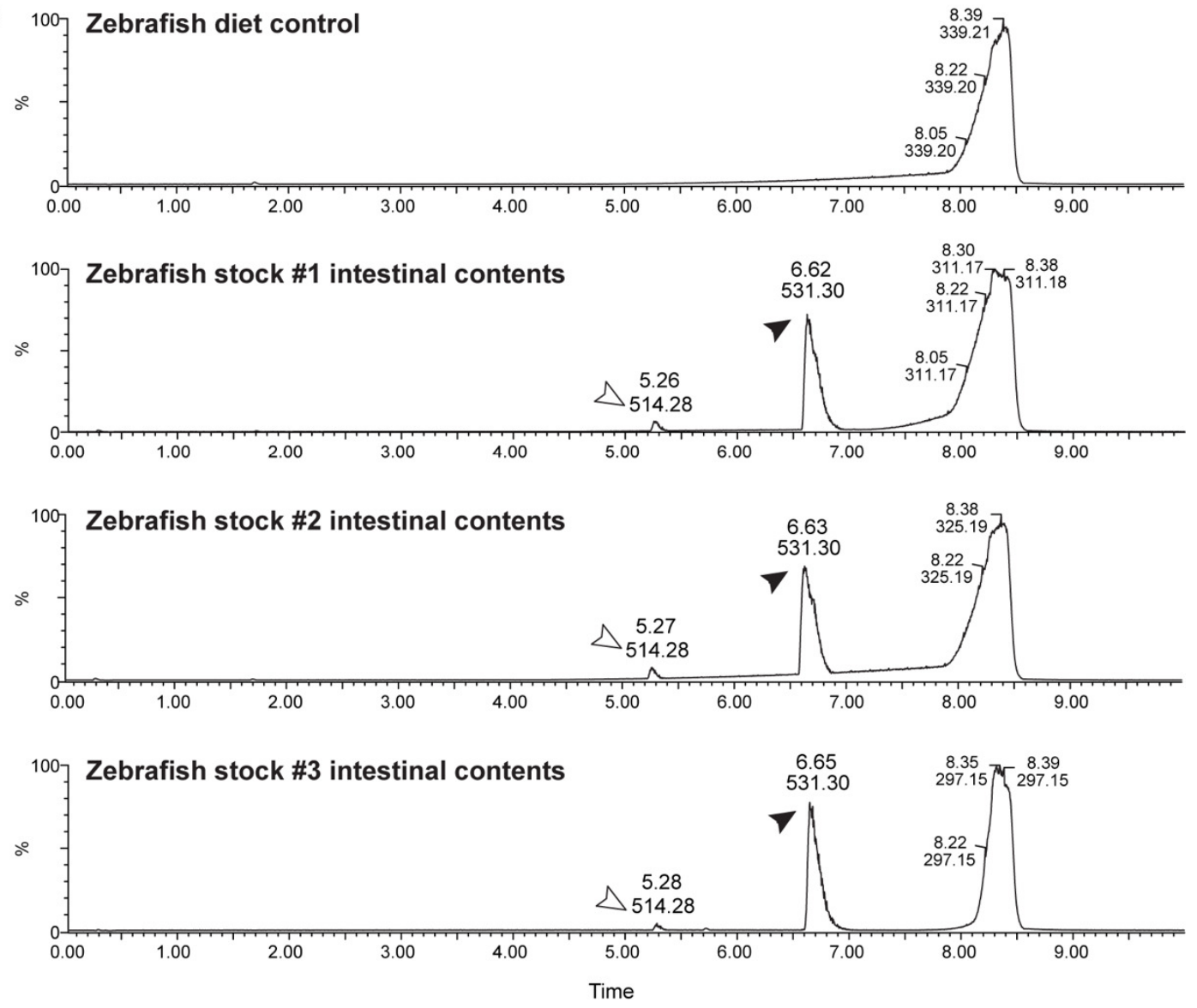

Supplementary Figure 2. The major zebrafish biliary bile alcohol species is confirmed by NMR as $5 \alpha$-cyprinol sulfate and is detected in the zebrafish intestinal contents.

A. Proton and Carbon-13 NMR chemical shifts of 5 $\alpha$-cyprinol sulfate isolated from zebrafish bile. The carbon-13 chemical shifts were determined relative to the CD3OD resonance and 
converted to the tetramethylsilane (TMS) scale using $\delta(\mathrm{CD} 3 \mathrm{OD})=49.3 \mathrm{ppm}$. Values in parentheses refer to proton chemical shifts ( $\delta$ ppm from TMS) and signal multiplicity: singlet, s; multiplet, m; doublet, d; triplet, t; brd, broad doublet; double doublet, dd. Arrows represents observed proton heteronuclear multiple bond correlations (HMBC). B. LC/MS chromatograms of metabolites extracted from the diet or intestinal contents of adult zebrafish from three randomly selected fish stocks. The arrowheads indicate the major zebrafish bile salts: black: $5 \alpha \mathrm{CS}$; white: TCA. 
bioRxiv preprint doi: https://doi.org/10.1101/2020.12.13.422569; this version posted December 13, 2020. The copyright holder for this preprint (which was not certified by peer review) is the author/funder, who has granted bioRxiv a license to display the preprint in perpetuity. It is made available under aCC-BY-NC 4.0 International license.
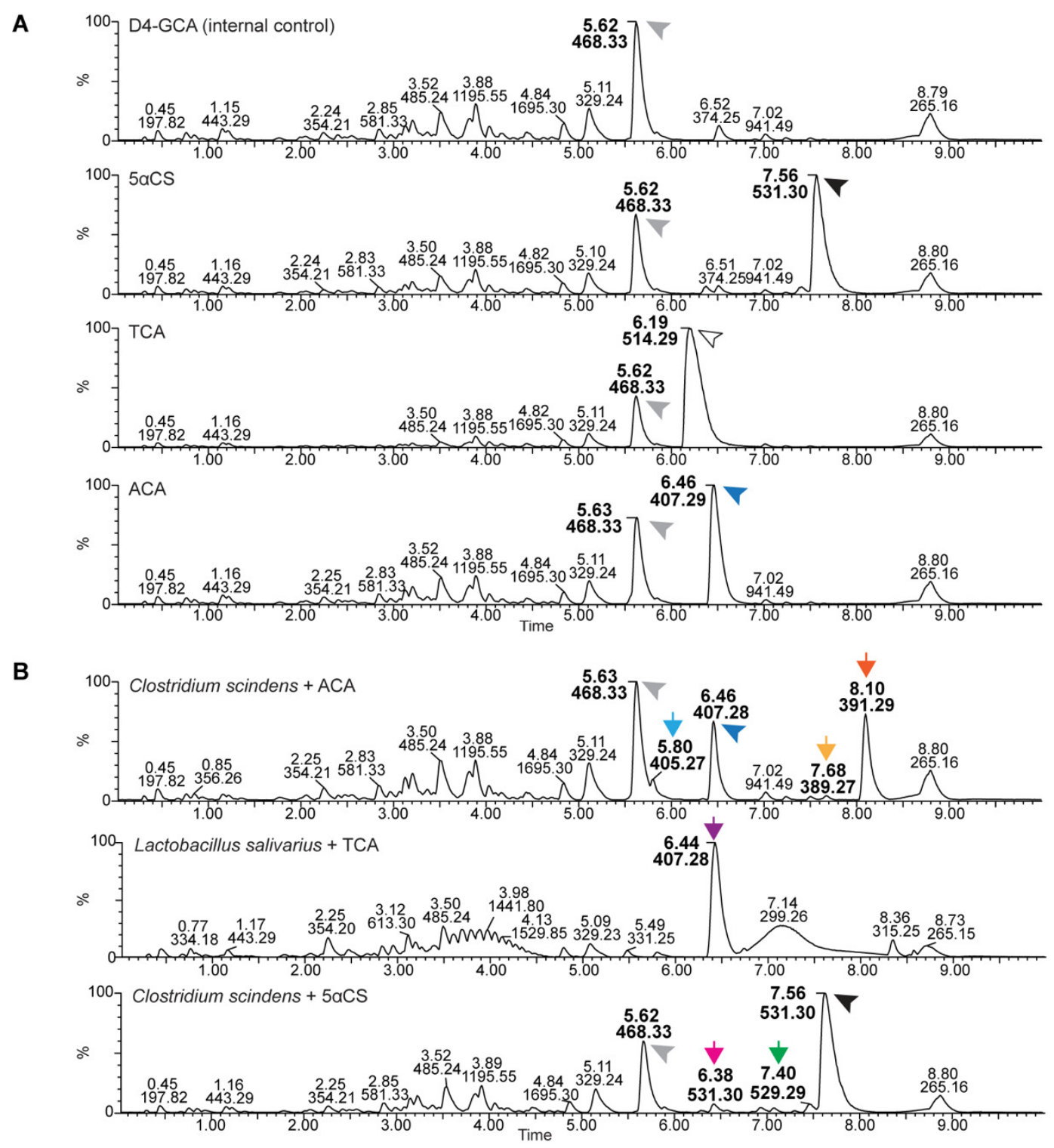

C
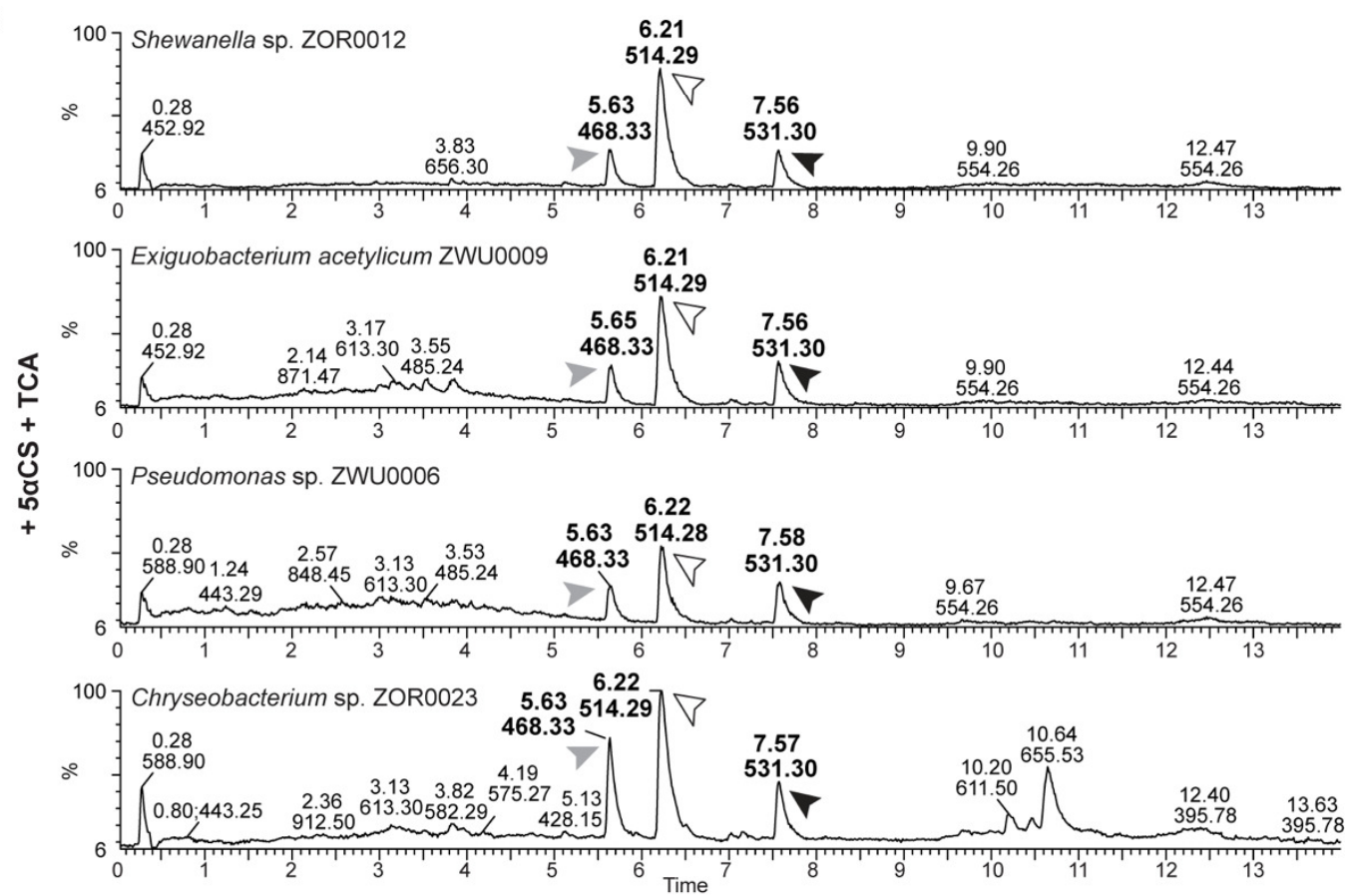
Supplementary Figure 3. In vitro bile salt metabolism assay reveals specific modifications of bile salts by mammalian or zebrafish gut microbes.

A. LC/MS chromatographs of metabolites extracted from medium incubated with internal standard D4-GCA, 5 $\alpha \mathrm{CS}$, TCA, and ACA for 24 hours. The arrowheads indicate the supplemented substrates: grey: internal standard D4-GCA; black: $5 \alpha C S$; white: TCA; blue: ACA. B. LC/MS chromatographs of bile salt metabolites extracted from enriched bacterial monocultures supplemented with $50 \mu \mathrm{M}$ known bile salts under anaerobic conditions. The bacteria and bile salt combinations are as follows: top: Clostridium scindens ATCC 35704 with ACA; middle: Lactobacillus salivarius JCM1046 with TCA; bottom: Clostridium scindens ATCC 35704 with $5 \alpha C S$. The arrowheads indicate the supplemented substrates: grey: internal standard D4-GCA; black: 5 $\alpha$ CS; white: TCA; blue: ACA. The arrows indicate bile salt metabolites resulted from microbial modification of the supplemented bile salts: light blue: dehydrogenated ACA; dark orange: allo-DCA; light orange: dehydrogenated allo-DCA; purple: CA; green: dehydrogenated $5 \alpha \mathrm{CS}$; magenta: epimerized $5 \alpha \mathrm{CS}$. No other modifications of bile salts were observed. C. LC/MS chromatographs of bile salt metabolites extracted from enriched monocultures of zebrafish intestinal microbes supplemented with $50 \mu \mathrm{M} 5 \alpha \mathrm{CS}$ and TCA under aerobic conditions. The bacteria were chosen to represent the major bacterial taxa in zebrafish gut and are listed as follows (from top to bottom): Shewanella sp. ZOR0012 (Proteobacteria), Exiguobacterium acetylicum ZWU0009 (Firmicutes), Pseudomonas sp. ZWU0006 (Proteobacteria), Chryseobacterium sp. ZOR0023 (Bacteroidetes). The arrowheads indicate the supplemented substrates: grey: internal standard D4-GCA; black: 5aCS; white: TCA. No modification of $5 \alpha \mathrm{CS}$ and TCA by these bacteria was observed. 
bioRxiv preprint doi: https://doi.org/10.1101/2020.12.13.422569; this version posted December 13, 2020. The copyright holder for this preprint (which was not certified by peer review) is the author/funder, who has granted bioRxiv a license to display the preprint in perpetuity. It is made available under aCC-BY-NC 4.0 International license.

A

A
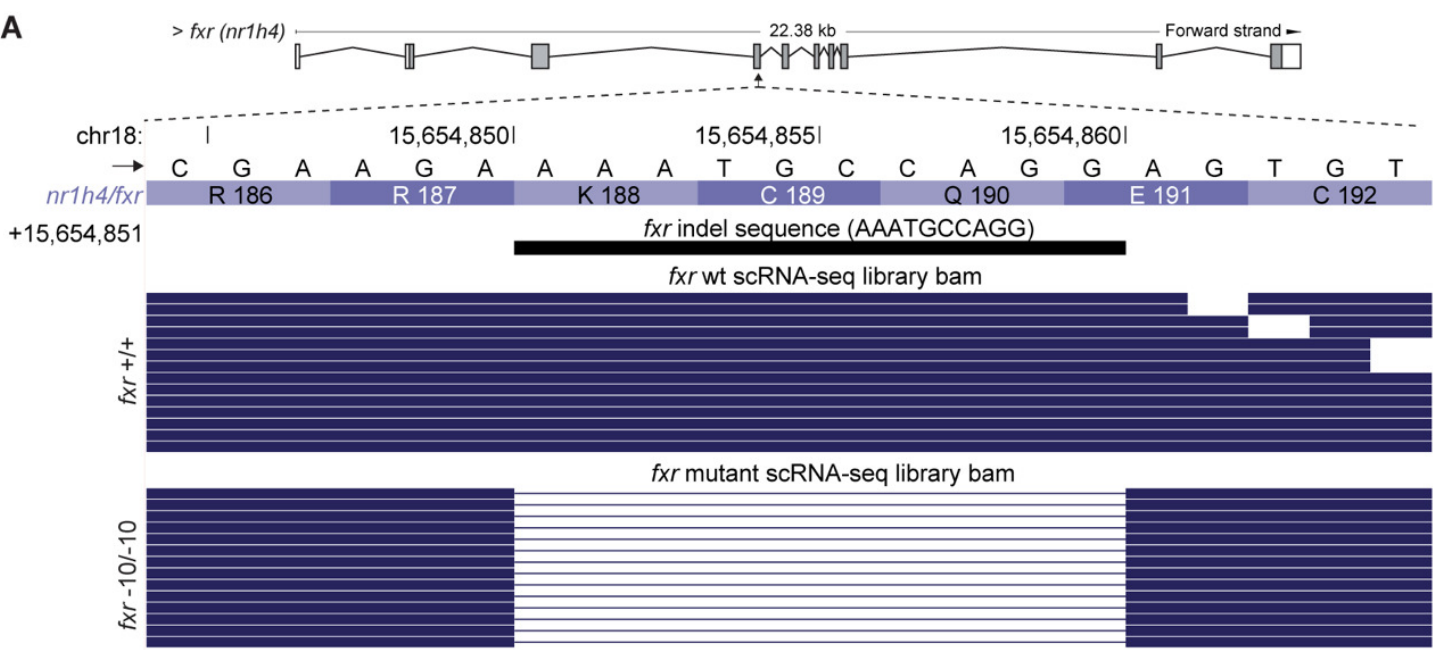

B
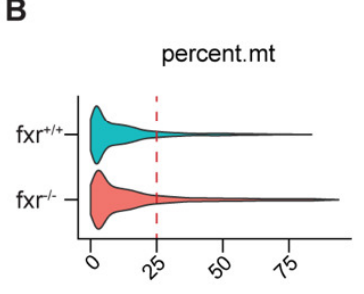

nCount_RNA

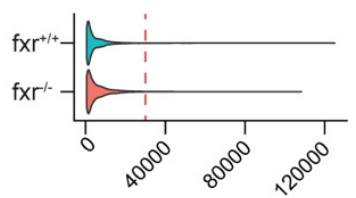

nFeature_RNA

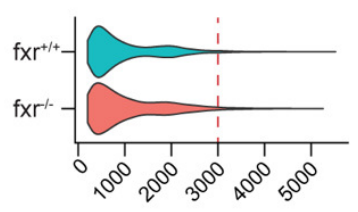

E
C
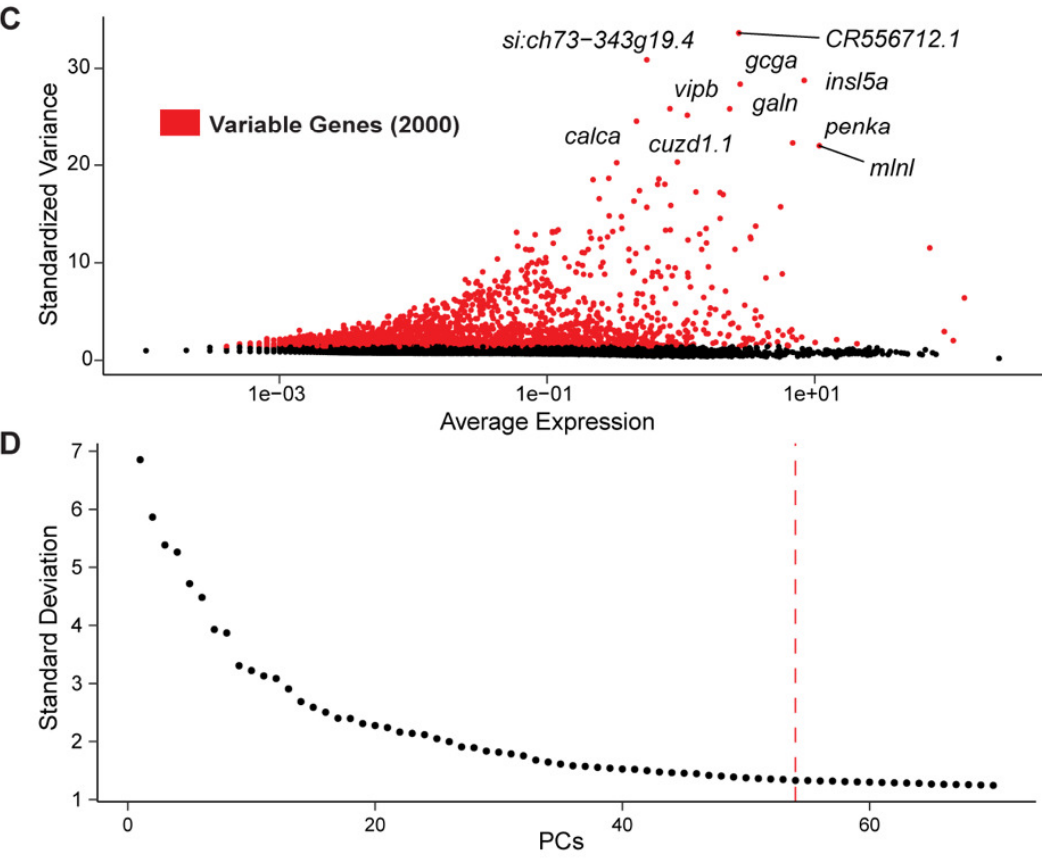

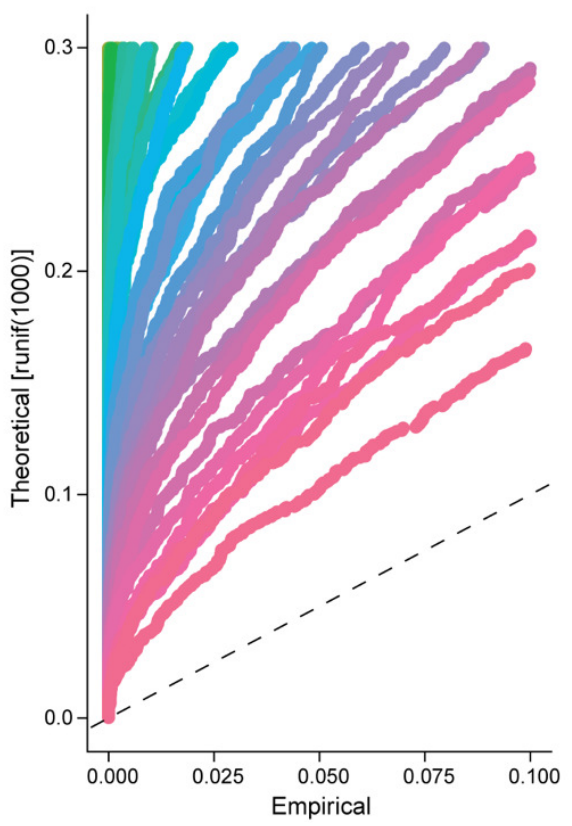

- PC 1: 2.36e-245 • PC 19: 1.69e-69 • PC 37: 1.88e-29

- PC 2: $1.47 \mathrm{e}-216$ - PC 20:9.11e-81 • PC 38: 1.38e-21

- PC 3: $1.65 \mathrm{e}-210$ - PC 21:5.88e-79 ค PC 39: 1.93e-20

- PC 4: $1.44 \mathrm{e}-248$ - PC 22: $1.72 \mathrm{e}-58$ ○ PC 40: 3.75e-18

- PC 5: 3.5e-118 - PC 23: 3.24e-62 • PC 41: 3.97e-21

- PC 6: $1.64 \mathrm{e}-206$ - PC 24: 1.5e-54 ค PC 42: 9.67e-10

- PC 7: 3.83e-183 • PC 25: 1.03e-62 • PC 43: 6.73e-21

- PC 8: $1.05 \mathrm{e}-120$ - PC 26: 2.07e-77 • PC 44: 5.92e-05

- PC 9: 4.05e-168 - PC 27: 3.73e-43 ค PC 45: 9.67e-10

- PC 10: $1.49 \mathrm{e}-147$ • PC 28: $1.77 \mathrm{e}-67$ • PC 46: 6.45e-13

- PC 11:4.91e-158 - PC 29:8.89e-56 • PC 47:4.64e-09

- PC 12: 9.78e-165 - PC 30:6.71e-34 • PC 48: 1.47e-06

- PC 13:2.79e-137 • PC 31: $3.77 \mathrm{e}-38$ • PC 49: 3.48e-05

- PC 14: 4.11e-122 • PC 32: 1.12e-37 • PC 50: 1.21e-05

- $P C$ 15: 2.65e-92 - PC 33: 1.71e-36 • PC 51: 0.000857

- PC 16:3.8e-84 - PC 34: 1.93e-20 - PC 52: 0.00759

- PC 17: 3.26e-127 - PC 35: 3.22e-29 • PC 53: 0.00253

- PC 18: 1.15e-107 • PC 36: 1.16e-26 • PC 54: 3.48e-05 


\section{Supplementary Figure 4. ScRNA-seq data are processed for quality control prior to clustering.}

A. Diagram representing a stack of randomly selected reads spanning the $f x r$ exon 4 from the scRNA-seq, aligned to the exact indel sequence of $f x r^{-/}$. B. Number of counts per cell, features (or genes) per cell and percent mitochondrial transcripts for both $f x r^{+/+}$(blue) and $f x r^{-/-}$(pink) libraries. Dash lines in each panel represent the QC threshold cutoff used to select cells for downstream analyses. C. Highly variable genes (in red) determined by the average expression and vst method. D. ElbowPlot (100 PCs included, red dashed line at 54) and E. Jackstraw analysis (54 significant PCs included) employed to determine the maximum number of PCs that significantly contributed to variation in the integrated dataset. 


\section{S5}
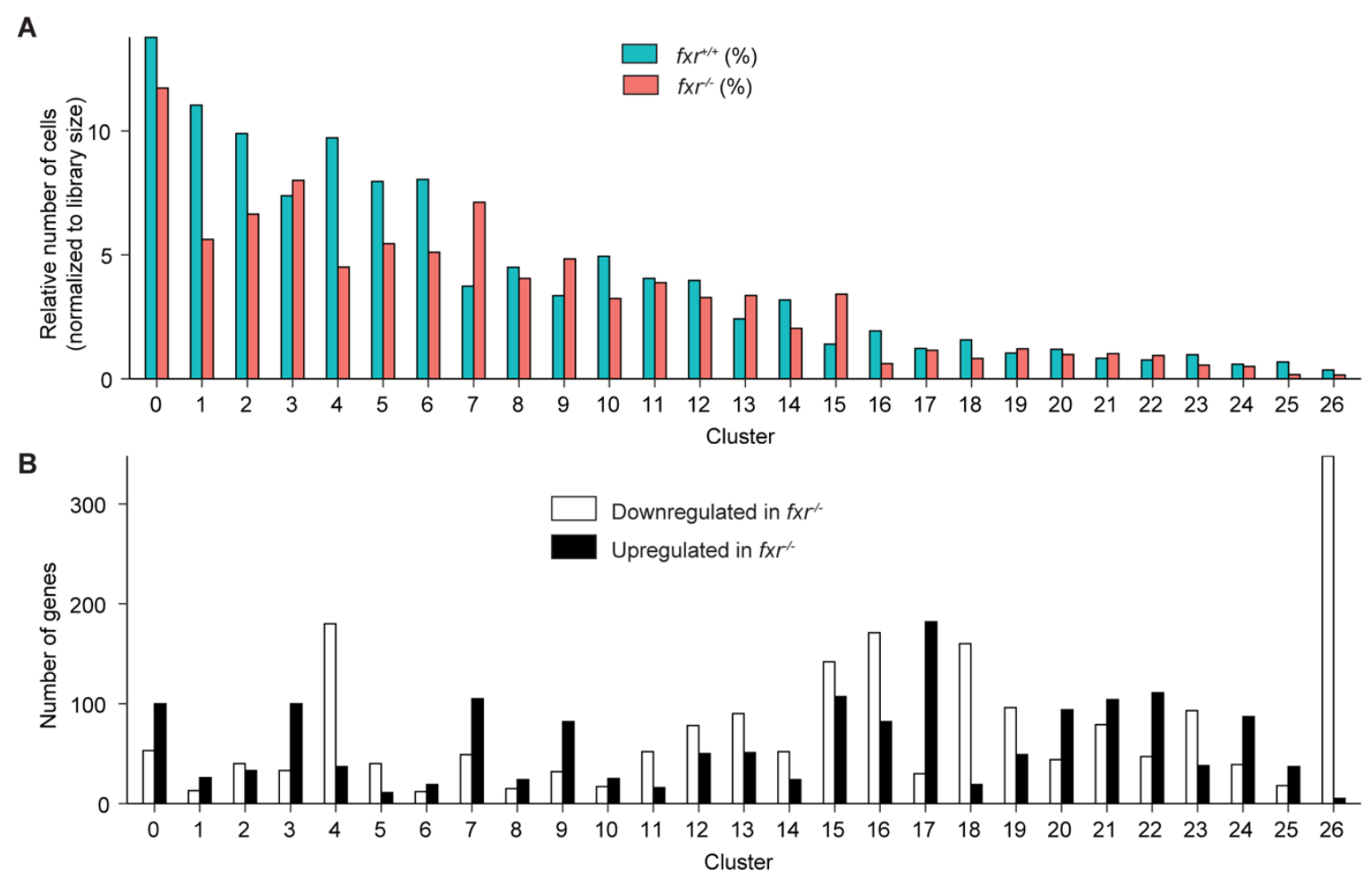

Supplementary Figure 5. Fxr mutation displays broad impacts on relative abundance and gene expression in multiple cell types of zebrafish intestinal epithelial cells.

A. Relative abundance of the $f x r^{+/+}$and $f x r^{-/-}$cells in each cluster. The relative abundance was calculated by dividing the raw cell abundances of a cluster by the total number of cells per genotype and represented as a percentage. B. Total number of genes upregulated or downregulated in $f x r^{-/-}$samples by cluster. 
bioRxiv preprint doi: https://doi.org/10.1101/2020.12.13.422569; this version posted December 13,2020 . The copyright holder for this preprint (which was not certified by peer review) is the author/funder, who has granted bioRxiv a license to display the preprint in perpetuity. It is made available under aCC-BY-NC 4.0 International license.
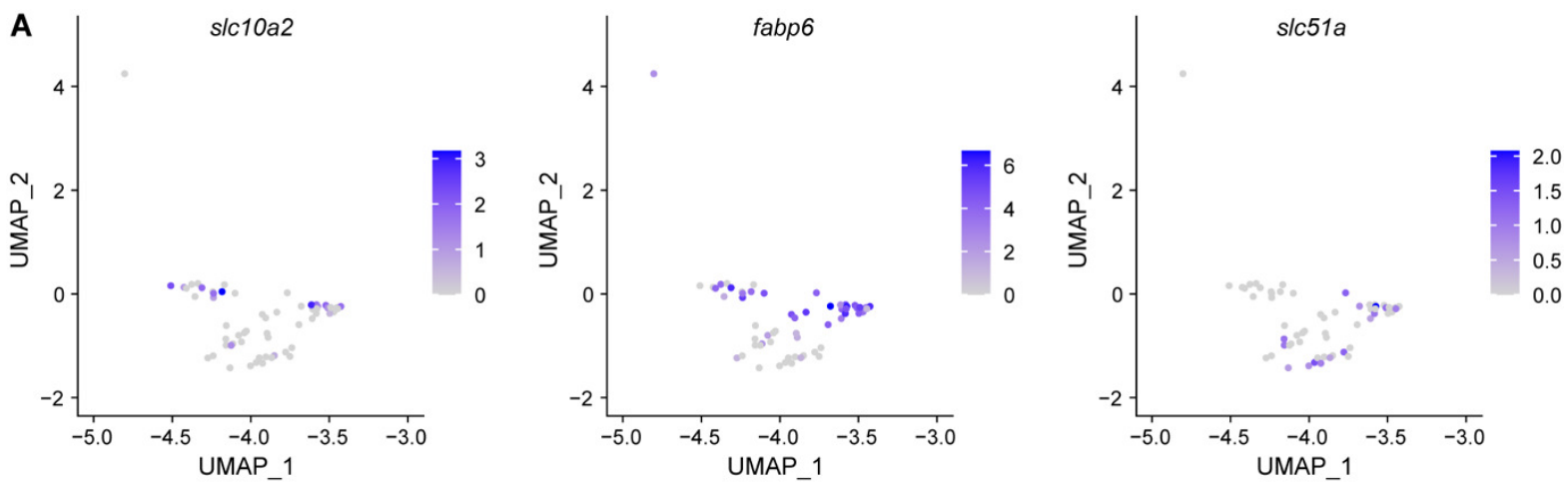

B Pathways enriched in upregulated cluster 17-enriched markers in fxr -/-

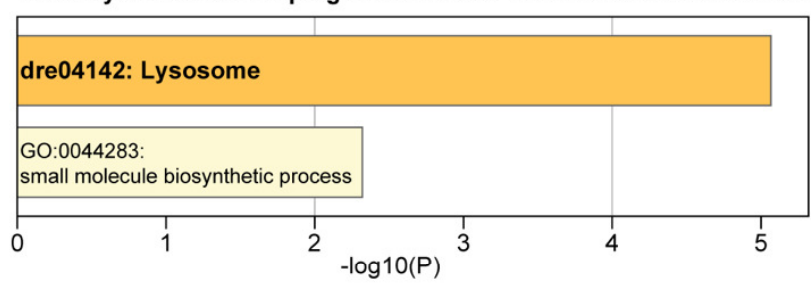

C Motifs enriched in upregulated genes in $\mathrm{fxr}-/$ - cells in cluster 17

\#1 ZBTB33 q-value=0.0432

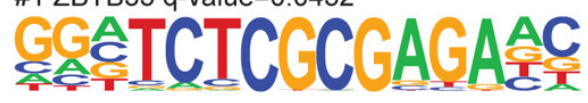

\#2 Atf2 q-value $=0.0432$

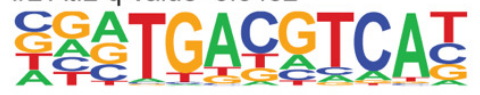

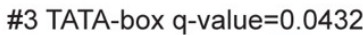

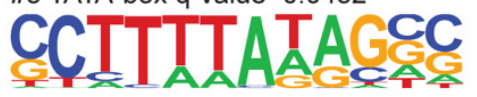

D subclustering cluster 17

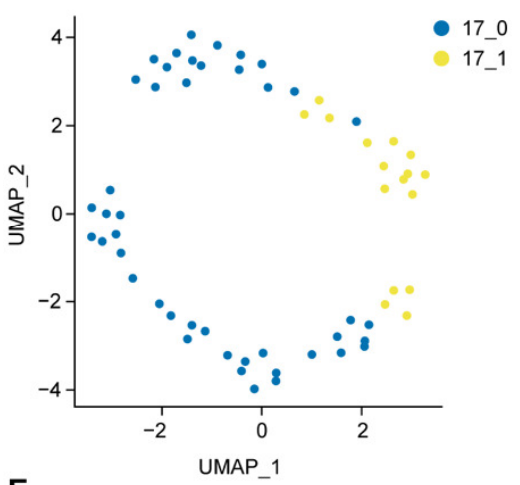

$\mathbf{E}$
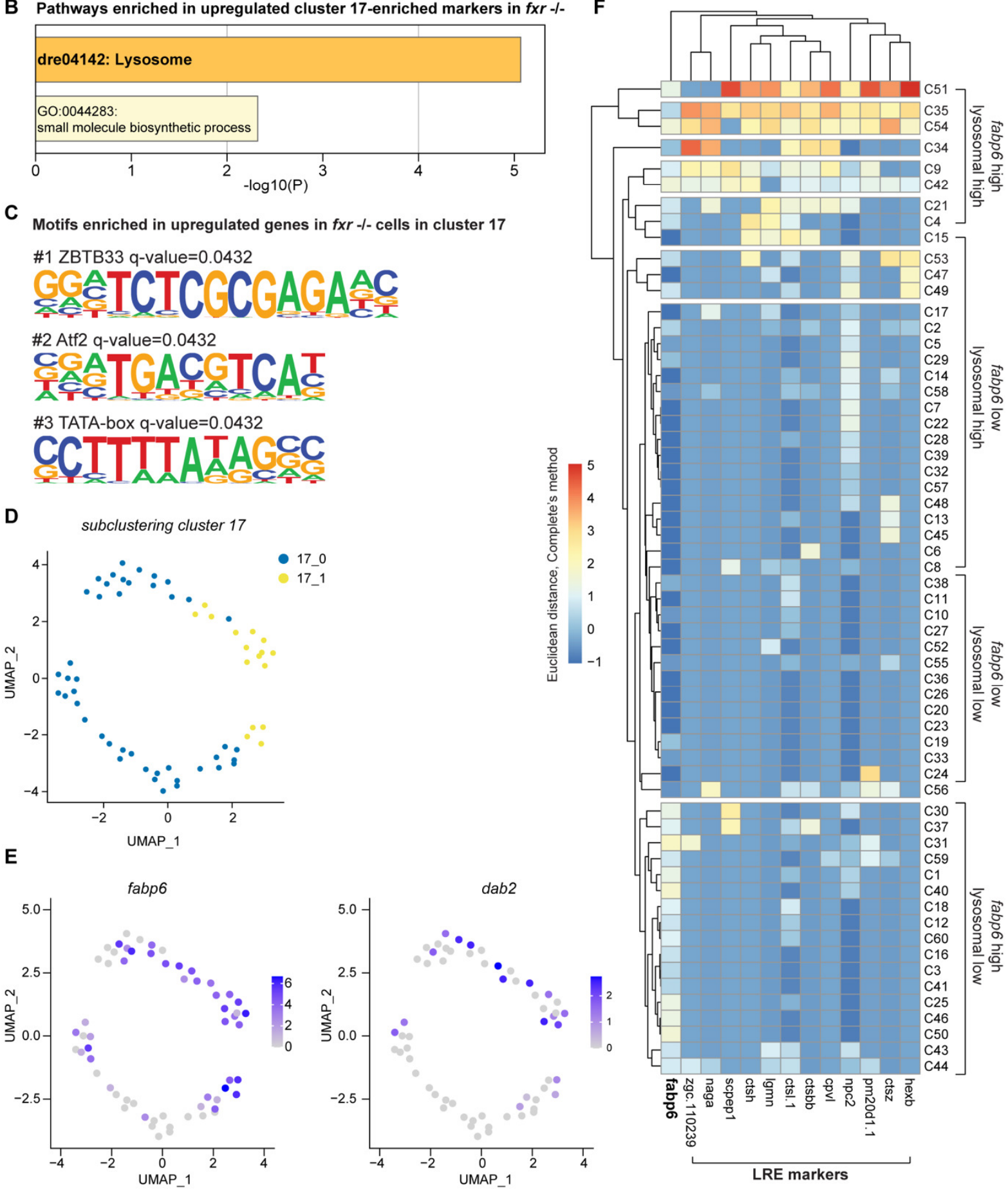


\section{Supplementary Figure 6. Single-cell RNA sequencing highlights transcriptomic heterogeneity in zebrafish ileal epithelial cells.}

A. UMAP plots revealing expression and distribution of genes related to bile salt transport in cluster 17 cells of the $f x r$ wt zebrafish. B. Non-redundant enrichment terms identified by Metascape upon analysis of upregulated cluster 17 -enriched markers of $f x r^{-1-}$ cells. The colors of enriched terms are scaled to represent statistical significance. C. The top 3 HOMER-identified enriched motifs in genes that were up regulated in the $f \mathrm{xr}^{-/-}$cells relative to $f \mathrm{xr}^{+/+}$cells in cluster 17. Shown are the position weight matrices (PWMs) of the enriched nucleotide sequences. The TF family that most closely matches the motif is indicated above the PWM. D. UMAP plot revealing two subclusters (17_0 and 17_1) of wt cells in cluster 17. E. FeaturePlots of ileocyte marker fabp6 and LRE marker dab2 showing concurrent expression in cluster 17 cells. F. Hierarchical clustering of $f x r^{+/+}$cluster 17 cells based on expression of bile absorption marker and lysosomal markers. Each row represents an individual cluster 17 cell and each column represents the expression of the indicated gene. Cells are manually assigned into four groups based on their expression profiles: fabp6 high/lysosomal marker high; fabp6 low/lysosomal marker high; fabp6 low/lysosomal marker low; fabp6 high/lysosomal marker low. 
bioRxiv preprint doi: https://doi.org/10.1101/2020.12.13.422569; this version posted December 13, 2020. The copyright holder for this preprint (which was not certified by peer review) is the author/funder, who has granted bioRxiv a license to display the preprint in perpetuity. It is made available under aCC-BY-NC 4.0 International license.

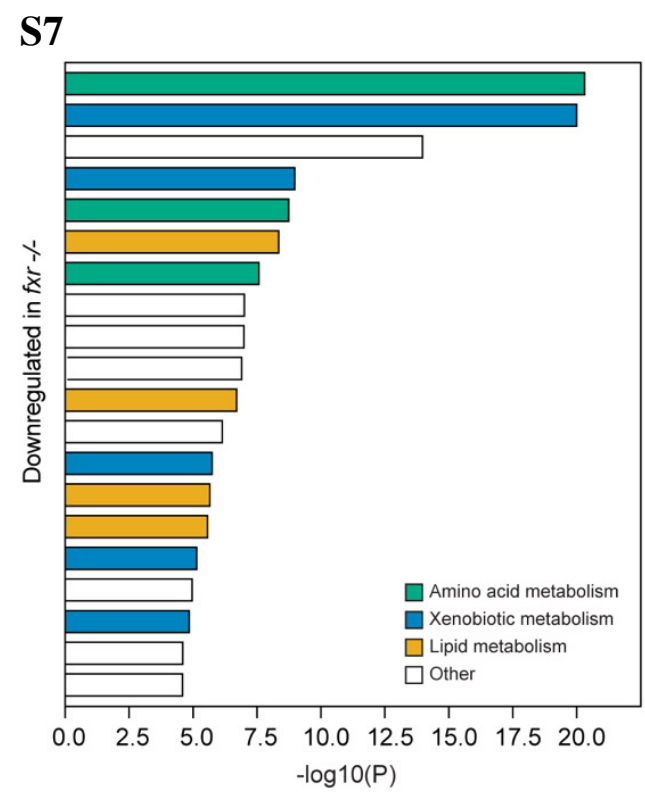

GO:0006518: peptide metabolic process GO:0017144: drug metabolic process GO:0055114: oxidation-reduction process GO:0016999: antibiotic metabolic process GO:0006575: cellular modified amino acid metabolic process GO:0016126: sterol biosynthetic process

R-DRE-71288: creatine metabolism GO:0006414: translational elongation GO:0042273: ribosomal large subunit biogenesis GO:0002181: cytoplasmic translation dre03320: PPAR signaling pathway R-DRE-211859: biological oxidations GO:0017001: antibiotic catabolic process GO:0034377: plasma lipoprotein particle assembly dre00640: propanoate metabolism GO:0009410: response to xenobiotic stimulus R-DRE-1428517: the citric acid cycle and respiratory electron transport GO:0006081: cellular aldehyde metabolic process R-DRE-6798695: neutrophil degranulation GO:0006457: protein folding

\section{Supplementary Figure 7. Metabolism pathways are enriched within genes downregulated in cluster 4 cells upon $f x r$ mutation.}

Top 20 non-redundant enrichment terms identified by Metascape upon analysis of genes that were down regulated in the $f x r^{---}$cells relative to $\mathrm{xxr}^{+/+}$cells in cluster 4. Enriched terms related to metabolism are color coded as follows: orange: lipid metabolism; green: amino acid metabolism; blue: xenobiotic metabolism; white: others. 
bioRxiv preprint doi: https://doi.org/10.1101/2020.12.13.422569; this version posted December 13, 2020. The copyright holder for this preprint (which was not certified by peer review) is the author/funder, who has granted bioRxiv a license to display the preprint in perpetuity. It is made available under aCC-BY-NC 4.0 International license.

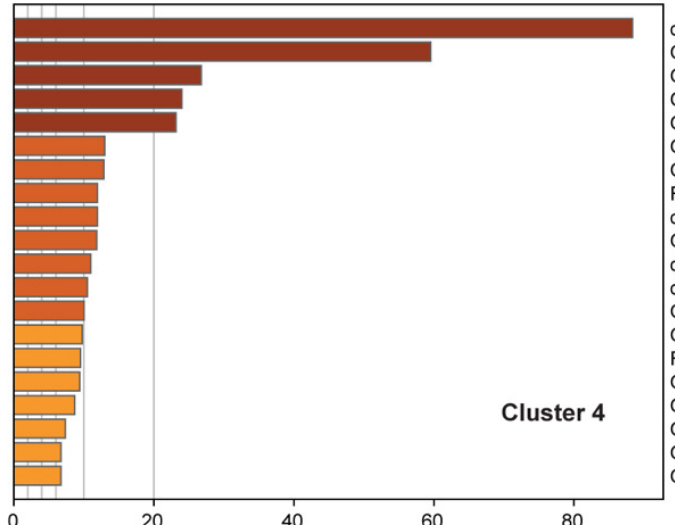

dre00190: Oxidative phosphorylation

GO:0055114: oxidation-reduction process

GO:0006082: organic acid metabolic process

GO:0009060: aerobic respiration

GO:0015985: energy coupled proton transport, down electrochemical gradient

GO:0006629: lipid metabolic process

GO:0044282: small molecule catabolic process

R-DRE-211859: Biological oxidations

dre04260: Cardiac muscle contraction

GO:0051186: cofactor metabolic process

dre00980: Metabolism of xenobiotics by cytochrome P450

dre03010: Ribosome

GO:0009410: response to xenobiotic stimulus

GO:0032787: monocarboxylic acid metabolic process

R-DRE-71291: Metabolism of amino acids and derivatives

GO:0042737: drug catabolic process

G.0006575: cellular modified amino acid metabolic process

GO:0006979: response to oxidative stress

GO:0006122: mitochondrial electron transport, ubiquinol to cytochrome c

GO:0016126: sterol biosynthetic process

0

$-\log 10(P)$

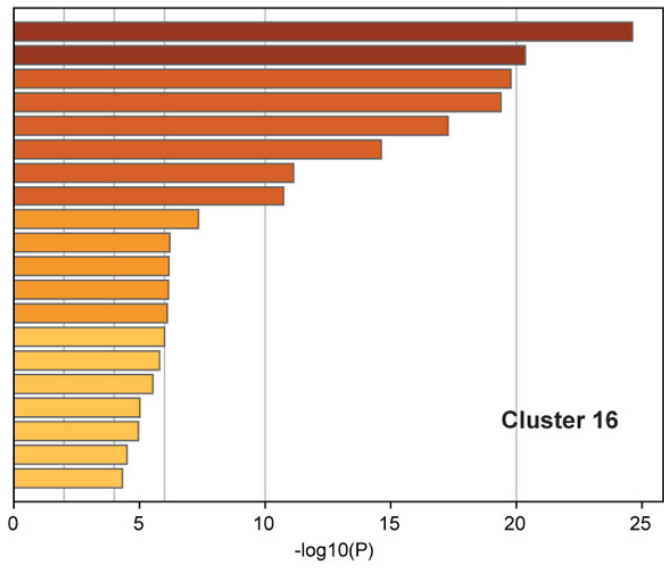

R-DRE-8953854: Metabolism of RNA dre00190: Oxidative phosphorylation

GO:0051276: chromosome organization

GO:0000280: nuclear division

GO:0022613: ribonucleoprotein complex biogenesis

R-DRE-1640170: Cell Cycle

GO:1902850: microtubule cytoskeleton organization involved in mitosis

R-DRE-72163: mRNA Splicing - Major Pathway

R-DRE-6782135: Dual incision in TC-NER

R-DRE-6782135: Dual incision in TC-NER

Rre04110: Cell cycle
dre

dre03008: Ribosome biogenesis in eukaryotes

GO:0022618: ribonucleoprotein complex assembly

GO:1903046: meiotic cell cycle process

GO:0006323: DNA packaging

R-DRE-5389840: Mitochondrial translation elongation

R-DRE-110312: Translesion synthesis by REV1

GO:0006119: oxidative phosphorylation

GO:0006310: DNA recombination

GO:0009221: pyrimidine deoxyribonucleotide biosynthetic process

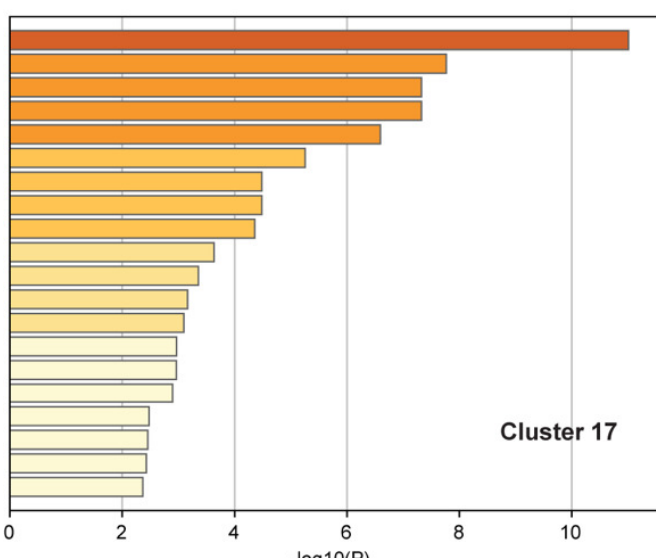

GO:0045333: cellular respiration

R-DRE-1428517: The citric acid (TCA) cycle and respiratory electron transport dre00020: Citrate cycle (TCA cycle)

R-DRE-70263: Gluconeogenesis

GO:0019752: carboxylic acid metabolic process

GO:0042255: ribosome assembly

GO:0042255: ribosome assembly

RO:0006094: gluconeogenesis

GO:0015850: organic hydroxy compound transport

R-DRE-425393: Transport of inorganic cations/anions and amino acids/oligopeptides

GO:0015721: bile acid and bile salt transport

GO:1901565: organonitrogen compound catabolic process

dre03320: PPAR signaling pathway

GO:0001666: response to hypoxia

GO:0009620: response to fungus

GO:0034620: cellular response to unfolded protein

dre02010: ABC transporters

GO:0072073: kidney epithelium development

GO:0072073: kidney epithelium developm

R-DRE-2142753: Arachidonic acid metabolism

$$
0
$$

$-\log 10(P)$

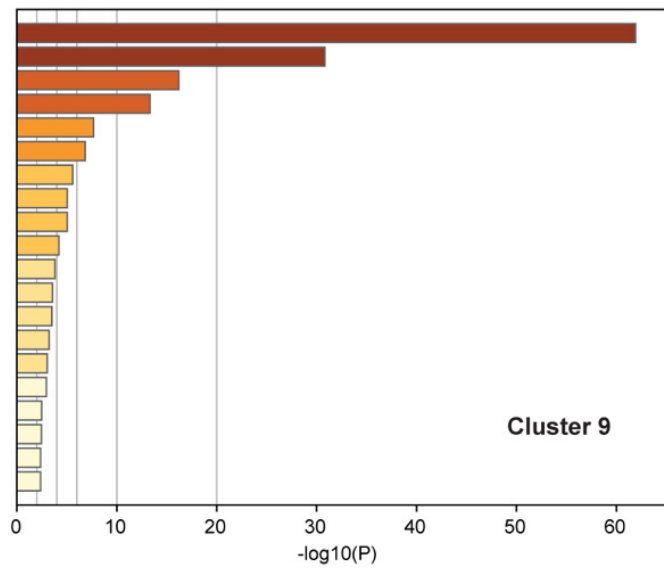

dre00190: Oxidative phosphorylation

R-DRE-163200: Respiratory electron transport ATP synthesis, and heat production

R-DRE-72706: GTP hydrolysis and joining of the 60S ribosomal subunit

GO:0015985: energy coupled proton transport, down electrochemical gradient

GO:0006122: mitochondrial electron transport, ubiquinol to cytochrome c

GO:0097250: mitochondrial respiratory chain supercomplex assembly

GO:0043297: apical junction assembly

R-DRE-111453: BH3-only proteins associate with and inactivate anti-apoptotic BCL-2 members

GO:0015988: energy coupled proton transmembrane transport, against electrochemical gradient

GO:0006120: mitochondrial electron transport, NADH to ubiquinone

GO:0072593: reactive oxygen species metabolic process

GO:0002262: myeloid cell homeostasis

GO:0097190: apoptotic signaling pathway

R-DRE-8979227: Triglyceride metabolism

GO:0008219: cell death

R-DRE-3299685: Detoxification of Reactive Oxygen Species

GO:0051147: regulation of muscle cell differentiation

GO:0031101: fin regeneration

GO:0017004: cytochrome complex assembly

R-DRE-8866652: Synthesis of active ubiquitin: roles of E1 and E2 enzymes 


\section{Supplementary Figure 8. Functional categorization analysis reveals enriched pathways in each enterocyte cluster.}

Top 20 non-redundant enrichment terms identified by Metascape upon analysis of marker genes of each enterocyte cluster defined by our scRNA-seq analysis. The colors of enriched terms are scaled to represent statistical significance. Shown from top to bottom are functional enrichment analysis of cluster $4,16,17$, and 9 . 
Supplementary Table 1. Annotation of cell clusters based on single-cell RNA-seq analysis of wild-type zebrafish intestinal epithelial cells.

\begin{tabular}{|c|c|c|c|}
\hline Cluster \# & Cluster name & Predicted cell type & Other description \\
\hline 0 & Ion1 & ionocytes & \\
\hline 1 & $\mathrm{Fg} 1$ & foregut epithelium & \\
\hline 2 & Ion2 & ionocytes & \\
\hline 3 & GC2 & goblet cells & \\
\hline 4 & Ent 1 & enterocytes & $\begin{array}{c}\text { anterior intestine; also called segment } 1 \text { or } \\
\text { intestinal bulb }\end{array}$ \\
\hline 5 & PreEEC & secretory precursor & $\begin{array}{c}\text { maybe EEC precursors or another EEC } \\
\text { subtype }\end{array}$ \\
\hline 6 & PreSec & secretory precursor & $\begin{array}{c}\text { maybe precursors of secretory or additional } \\
\text { lineages }\end{array}$ \\
\hline 7 & $\mathrm{Fg} 2$ & foregut epithelium & \\
\hline 8 & $\mathrm{EEC} 1$ & enteroendocrine cells & maybe related to M-cell EEC subtype \\
\hline 9 & Ent3 & enterocytes & posterior intestine; also called segment 3 \\
\hline 10 & $\mathrm{Fg} 3$ & foregut epithelium & \\
\hline 11 & EEC4 & enteroendocrine cells & maybe incompletely differentiated EEC \\
\hline 12 & EEC5 & enteroendocrine cells & $\begin{array}{l}\text { maybe related to enterochromaffin cell } \\
\text { EEC subtype }\end{array}$ \\
\hline 13 & GC3 & goblet cells & $\begin{array}{l}\text { maybe related to tuft cells or microfold } \\
\text { cells }\end{array}$ \\
\hline 14 & $\mathrm{GC} 1$ & goblet cells & \\
\hline 15 & Ion3 & ionocytes & $\begin{array}{l}\text { maybe stress responsive as indicated by } \\
\text { enrichment for } h s p 70 / h s p 90 \text { genes }\end{array}$ \\
\hline 16 & Ent1p & enterocytes & $\begin{array}{c}\text { anterior intestine, proliferative; also called } \\
\text { segment } 1 \text { or intestinal bulb }\end{array}$ \\
\hline 17 & Ent2 & enterocytes & mid-intestine/ileum; also called segment 2 \\
\hline 18 & Leuk & leukocytes & \\
\hline 19 & Mes & mesenchymal cells & \\
\hline 20 & Pan & exocrine pancreas & \\
\hline 21 & EEC3 & enteroendocrine cells & \\
\hline 22 & EEC2 & enteroendocrine cells & maybe related to L-cell EEC subtype \\
\hline 23 & Epi1 & epidermis & maybe basal layer cells \\
\hline 24 & Unk & unknown & \\
\hline 25 & $\mathrm{RBC}$ & red blood cells & \\
\hline 26 & Epi2 & epidermis & maybe peridermis cells \\
\hline
\end{tabular}


Supplementary Table 2. Oligonucleotides used in this study

\begin{tabular}{|c|c|}
\hline Oligonucleotide name & Oligonucleotide sequence \\
\hline fxr sgRNA_exon4 & $\begin{array}{l}\text { AAAGCACCGACTCGGTGCCACTTTTTCAAGTTGATAACGG } \\
\text { ACTAGCCTTATTTTAACTTGCTATTTCTAGCTCTAAAACG } \\
\text { GCATTTTCTTCGCATGTACTATAGTGTCACCTAAATCGC }\end{array}$ \\
\hline$f x r$ genotyping Forward & GTAAGAGTGGAGGAAACTGTGAG \\
\hline fxr genotyping Reverse & CTTTGCACTTCCTGAGTCGAC \\
\hline fxr HRMA forward & GTTTCTTCAGAAGGAGCATCAC \\
\hline$f x r$ HRMA reverse & CAAGCATGCCCATCTCTTTG \\
\hline fxr qPCR forward & CTGAGGTGCTGGAAGACAGG \\
\hline fxr qPCR reverse & TGGCGGTGAGTAAAGCATGT \\
\hline cyp7a1 sgRNA_exon2 & $\begin{array}{c}\text { AATTAATACGACTCACTATAGGTCAAGGTGCCTTCCTTGA } \\
\text { GTTTTAGAGCTAGAAATAGC }\end{array}$ \\
\hline $\begin{array}{l}\text { cyp7al genotyping } \\
\text { forward }\end{array}$ & GTGATCCATTCTCCTACCATG \\
\hline $\begin{array}{l}\text { cyp7al genotyping } \\
\text { reverse }\end{array}$ & CGCAGAGGCATCAAAGTG \\
\hline cyp7al HRMA forward & GCTGGGCAGTATGTTCATTT \\
\hline cyp7al HRMA reverse & CATTTACCTTCGCAGAGGCAT \\
\hline cyp7al qPCR forward & GCAGGCGTGCCAATGTG \\
\hline cyp7al qPCR reverse & CAGCTCGTTGAAGGTAGATAGTGTGT \\
\hline $\begin{array}{l}\text { slc10a2 genotyping } \\
\text { forward }\end{array}$ & CACGTCTTGCCTGGTG \\
\hline $\begin{array}{l}\text { slc10a2 genotyping } \\
\text { reverse }\end{array}$ & TCCTGTCATGTTTGGAAAGCAC \\
\hline slc10a2 qPCR forward & GTTCCTCTTGGCACGCTTTGTG \\
\hline slc10a2 qPCR reverse & TCTGCAGGGCTAAAGGACAACTG \\
\hline $18 S \mathrm{qPCR}$ forward & CACTTGTCCCTCTAAGAAGTTGCA \\
\hline $18 S \mathrm{qPCR}$ reverse & GGTTGATTCCGATAACGAACGA \\
\hline efla qPCR forward & CTTCTCAGGCTGACTGTGC \\
\hline efla $\mathrm{qPCR}$ reverse & CCGCTAGGATTACCCTCC \\
\hline fgf19 qPCR forward & CTGGGAAACCTGTACGGATCG \\
\hline fgf19 qPCR reverse & CAAGAGCTCCGTGTTTGCTC \\
\hline$a b c b 11 b$ qPCR forward & ATTTCCGCAGCAAAGAAGGC \\
\hline$a b c b 11 b$ qPCR reverse & GTTTTTGACCCCGGGAAAGC \\
\hline amn qPCR forward & CTGCGATAACTCTAGGAATCGTG \\
\hline amn qPCR reverse & GTAGACAAGAGCGCCACAAAC \\
\hline
\end{tabular}


$c t s b b$ qPCR forward $c t s b b$ qPCR reverse

-1.7 fabp6 cloning forward

$-1.7 f a b P 6$ cloning reverse

egfp genotyping forward egfp genotyping reverse
CTGTGTGGGACGGTTCTGAAG

CTTACAGTTCGGCCACTGGTC

TTAAGGCCGGCCGATGATCCCAACCCTGTAATGAGTTCCT GG

AATTGGCGCGCCTTGAGAGCTGAGGTACTGATGGGTGAA

$\mathrm{G}$

\section{Supplementary data files S1-S5:}

Dataset 1. Average expression of genes in individual cell clusters identified by scRNA-seq analysis of wild-type zebrafish intestinal epithelial cells

Dataset 2. Cluster markers of individual cell clusters identified by scRNA-seq analysis of wildtype zebrafish intestinal epithelial cells

Dataset 3. Cluster-enriched markers of individual clusters identified by scRNA-seq analysis of wild-type zebrafish intestinal epithelial cells

Dataset 4. Differentially expressed genes between fxr wild-type and mutant cells in individual cluster clusters identified by scRNA-seq analysis of wild-type zebrafish intestinal epithelial cells

Dataset 5. Comparisons of Fxr regulon in larval zebrafish intestine and adult mouse intestine 